\title{
Altair Descent and Ascent Reference Trajectory Design and Initial Dispersion Analyses
}

\author{
Larry D. Kos and Tara T. Polsgrove \\ Marshall Space Flight Center, Mail Code ED04 \\ Huntsville, AL 35812 \\ Larry.Kos@nasa.gov \\ 256-544-1522 \\ Ronald R. Sostaric, Ellen M. Braden and Jacob J. Sullivan \\ Johnson Space Center, Mail Code EG \\ Houston, TX 77058 \\ Thanh T. Le \\ Engineering and Science Contract Group / Johnson Space Center \\ Webster, TX 77598
}

The Altair Lunar Lander is the linchpin in the Constellation Program (CxP) for human return to the Moon. Altair is delivered to low Earth orbit (LEO) by the Ares $V$ heavy lift launch vehicle, and after subsequent docking with Orion in LEO, the Altair/Orion stack is delivered through translunar injection (TLI). The Altair/Orion stack separating from the Earth departure stage (EDS) shortly after TLI and continues the flight to the Moon as a single stack.

Altair performs the lunar orbit insertion (LOI) maneuver, targeting a 100-km circular orbit. This orbit will be a polar orbit for missions landing near the lunar South Pole. After spending nearly 24 hours in low lunar orbit (LLO), the lander undocks from Orion and performs a series of small maneuvers to set up for descending to the lunar surface. This descent begins with a small deorbit insertion (DOI) maneuver, putting the lander on an orbit that has a perilune of $15.24 \mathrm{~km}$ $(50,000 \mathrm{ft})$, the altitude where the actual powered descent initiation (PDI) commences.

At liftoff from Earth, Altair has a mass of 45 metric tons $(\mathrm{mt})$. However after LOI (without Orion attached), the lander mass is slightly less than $33 \mathrm{mt}$ at PDI. The lander currently has a single descent module main engine, with TBD $\mathrm{lb}_{\mathrm{f}}$ thrust (TBD N), providing a thrust-to-weight ratio of approximately TBD Earth g's at PDI.

LDAC-3 (Lander design and analysis cycle \#3) is the most recently closed design sizing and mass properties iteration. Upgrades for loss of crew (LDAC-2) and loss of mission (LDAC-3) have been incorporated into the lander baseline design (and its Master Equipment List). Also, recently, Altair has been working requirements analyses (LRAC-1). All nominal data here are from the LDAC-3 analysis cycle. All dispersions results here are from LRAC-1 analyses.

\section{Descent Phase}

There are three subphases comprising the descent phase of the Altair mission: the braking burn (BB), the approach, and terminal (note a short pitch-up maneuver will be executed near the beginning of approach). The descent subphases are depicted shown in Figure 1.

Implicit guidance algorithms will be used to design the reference trajectories in all these descent subphases. In this approach, we can define, in advance of the mission, a reference trajectory as a vector polynomial function of time that evolves backward from the target state. But the reference trajectory cannot be expected to intersect the initial state of the vehicle due 
to navigation and control dispersions. Implicit guidance will generate acceleration commands that consist of that computed using the reference trajectory plus two feedback terms. The first "feedback" acceleration correction is proportional to the difference between the actual and reference vehicle's positions. The second term is proportional to the difference between the actual and reference vehicle's velocities. Implicit guidance algorithm will "drive" the vehicle to achieve the target state in the presences of controller errors, navigation state estimation error and possible re-designation of the landing site.

The braking burn starts at the descent orbit perilune altitude of $15.24 \mathrm{~km}$ with the descent module (DM) main engine aligned with the lander's velocity vector. It is done at TBD\% thrust to remove the orbital energy at the highest efficiency possible, but not at full thrust to allow for thrust margin between the BB set throttle and the maximum available engine power.

When the braking burn is completed, the lander will perform the pitch-up maneuver. The "nearly vertical" attitude of the lander will provide the crew with better visibility to detect terrain hazards surrounding the landing site. Re-designation of the landing target can then be performed after the pitch-up is completed.

In the approach subphase, the throttle will vary between $60 \%$ and $40 \%$ full engine power (i.e. thrust). The direction of thrust also varies to track the reference trajectory selected for the approach phase. There will be a hazard detection sensor carried onboard Altair. This critical function will be performed during the approach phase. Using data provided by the hazard detection sensor system, the crew will have to make a decision on the possible need to redesignate a "safer" landing site. The approach subphase ends at 30 meters vertically above the final (selected) touchdown site. A very important factor in this subphase is viewing (both crew look angles and terrain hazard detection sensor viewing).

The terminal subphase is intended to be a quiescent, controlled, vertical descent for 30 seconds at a constant $1 \mathrm{~m} / \mathrm{s}$ velocity, until its time to shut down the DM engine. This shutdown is intended to occur at 1 meter above the surface. This means the touchdown velocity could be as high as $2.1 \mathrm{~m} / \mathrm{s}$.

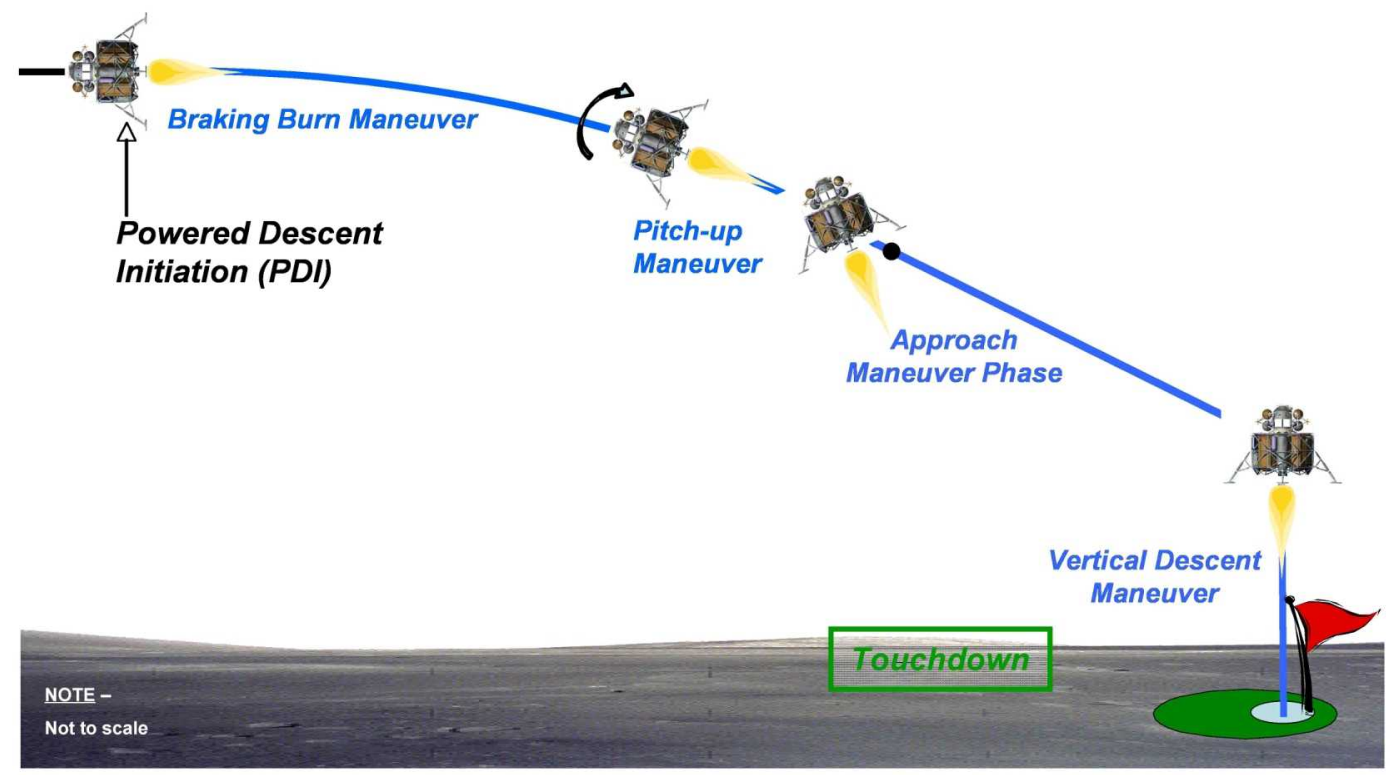

FIGURE 1 -- LUNAR DESCENT SUBPHASES 
The mission delta velocities ( $\Delta V \mathrm{Vs})$ are tabulated in Table 1. The total main propulsion system (MPS) descent $\Delta V$ for the piloted missions is TBD $\mathrm{m} / \mathrm{s}$ (TBD $\mathrm{m} / \mathrm{s}$ for cargo), while the current reaction control subsystem (RCS) budget $\Delta V$ is TBD $\mathrm{m} / \mathrm{s}$.

The main engine first lights up for the LOI burn (up to three LOI burns for non-polar sites). It will then perform the LLO plane change maneuver (when doing polar missions, if necessary). The final burn is the continuous descent and landing burn until shutdown at an altitude of $1 \mathrm{~m}$. There are many small trajectory tuning maneuvers, as well as other RCS propellant usage for attitude control, all done with the RCS thrusters.

The LOI burn $\Delta V$ budget for polar missions is $891 \mathrm{~m} / \mathrm{s}$, with the global access LOI 3-burn total currently bought in at $950 \mathrm{~m} / \mathrm{s}$. The cargo LOI burn is $889 \mathrm{~m} / \mathrm{s}$ due to smaller g-losses during LOI (better T/W ratio).

The descent $\Delta V$ budget currently also includes values for a small redesignation capability and a placeholder dispersions $\Delta V$ budget estimates using experience from Apollo 11.

TABLE 1 -- ALTAIR DESCENT MODULE $\Delta$ VS

\section{LDAC-3 Descent \& Ascent Module Reference Trajectory I $\Delta$ V Summaries}

\begin{tabular}{|c|c|c|c|}
\hline Descent $\Delta V$ Summary & Sortie, $950 \mathrm{~m} / \mathrm{s}$ & Outpost & Cargo \\
\hline Maneuver: & $\Delta \mathrm{V}, \mathrm{m} / \mathrm{s}$ & $\Delta \mathrm{V}, \mathrm{m} / \mathrm{s}$ & $\Delta \mathrm{V}, \mathrm{m} / \mathrm{s}$ \\
\hline TCMs (up to 4 of them/RCS) & TBD & TBD & TBD \\
\hline LOI-1 (MPS) & 326.0 & 891.0 & 889.0 \\
\hline LOI-2 (MPS) & 59.0 & & \\
\hline LOI-3 (MPS) & 565.0 & & \\
\hline LLO plane change (MPS) & 0.0 & 28.5 & 0.0 \\
\hline DOI (RCS) & 19.4 & 19.4 & 19.4 \\
\hline PDI (MPS) & 2016 & 2016 & 2149 \\
\hline Redesignation (MPS) & TBD & TBD & TBD \\
\hline Total Powered Descent & TBD & TBD & TBD \\
\hline Dispersions (MPS) & 53.0 & 53.0 & $\overline{53.0}$ \\
\hline Descent RCS & TBD & TBD & TBD \\
\hline Total MPS Desc. $\Delta \mathrm{V}+$ Dispersions: & TBD & TBD & TBD \\
\hline Total MPS $\triangle$ V/Prop: & TBD & TBD & TBD \\
\hline Total RCS $\triangle$ V/Prop+misc.: & TBD & TBD & TBD \\
\hline
\end{tabular}

The first iteration of the descent dispersions analysis was performed during LRAC-1 to begin affirming the $\Delta \mathrm{V}$ value documented in the $\mathrm{CxP}$ descent $\Delta \mathrm{V}$ requirements. The tool utilized in this work is the ANTARES simulation code (Advanced NASA Technology ARchitecture for Exploration Studies). The approach used was to first disperse one variable at a time. The variables that are currently captured in the "to disperse" list include DM main engine (ME) thrust, ME specific impulse ( $\left.I_{s p}\right)$, propellant mass, c.m. locations $(x, y, z)$ and inertia properties $\left(I_{x x}, I_{y y}, I_{z z}, I_{x y}, I_{x z}, I_{y z}\right)$. Additional variables will be added to the dispersions list as the model is further developed.

The results from each individual contribution were root-sum-squared together to provide an interim estimate of total dispersion. This value came out to be TBD $\mathrm{m} / \mathrm{s}$. Note that with a subset of the variables that could possibly be dispersed, this value is less than the Apollo 11/Apollo 12 value in the $\Delta \mathrm{V}$ table above. Future work includes dispersing all parameters together in one Monte Carlo exercise. 


\section{Ascent Phase}

The ascent phase, also comprised of three subphases, is performed by only the Altair ascent module (AM). These three are the vertical rise, the single axis rotation (SAR), and the PEG (powered explicit guidance) subphases. Each of these has a particular purpose in flight and are depicted in Figure 2.

The vertical rise subphase is to immediately get the lander to a sufficient altitude to allow clearing of local terrain in the subsequent subphases. Although the AM is flying directly against (lunar) gravity to a height of approximately $100 \mathrm{~m}$, which is quite an inefficient way to fly, it is only for a short time -- not more than 10 seconds.

The single axis rotation (SAR) maneuver subphase is to get the AM over to the desired flight path angle as quickly as possible. This is desired so that the subsequent ascent $\Delta \mathrm{V}$ can be minimized. The earlier in the ascent the SAR is completed, the sooner the optimal flight path can be attained. This subphase is less than 15 seconds (currently TBD s), allowing PEG to be engaged at approximately TBD seconds after lunar liftoff.

The powered explicit guidance (PEG) subphase is then flown until the AM hits its main engine cutoff (MECO) targets (the AM state at MECO). The current AM flight times to MECO are TBD sec for both the Outpost and Sortie missions, so PEG is flying the last TBD seconds of the ascent trajectory. PEG is attempting to minimize the AM propellant required (e.g. the $\Delta \mathrm{V}$ as well), so a significant majority of the ascent is optimally controlled.

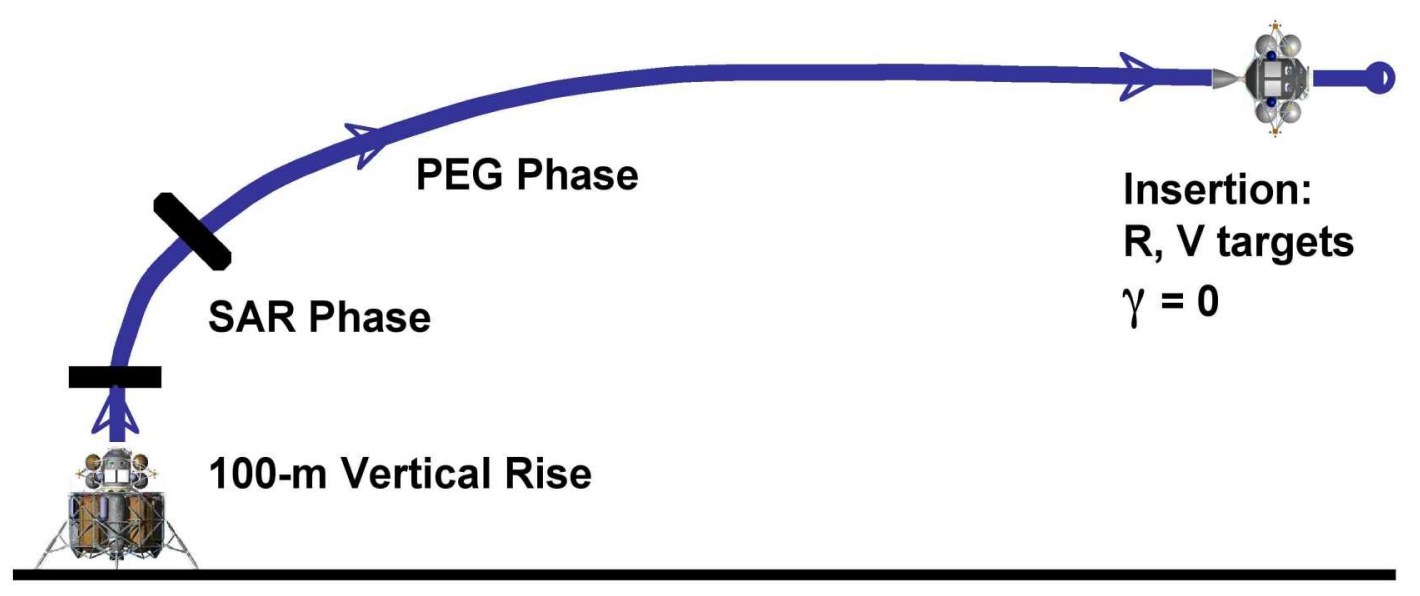

FIGURE 2 -- ASCENT TRAJECTORY SCHEMATIC

Ascent dispersions were also run during LRAC-1. Again these analyses were performed by dispersing one variable at a time. The variables studied in this analysis included AM main engine (ME) thrust, AM ME specific impulse, and AM initial (propellant) mass.

The results from each individual variable was root-sum-squared together to provide an interim total dispersion. This value came out to be TBD $\mathrm{m} / \mathrm{s}$. Note that this is only a subset of the variables that could possibly be dispersed. This effort was done using the Simulation and Optimization of Rocket Trajectories (SORT) trajectory tool. The next analysis cycle will have this analyses included in the ANTARES simulation development with results reported. As with the descent, future work will involve dispersing all parameters simultaneously. 


\section{Rendezvous, Proximity Operations and Docking Phase}

As the name implies, the Rendezvous, Proximity Operations, and Docking (RPOD) phase is also comprised of three subphases. The rendezvous phase involves infrequent, discrete maneuvers with coasting phases. The proximity operations phase consists of smaller, more frequent maneuvers, and docking initiates at docking port contact. A simplified graphic of the reference trajectory is shown below in Figure 3.

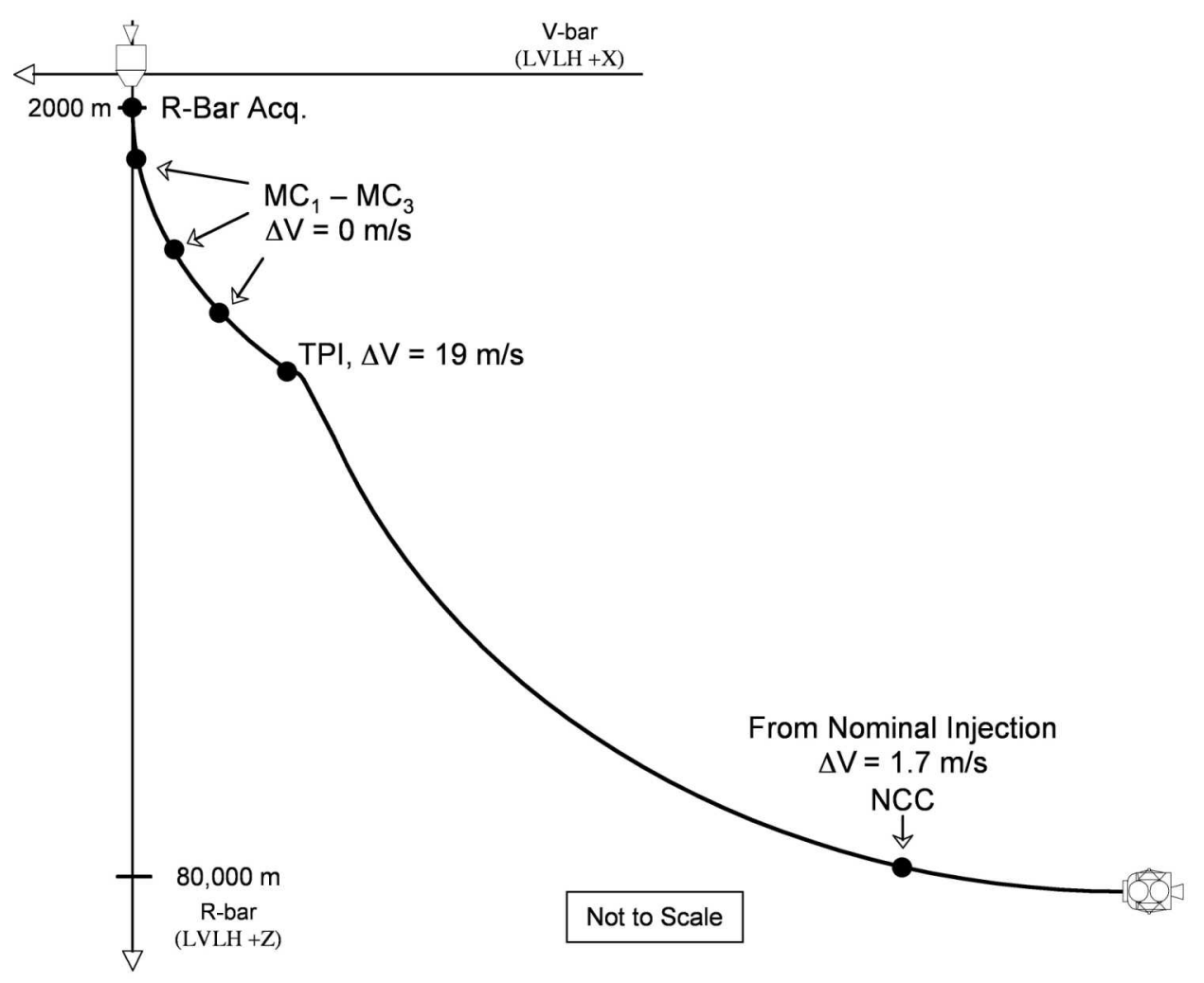

\section{FIGURE 3 -- RENDEZVOUS TRAJECTORY SCHEMATIC}

To deliver the Altair back to Orion, the RPOD trajectory utilizes an R-bar approach. The rendezvous phase begins at insertion and continues until Altair acquires the R-bar. During this time, there are five maneuvers. The Corrective Combination (NCC) burn occurs 10 minutes after insertion to clean up any ascent dispersions and target the proper Terminal Phase Initiation (TPI) point. The TPI burn places Altair on a natural coasting trajectory to acquire the R-bar at a point $2 \mathrm{~km}$ from Orion with a purely radial (Local Vertical, Local Horizontal (LVLH) -$\mathrm{Z}$ ) relative velocity. Between TPI and the R-bar, three Midcourse (MC) maneuvers shape the trajectory and correct any dispersions.

The $2 \mathrm{~km}$ acquisition range was chosen as part of a trade study performed during LDAC-2. It must be noted that since the trajectory from TPI to the R-bar is a "coasting" trajectory, the Rbar acquisition distance uniquely determines the location of the TPI point in space. This, in turn, defines the required apolune achieved during ascent.

The Proximity Operations phase begins at R-bar acquisition and concludes at docking port soft contact. To close the distance between the vehicles, Altair performs a series of "glide slope" maneuvers, along with two braking gates which serve to reduce the total profile time. At the conclusion of the glideslope maneuvers, Altair is delivered to a docking port-to-docking port 
(DP-to-DP) range of $10 \mathrm{~m}$ with the proper range-rate for docking, thanks to natural braking from orbital mechanics. This velocity is held constant for the final $10 \mathrm{~m}$ until docking port contact.

A summary of the major RPOD events, the time frame, translational $\Delta \mathrm{Vs}$, and the apolune and perilune are provided in Table 2.

TABLE 2 -- RENDEZVOUS SEQUENCE FOR ALTAIR TO ORION, 1-REV

\begin{tabular}{|l|c|l|l|}
\hline Trajectory Event & $\begin{array}{c}\text { Phase Elapsed } \\
\text { Time, h:mm:ss }\end{array}$ & $\begin{array}{c}\Delta \mathbf{V}, \text { Translation } \\
\text { Maneuver }\end{array}$ & $\begin{array}{c}\text { Resultant Apolune } \\
\text { x Perilune }\end{array}$ \\
\hline AM Lunar Liftoff & & & \\
\hline Insertion / MECO & & & \\
\hline Corrective Combination & & & \\
\hline Terminal Phase Initiation & & & \\
\hline Midcourse Corrections 1,2,3 & & & \\
\hline R-bar Acquisition & & & \\
\hline 1st \& 2nd Braking Gates & & & \\
\hline Glide slope maneuvers, total & & & \\
\hline Docking & & & \\
\hline \multicolumn{1}{r|}{ Totals: } & $2: 23: 29$ & $24.4 \mathbf{~ m / s}$ & \\
\hline
\end{tabular}

An initial analysis of the RPOD maneuver dispersions was performed as a part of the RAC-1 analysis. The tool utilized was a Linear Covariance (LinCov) analysis code. Five different dispersion sources were considered one at a time. These error sources were environment process noise (from gravity perturbations or movement within Altair), the Orion initial navigation state knowledge, RCS performance (variations in thrust and $\mathrm{I}_{\mathrm{sp}}$ ), RCS misalignment, and an estimate of insertion errors from the Ascent phase.

The five individual error sources were then simultaneously run to estimate the total profile $\Delta \mathrm{V}$ dispersion. The resultant value was TBD $\mathrm{m} / \mathrm{s}$. As part of the next analyses cycles, the dispersion sources will be updated with improved vehicle knowledge, and ANTARES simulation development will provide independent verification.

\section{Summary/Conclusions/Future work}

The current budget has captured all the major $\Delta \mathrm{V}$ needs of the mission and is a good foundation from which to continue improving fidelity of the trajectory analyses and simulation development. The Altair lunar lander $\Delta \mathrm{V}$ budget estimate and the dispersions for that estimate are continuing to progress over time as the Altair Project Office (APO) Integrated Performance Team works to mature the Altair vehicle models and trajectories.

Simulation work will also continue for quite some time. As flight hardware is selected, the components can be modeled in the simulation for eventual full system simulation, as well as possible hardware-in-the-loop simulation at some point in the future. 


\section{References:}

1. Apollo Lunar Descent and Ascent Trajectories, NASA TM X-58040, March 1970 (presented at the AIAA 8th Aerospace Sciences Meeting, New York, New York, January 19-21, 1970).

2. Jaggers, Roland F., "Shuttle Powered Explicit Guidance (PEG) Algorithm", Rockwell Space Operations Company, November 1992, JSC-26122.

3. McHenry, R.L, Brand, T.J., Long, A.D, Cockrell, B.F., Thibodeau, J.R., "Space Shuttle Ascent Guidance, Navigation, and Control", The Journal of the Astronautical Sciences, Vol. XXVII, No. 1, January-March, 1979.

4. Ives, D.G., "Shuttle Powered Explicit Guidance Miscellaneous Papers", Aeroscience and Flight Mechanics Division, JSC-28774, November 1999. 


\title{
Altair Descent and Ascent Reference Trajectory Design and Initial Dispersion Analyses
}

\author{
Larry D. Kos ${ }^{1}$ and Tara P. Polsgrove ${ }^{2}$ \\ NASA Marshall Space Flight Center, Huntsville, AL, 35812 \\ Ronald R. Sostaric ${ }^{3}$, Ellen M. Braden ${ }^{4}$ and Jacob J. Sullivan ${ }^{5}$ \\ NASA Johnson Space Center, Houston, TX, 77058 \\ and
}

Thanh T. Le ${ }^{6}$

Jacobs Technology, Engineering and Science Contract Group / Johnson Space Center, Webster, TX, 77598

The Altair Lunar Lander is one element of NASA's Constellation Program for human return to the Moon. The Altair lander is responsible for several critical maneuvers on the way to and returning from the lunar surface. Since propellant to perform these maneuvers constitutes $50 \%$ (cargo) to greater than $60 \%$ (piloted) of the total lander mass, it is important to characterize the magnitude of these maneuvers as accurately as possible early in the design process. The Altair Lander descent module main engine performs the lunar orbit insertion burn(s), the low lunar orbit plane change burn when necessary, and the powered descent burn to lunar touchdown. The descent module also performs all trajectory correction maneuvers en route using a storable reaction control system as well as all attitude control functions. The Altair ascent module main engine performs the single, continuous ascent burn from the moon after the seven-day lunar surface mission to the low lunar orbit phasing ellipse. The ascent module then performs all rendezvous, proximity operations and docking maneuvers using the ascent module reaction control system. This paper describes the Altair performance characteristics and results determined thus far from the first four design and analysis cycles and presents the results of analysis and simulation work defining the Altair vehicle's required maneuvers as well as statistical analyses of anticipated dispersions in performance parameters.

\section{Nomenclature}

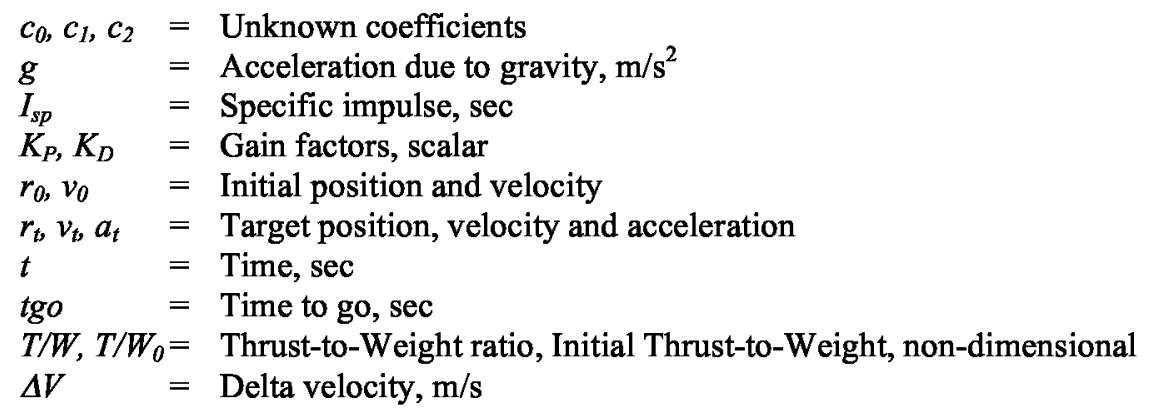

\footnotetext{
${ }_{1}^{1}$ Aerospace Engineer, Advanced Concepts Office, MSFC/ED04, Senior Member.

${ }^{2}$ Aerospace Engineer, Advanced Concepts Office, MSFC/ED04.

${ }^{3}$ Aerospace Engineer, Flight Mechanics and Trajectory Design Branch, JSC/EG5, Senior Member.

${ }^{4}$ Aerospace Engineer, Flight Mechanics and Trajectory Design Branch, JSC/EG5.

${ }^{5}$ Aerospace Engineer, GN\&C Autonomous Flight Systems Branch, JSC/EG6, Member.

${ }^{6}$ Aerospace Engineer, On-Orbit GN\&C Section, Mail Stop J3-B3-2.
} 
$\delta_{c m d}=$ Commanded pitch and yaw gimbal angles, rad

$\Theta_{\text {err }} \quad=$ Pitch and roll attitude errors, rad

$\omega_{\text {err }}=$ Pitch and roll angular rate errors, $\mathrm{rad} / \mathrm{sec}$

\section{Introduction}

Tis

HE Altair Lunar Lander is the linchpin in the Constellation Program (CxP) for human return to the Moon. Altair is delivered to low Earth orbit (LEO) by the Ares V heavy lift launch vehicle, and after subsequent docking with Orion in LEO, the Altair/Orion stack is delivered through trans-lunar injection (TLI). The Altair/Orion stack separates from the Ares V Earth departure stage (EDS) shortly after TLI and continues the flight to the Moon as a single stack.

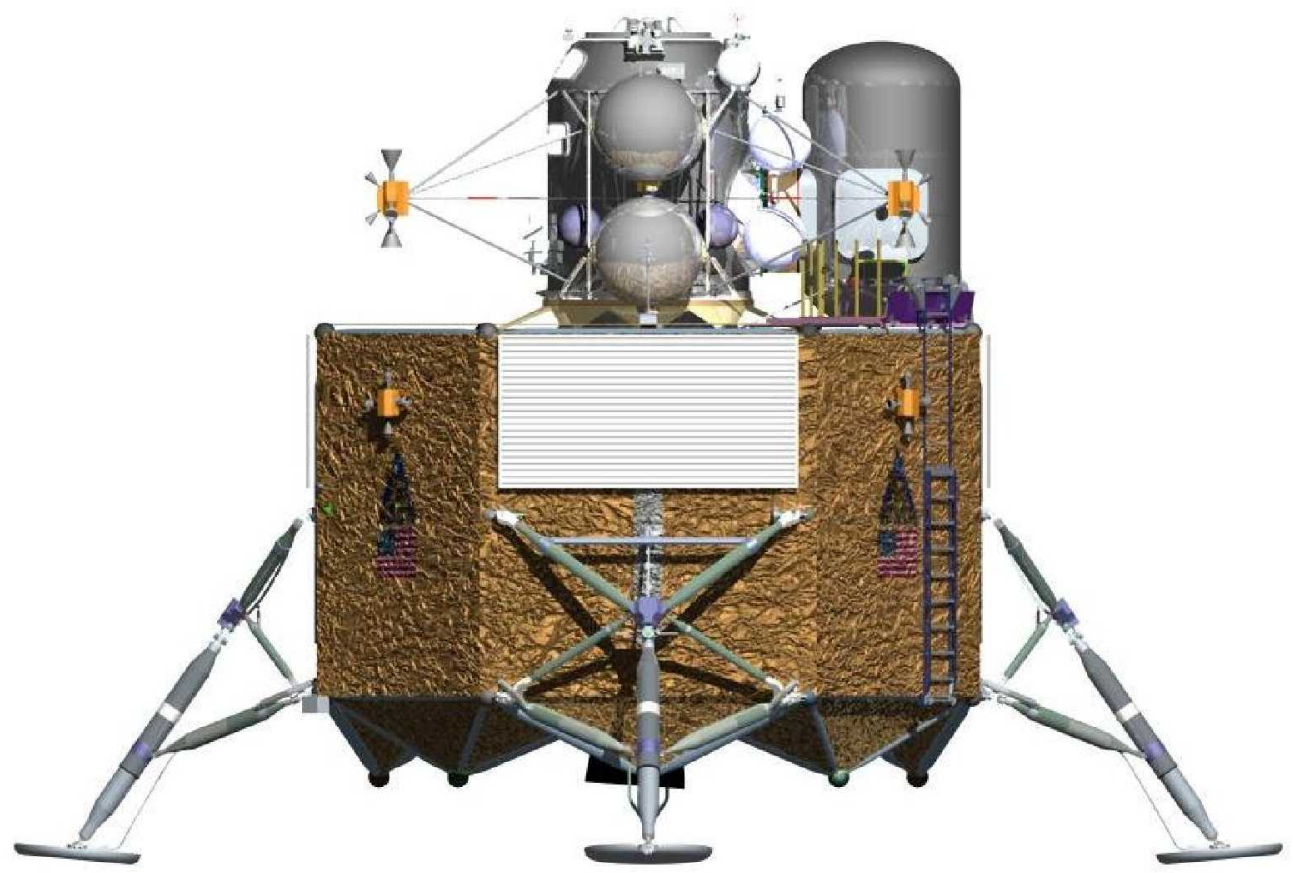

Figure 1. Altair Lunar Lander, Side View. The Altair Lunar Lander is comprised of an Ascent Module (top, center), an Airlock (top, right), and a Descent Module (bottom, gold Mylar).

Altair performs the lunar orbit insertion (LOI) maneuver(s), targeting a 100-kilometer (km) circular orbit. This orbit will be a polar orbit for Outpost missions landing near the lunar South Pole and other inclinations for Global Access missions to other points on the lunar surface. After spending approximately 20 to 116 hours in low lunar orbit (LLO), the lander undocks from Orion and performs a series of small maneuvers to set up for descending to the lunar surface. This descent begins with a small descent orbit insertion (DOI) maneuver, putting the lander on an orbit that has a perilune of $15.24 \mathrm{~km}(50,000 \mathrm{ft})$, the altitude where the actual powered descent initiation (PDI) commences.

The Altair design team began work in 2007 and has conducted a series of analysis cycles focusing on design and requirements maturation. With each cycle the design matures and evolves to improve reliability and compliance to program requirements. Nominal data presented here is from design and analysis cycle 4 (LDAC-4), completed June 2010. Trajectory dispersions data is from work conducted during the requirements analysis cycles 1 and 2 (LRAC-1 and LRAC-2), completed in June 2009 and December 2009 respectively.

Upgrades for loss of crew (LDAC-2) and loss of mission (LDAC-3) have previously been incorporated into the lander baseline design (and its Master Equipment List). All nominal data here are from the most recent LDAC-4 analysis cycle.

\section{Trans-lunar Injection through Descent Orbit Insertion}

While active in LEO, the Altair lander is not responsible for any maneuvers until after the TLI burn is completed by the Ares V EDS. The trans-lunar cruise (TLC) phase of the mission spans the 4 days between TLI and initiation 
of LOI. During this time Altair is responsible for attitude control of the Orion-Altair stack, and any trajectory correction maneuvers that may be required during transit. These maneuvers are performed by Altair's Descent Module reaction control system (RCS). The first firing of Altair's main engine occurs at LOI. The magnitude and quantity of LOI maneuvers required depends on the mission and landing site selection. Following LOI, the AltairOrion stack loiters in LLO for a minimum of 24 hours. This time is allocated to allow for sufficient state vector updates to enable a precision landing, and to allow for crew operations which include preparing the Orion vehicle for untended operations, preparing the Altair vehicle for descent, and a crew sleep period. During LLO loiter Altair is responsible for attitude control as well as altitude maintenance as needed. At the conclusion of the LLO loiter period, the uncrewed Orion vehicle separates and backs away from the now crewed Altair. Altair then executes a plane change maneuver if required, and the DOI maneuver.

\section{A. Trans-lunar Cruise (TLC)}

During the TLC the Altair will maintain a stack attitude where the Altair DM main engine and landing gear are pointed away from the Sun, and Orion's high gain antenna is pointed toward the Earth with deadbands as high as 20 degrees. Preliminary estimates indicate that this attitude can be maintained with a small amount of propellant, possibly on the order of $6 \mathrm{~kg} / \mathrm{day} .{ }^{1}$

There are four trajectory correction maneuvers (TCM) planned in the Altair nominal TLC, however it is anticipated that all four will not be executed every mission. These maneuvers are intended to correct for TLI inaccuracies, both natural and induced perturbations to the vehicle, and any navigation errors that accumulate during the transit to the moon. More information about navigation during TLC can be found in Ref. 2. The allocation of delta velocity $(\Lambda \mathrm{V})$ for each TCM and an anticipated schedule are given in Table 1. Actual TCMs, when required, will be performed at a magnitude and schedule that is optimized during each mission. The root-sum-square (RSS) total budget for the four TCM $\Delta \mathrm{Vs}$ is $25.4 \mathrm{~m} / \mathrm{s}$.

Table 1. Altair TLC Trajectory Correction Maneuver $\Delta V$ Summary.

\begin{tabular}{|c|c|c|c|}
\hline TCM \# & $3 \sigma \Delta V, m / s$ & Time from TLI, hours & Time from LOI, hours \\
\hline TCM-1 & 21.5 & 2 to 3 & 93 to 94 \\
\hline TCM-2 & 2.0 & $\sim 24$ & $\sim 72$ \\
\hline TCM-3 & 3.7 & $\sim 62$ & $\sim 34$ \\
\hline TCM-4 & 2.6 & $\sim 88$ & $\sim 8$ \\
\hline RSS Total: & $25.4 \mathrm{~m} / \mathrm{s}$ & & \\
\hline
\end{tabular}

\section{B. Lunar Orbit Insertion (LOI)}

The LOI burn was determined by CxP Level 2 analyses. ${ }^{3,4}$ The LOI $\Delta V s$ are $894 \mathrm{~m} / \mathrm{s}$ for the piloted Outpost mission, $953 \mathrm{~m} / \mathrm{s}$ for the Global Access Sortie mission, and $892 \mathrm{~m} / \mathrm{s}$ for the Cargo mission. ${ }^{3,4}$ LOI dispersions were determined by the same analyses which generated the TCM $\Delta \mathrm{Vs}$ in the previous section resulting in an additional $3 \mathrm{~m} / \mathrm{s}$ to cover for various error sources. ${ }^{2}$

At the Lunar Capability Concept Review (LCCR) in June 2008, CxP decided to allocate $950 \mathrm{~m} / \mathrm{s}$ for the Global Access mission for LOI. ${ }^{4}$ This value is a compromise between percentage of the lunar surface that is accessible, the temporal availability of the more difficult sites, and the desire to minimize the LLO loiter duration and the LOI $\Delta \mathrm{V}$ requirement. The Outpost and Cargo $\Delta \mathrm{Vs}$ are just a resultant of the same analyses, but sized for just the South Pole location. All of these LOI $\Delta \mathrm{Vs}$ are intended to accommodate as many departure (TLI) and arrival (LOI) epochs as possible over the course of the 18.6-year cycle of the Moon's inclination variation.

\section{Low Lunar Orbit (LLO)}

During the LLO loiter period, Altair is responsible for both the attitude and altitude maintenance for the Altair/Orion stack. It is important to keep the stack oriented in a solar inertial attitude so that Orion's solar arrays are pointed toward the Sun for power generation. For Orion thermal constraints, it is desired to keep the lunar orbit altitude within a $10-\mathrm{km}$ deadband about the nominal $100-\mathrm{km}$ altitude. For polar missions, the loiter time will be approximately 24 hours. For global access missions, the low lunar loiter time could be up to four additional days beyond the normal 1-day LLO loiter. 
To determine an ACS budget, a scan of different solar beta angles, lunar orbit inclinations and ascending nodes was completed. From these studies, an average propellant usage for attitude and altitude maintenance was determined. For the attitude maintenance budget, $30 \mathrm{~kg} / \mathrm{day}$ was budgeted. For the altitude maintenance budget, although none is needed for a 1-day loiter, $35 \mathrm{~kg} /$ day was budgeted for the 5-day loiter.

For the Outpost mission, it will likely be necessary to perform a LLO plane change maneuver to place the orbit plane over the landing site if the Outpost site is not located very close to the pole. The Altair lander can perform up to a 1 degree maneuver and the corresponding $\Delta V$ budget for this maneuver is $28.5 \mathrm{~m} / \mathrm{s}$. This is done with the DM MPS system to minimize the propellant needed for the maneuver.

\section{Descent Orbit Insertion}

The descent orbit insertion burn is done using the DM RCS. The DOI maneuver drops the lander from the LLO circular orbit to an elliptical orbit with perilune much nearer the surface. This maneuver is done approximately half of an orbit from the landing point. This is done with the DM RCS to preserve the accuracy of the knowledge of the lander state to facilitate landing within the constraint of achieving $1 \mathrm{~km}$ accuracy at touchdown for Sortie missions (and prior to Outpost establishment) and 100-meter accuracy for Outpost missions after it has been established.

\section{Descent Phase}

The descent phase is one continuous burn, beginning at Powered Descent Initiation (PDI). There are three subphases comprising the descent phase of the Altair mission: the braking burn (BB), the approach, and terminal (note a short pitch-up maneuver will be executed near the beginning of approach), all shown in Figure 1.

At liftoff from Earth, for the Sortie and Outpost mission, the Altair lander has a mass of 45 metric tons (mt). In LLO after separation from Orion, the lander masses are $31 \mathrm{mt}$ and $32 \mathrm{mt}$ at PDI, respectively. The DM main propulsion system (MPS) currently has a single descent module main engine, a nominal specific impulse $\left(\mathrm{I}_{\mathrm{sp}}\right)$ of $450.1 \mathrm{sec}$ (with a minimum guaranteed $\mathrm{I}_{\mathrm{sp}}$ of $448.6 \mathrm{sec}$ ), with $18,627 \mathrm{lb}_{\mathrm{f}}$ thrust $(82,900 \mathrm{~N}$ ), providing a thrust-toweight $(\mathrm{T} / \mathrm{W})$ ratio of 0.24 Earth g's at PDI. The cargo mission masses are $54.5 \mathrm{mt}$ at liftoff and $43.5 \mathrm{mt}$ at PDI (Cargo T/W $=0.18$ Earth g's).

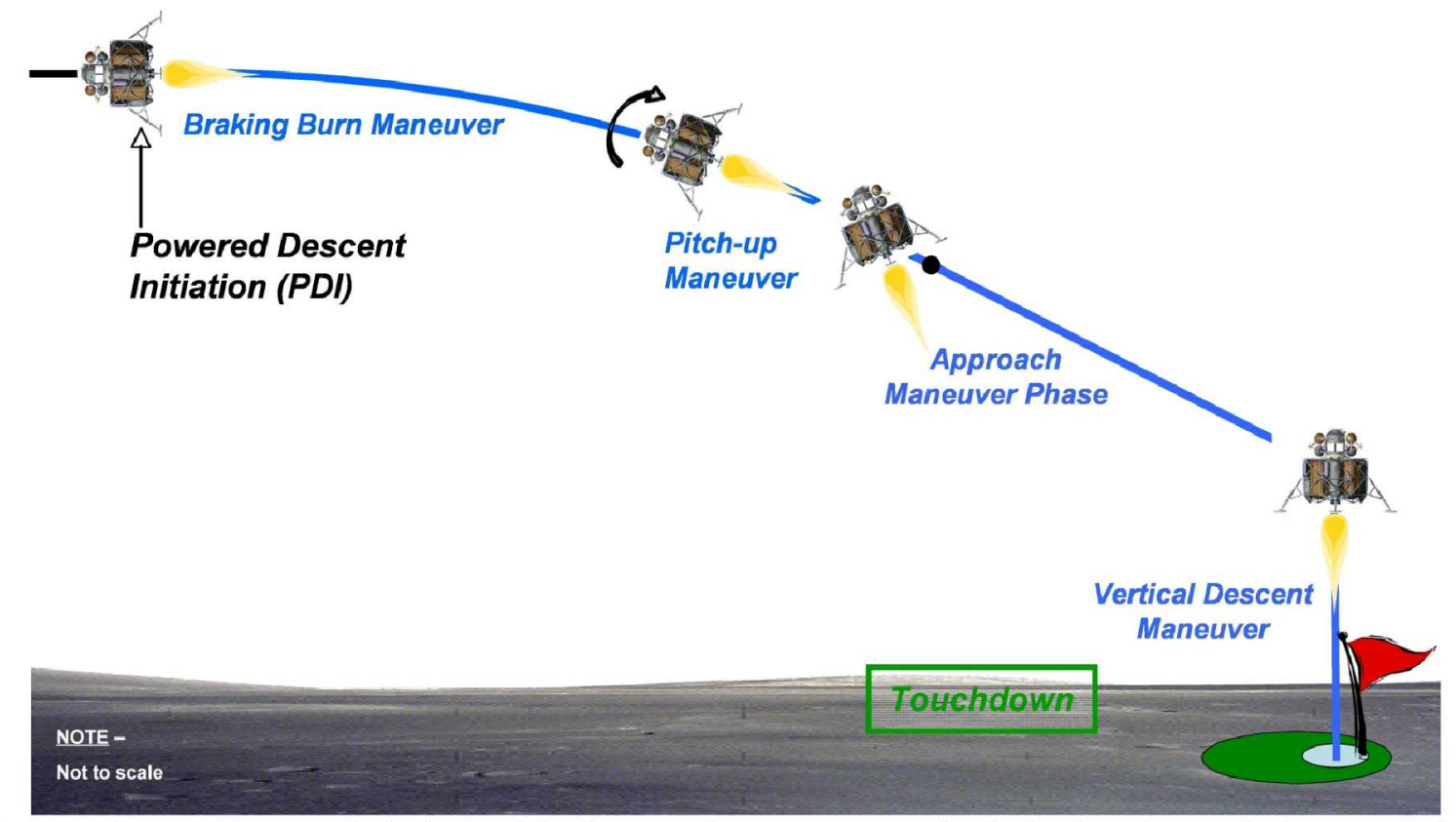

Figure 2. Lunar Descent Subphases. The descent phase is comprised of a braking burn subphase, a pitch-up maneuver, an approach subphase and a terminal descent subphase.

\section{A. Braking Burn}

The braking burn starts at the descent orbit perilune altitude of $15.24 \mathrm{~km}$ with the descent module (DM) main engine aligned with the lander's velocity vector. It is done at $92 \%$ thrust to remove the orbital energy at the highest efficiency possible, but not at full thrust to allow for thrust margin between the BB set throttle and the maximum available engine power. Thrust margin is necessary in order be able to remove dispersions during the braking burn. 


\section{B. Pitch-up Maneuver}

When the braking burn is completed, the lander will perform the pitch-up maneuver. The "nearly vertical" attitude of the lander will provide the crew with better visibility to detect terrain hazards surrounding the landing site. Re-designation of the landing target can then be performed after the pitch-up is completed.

\section{Approach}

During the approach phase, the vehicle descends at a lower throttle (roughly between $60 \%$ and $40 \%$ full engine thrust) while the landing area is examined for hazards. The magnitude and direction of thrust varies to track the reference trajectory selected for the approach phase. A hazard detection sensor carried onboard is used to assist in identification of the best location in which to land. For the piloted mission, the crew will have to make a decision on the possible need to re-designate to a "safer" landing site. This function can also be carried out autonomously for a cargo mission or in case of an incapacitated crewmember. The trajectory design must account for providing a landing approach that enables adequate viewing of the landing area by the both the crew and the hazard detection system. ${ }^{5-10}$

If a new landing location is selected, the target is updated in the GN\&C software and the guidance calculates an updated trajectory that delivers the vehicle to the new location. This changes the throttle and attitude profile for the remaining portion of the phase. An additional amount of propellant is expected to be used and this has been allocated in the $\Delta \mathrm{V}$ budget. Redesignation can occur multiple times during the Approach Phase.

Whether redesignation occurs or not, the approach subphase ends at 30 meters vertically above the final (selected) touchdown site.

\section{Terminal}

The terminal subphase is intended to be a quiescent, controlled, vertical descent for 30 seconds at a constant 1 $\mathrm{m} / \mathrm{s}$ velocity over the last 30 meters of altitude. The DM engine shutdown occurs just prior to touchdown and the shutdown sequence is initiated at 1 meter above the surface. Assuming a free fall from $1-\mathrm{m}$ height at $-1 \mathrm{~m} / \mathrm{s}$, the expected worst case touchdown velocity is $2.1 \mathrm{~m} / \mathrm{s}$.

\section{E. Descent Dispersions}

The first iteration of the descent dispersions analysis was performed during LRAC-1 to begin affirming the $\Delta \mathrm{V}$ dispersions budget documented in the CxP descent $\Delta V$ requirements. The tool utilized in this work is the ANTARES simulation code (Advanced NASA Technology ARchitecture for Exploration Studies). This 6-DOF simulation was developed under Altair for use in both GN\&C development and performance assessment. Guidance and control algorithms, along with a perfect navigation assumption, were used. The study approach used was to first disperse one variable at a time. The variables that are currently captured in the "to disperse" list include DM main engine (DME) thrust, DME specific impulse $\left(I_{\mathrm{sp}}\right)$, propellant mass, c.m. locations $(x, y, z)$ and inertia properties $\left(I_{\mathrm{xx}}, \mathrm{I}_{\mathrm{yy}}, \mathrm{I}_{\mathrm{zz}}\right.$, $\mathrm{I}_{\mathrm{xy}}, \mathrm{I}_{\mathrm{xz}}, \mathrm{I}_{\mathrm{yz}}$ ). Additional variables will be added to the dispersions list as the model is further developed.

The results from each individual contribution were RSS'd together to provide an interim estimate of total dispersion. This value came out to be $28.2 \mathrm{~m} / \mathrm{s}$. Note that with a subset of the variables that could possibly be dispersed, this value is less than the Apollo 11/Apollo $12 \Delta \mathrm{V}$ value in Table 2 below. ${ }^{11}$ Future work includes dispersing all parameters together in one Monte Carlo exercise. ${ }^{12}$

\section{F. Guidance Description}

The guidance algorithm is based on the Apollo Lunar Module Guidance. ${ }^{5}$ During the braking and approach phases, the acceleration profile is restricted to be a quadratic equation of time.

$$
a=c_{0}+c_{1} t+c_{2} t^{2}
$$

Analytic equations for velocity and position can be integrated from this equation and the coefficients $c_{1}$ and $c_{2}$ can solved using the initial position and velocity, $v_{0}$ and $r_{0}$.

$$
c_{0}=a_{t}-6 \frac{\left(v_{t}+v_{0}\right)}{\operatorname{tgo}}+12 \frac{\left(r_{t}-r_{0}\right)}{\operatorname{tgo}^{2}}
$$




$$
\begin{aligned}
& c_{1}=-6 \frac{a_{t}}{\operatorname{tgo}}+6 \frac{\left(5 v_{t}+3 v_{0}\right)}{\operatorname{tgo}^{2}}-48 \frac{\left(r_{t}-r_{0}\right)}{\operatorname{tgo}^{3}} \\
& c_{2}=6 \frac{a_{t}}{\operatorname{tgo}^{2}}-12 \frac{\left(2 v_{t}+v_{0}\right)}{\operatorname{tgo}^{3}}+36 \frac{\left(r_{t}-r_{0}\right)}{\operatorname{tgo}^{4}}
\end{aligned}
$$

The length of the burn, tgo, and the position, velocity, and acceleration targets $\left(r_{t}, v_{t}, a_{t}\right)$ must be provided. These equations are solved in each axis. A new set of targets is used for each phase.

\section{G. Controller Description}

The control algorithm uses thrust vector control to steer the vehicle and was developed by the Autonomous Landing and Hazard Avoidance Technology (ALHAT). ${ }^{6}$ The thrust vector control (TVC) is used to control the vehicle's pitch and yaw. The TVC has no control authority in the roll axis. RCS jets are used to control roll. A simple proportional-derivative (PD) controller is driven by pitch and yaw attitude and angular velocity errors.

$$
\delta_{c m d}=K_{P} \Theta_{e r r}+K_{D} \omega_{e r r}
$$

Where the commanded pitch and yaw gimbal angles, $\delta_{\text {cmd }}$, is determined by the pitch and roll attitude errors, $\Theta_{\text {err }}$, and pitch and yaw angular rate errors, $\omega_{\text {err }}$. The two gains, $\mathrm{K}_{\mathrm{P}}$ and $\mathrm{K}_{\mathrm{D}}$ are scalars.

\section{H. Descent Module Delta Velocities $(\Delta V \mathbf{V})$}

The mission $\Delta \mathrm{Vs}$ for the descent module are tabulated in Table 2. The total MPS descent $\Delta \mathrm{V}$ for the piloted missions requires $2074 \mathrm{~m} / \mathrm{s}(2202 \mathrm{~m} / \mathrm{s}$ for cargo), while the current RCS budget $\Delta V$ requires up to $76 \mathrm{~m} / \mathrm{s}$.

The main engine first lights up for the LOI burn (up to three LOI burns for non-polar sites). It will then perform the LLO plane change maneuver (when doing polar missions, if necessary). The final burn is the continuous descent

Table 2. Altair Descent Module MPS and RCS $\triangle$ V Summary.

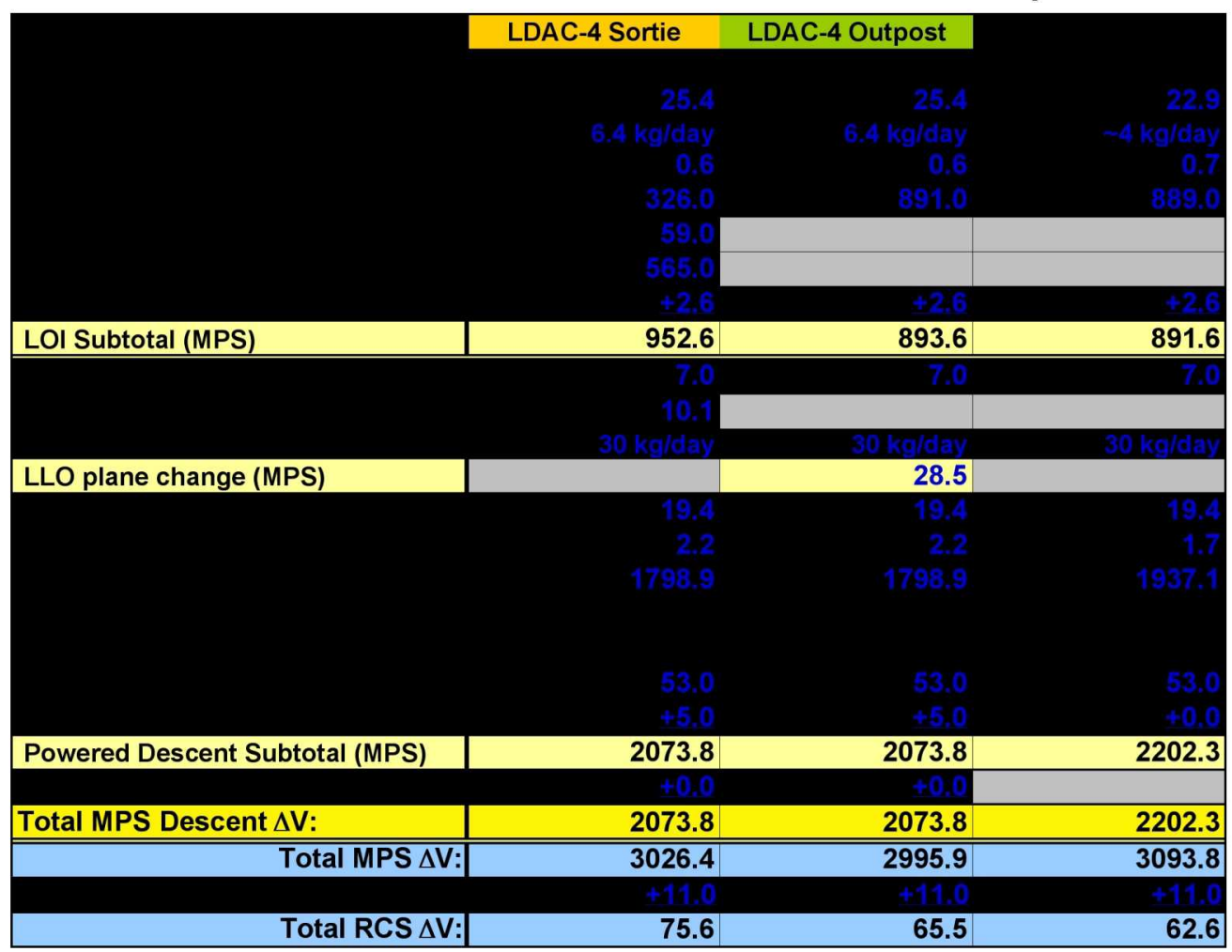

6

American Institute of Aeronautics and Astronautics 
and landing burn until shutdown at an altitude of $1 \mathrm{~m}$. The descent $\Delta \mathrm{V}$ budget currently also includes values for a small redesignation capability and a placeholder dispersions $\Delta \mathrm{V}$ budget estimates using experience from Apollo $11{ }^{11}$ The DME is lit as many as four times and as few as two for this stable of missions.

There are many small trajectory tuning maneuvers shown in the table, as well as other RCS propellant usage for attitude control, all done with the RCS thrusters.

\section{Ascent Phase}

The ascent phase, also comprised of three subphases, is performed by only the Altair ascent module (AM). These three subphases are the vertical rise, the single axis rotation (SAR), and the powered explicit guidance (PEG) subphases. Each of these has a particular purpose in flight and are depicted in Figure 3.

\section{A. Vertical Rise}

The vertical rise subphase is to immediately get the lander to a sufficient altitude to allow clearing of local terrain in the subsequent subphases. Although the AM is flying directly against (lunar) gravity to a height of approximately 100 meters, which is quite an inefficient way to fly, it is only for a short time -- not more than 10 seconds.

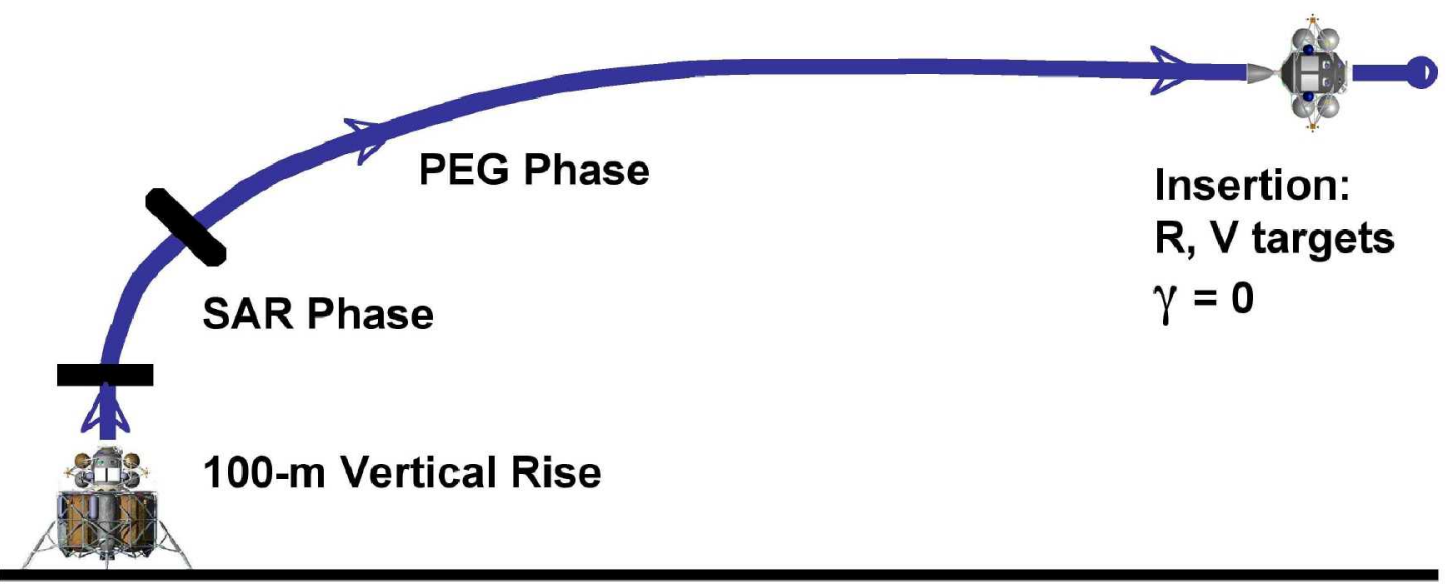

Figure 3. Lunar Ascent Trajectory Schematic. The ascent phase is comprised of a vertical rise subphase, a single-axis rotation maneuver, and a powered explicit guidance (PEG) subphase.

\section{B. Single Axis Rotation}

The SAR maneuver is an attitude-rate and attitude-acceleration limited maneuver designed to re-orient the AM to the desired attitude for the start of the PEG phase as quickly as possible. The earlier in the ascent the SAR is completed, the sooner the optimal flight path can be attained. This subphase is less than 15 seconds (currently 11 seconds), allowing PEG to be engaged at approximately 20 seconds after lunar liftoff. The maximum and desired pitch rate during SAR is 5 degrees per second.

\section{Powered Explicit Guidance}

The PEG subphase is then flown until the AM hits its main engine cutoff (MECO) targets (the AM state at MECO). The current AM flight times to MECO are 401 sec for the Sortie mission, so PEG is flying approximately the last 380-385 seconds of the ascent trajectory. The Outpost mission has a burn time of $430 \mathrm{sec}(\sim 410-415 \mathrm{sec}$ for PEG). PEG is attempting to minimize the AM propellant required (e.g. the $\Delta \mathrm{V}$ as well), so about $95 \%$ of the ascent is optimally controlled. ${ }^{13,14,15}$

\section{Ascent Module Delta Velocities $(\Delta V s)$}

The mission $\triangle \mathrm{Vs}$ for the $\mathrm{AM}$ are tabulated in Table 3 for both the Sortie and Outpost piloted cases. The lunar ascent is a single continuous burn for the AM MPS. The AM MPS uses a $5000 \mathrm{lb}_{\mathrm{f}}(24,500 \mathrm{~N})$ storable propellant engine with an Isp of $320 \mathrm{sec}$, the major difference between the two cases is the different initial mass at lunar liftoff (or abort during descent) for each variation of the vehicle, thus requiring a slightly higher $\Delta \mathrm{V}$ done by the MPS for 
the Outpost mission (Sortie $\mathrm{T} / \mathrm{W}_{0}=0.35$; Outpost $\mathrm{T} / \mathrm{W}_{0}=0.33$ ). The subsequent portions of the missions are nearly identical for the two cases.

The $\Delta \mathrm{V}$ budgets for both the MPS dispersions and a lunar launch window are added to that performed by the MPS. The launch window analyses was performed for a range of launch site latitudes and target orbit inclinations. To envelope three launch opportunities (one attempt two hours prior to nominal liftoff and one attempt two hours after nominal liftoff), $8 \mathrm{~m} / \mathrm{s}$ was determined to be necessary for the worst-case lunar surface location.

Table 3. Altair Ascent Module MPS and RCS $\Delta$ V Summary.

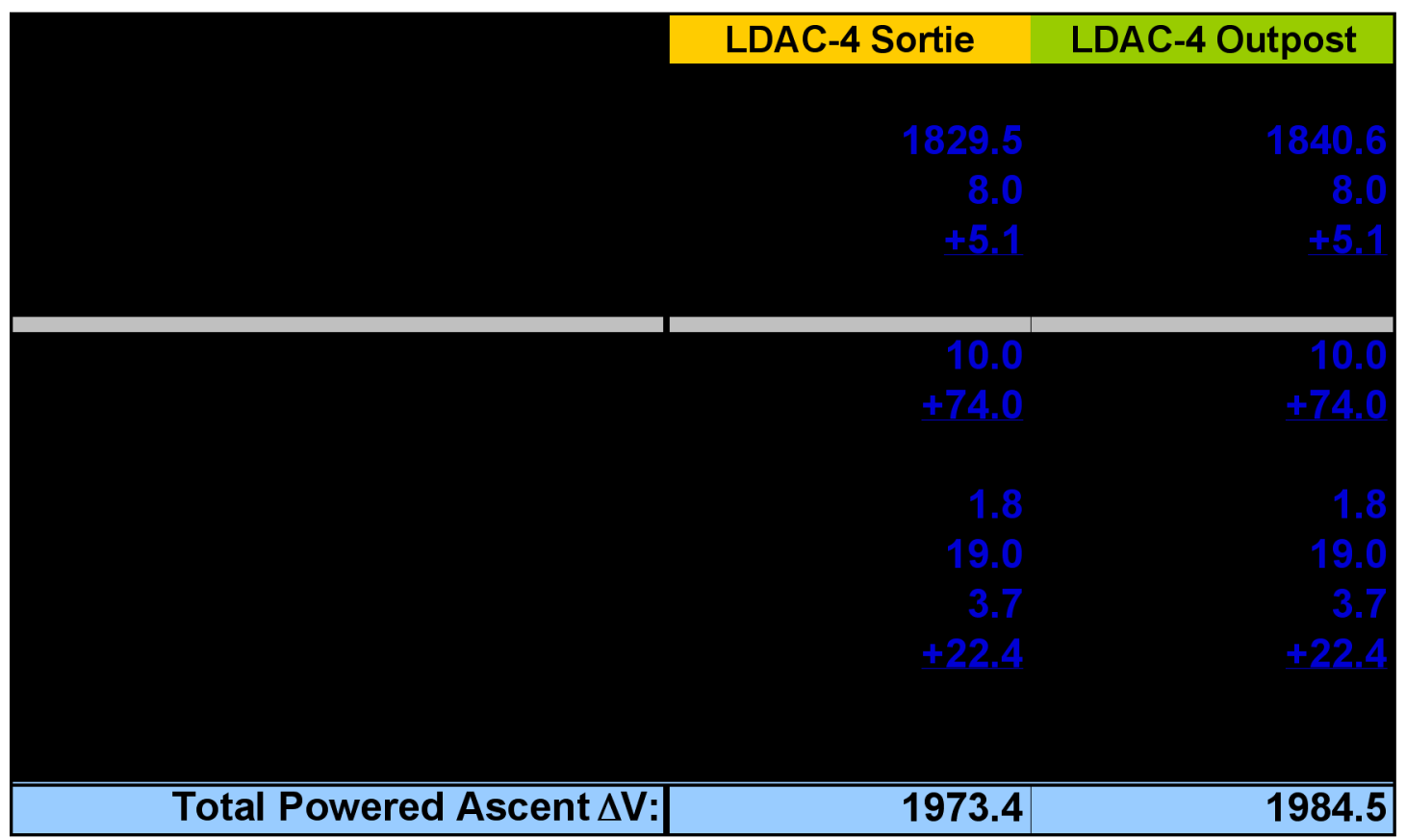

\section{Rendezvous, Proximity Operations and Docking Phase}

As the name implies, the Rendezvous, Proximity Operations, and Docking (RPOD) phase is also comprised of three subphases. The rendezvous phase involves infrequent, discrete maneuvers with coasting phases. The proximity operations phase consists of smaller, more frequent maneuvers, and docking initiates at docking port contact. A simplified graphic of the reference trajectory is shown below in Figure 4.

\section{A. Rendezvous}

To deliver the Altair back to Orion, the RPOD trajectory utilizes an R-bar (i.e. the orbit radius vector) approach. The rendezvous phase begins at insertion and continues until Altair acquires the R-bar. During this time, there are five maneuvers. The Corrective Combination (NCC) burn occurs 10 minutes after insertion to clean up any ascent dispersions and target the proper Terminal Phase Initiation (TPI) point. This time delay should allow Altair to perform relative navigation using its star tracker and S-band communication system for post-insertion estimates of bearing and range/range-rate, respectively.

The TPI burn places Altair on a natural coasting trajectory to acquire the R-bar at a point $2 \mathrm{~km}$ below Orion with a purely radial (Local Vertical, Local Horizontal (LVLH)-Z) relative velocity. Between TPI and the R-bar, three Midcourse (MC) maneuvers shape the trajectory and correct any dispersions.

The MC burns were placed to allow the Altair Laser Imaging, Detection, and Ranging (LIDAR) system to acquire Orion between $\mathrm{MC}_{2}$ and $\mathrm{MC}_{3}$. There is roughly 330 seconds between the outer edge of the LIDAR range and the $\mathrm{MC}_{3}$ burn, which allows plenty of time for the LIDAR to acquire the target and process navigation knowledge prior to performing $\mathrm{MC}_{3}$. Using the improved state knowledge from the LIDAR, Altair is able to significantly reduce its dispersions (by a factor of 4 for downrange and a factor of 22 for altitude) before R-bar acquisition. 
The $2 \mathrm{~km}$ acquisition range was selected as part of a trade study performed during LDAC-2. It must be noted that since the trajectory from TPI to the R-bar is a "coasting" trajectory, the R-bar acquisition distance uniquely determines the location of the TPI point in space. This, in turn, defines the required apolune achieved during ascent.

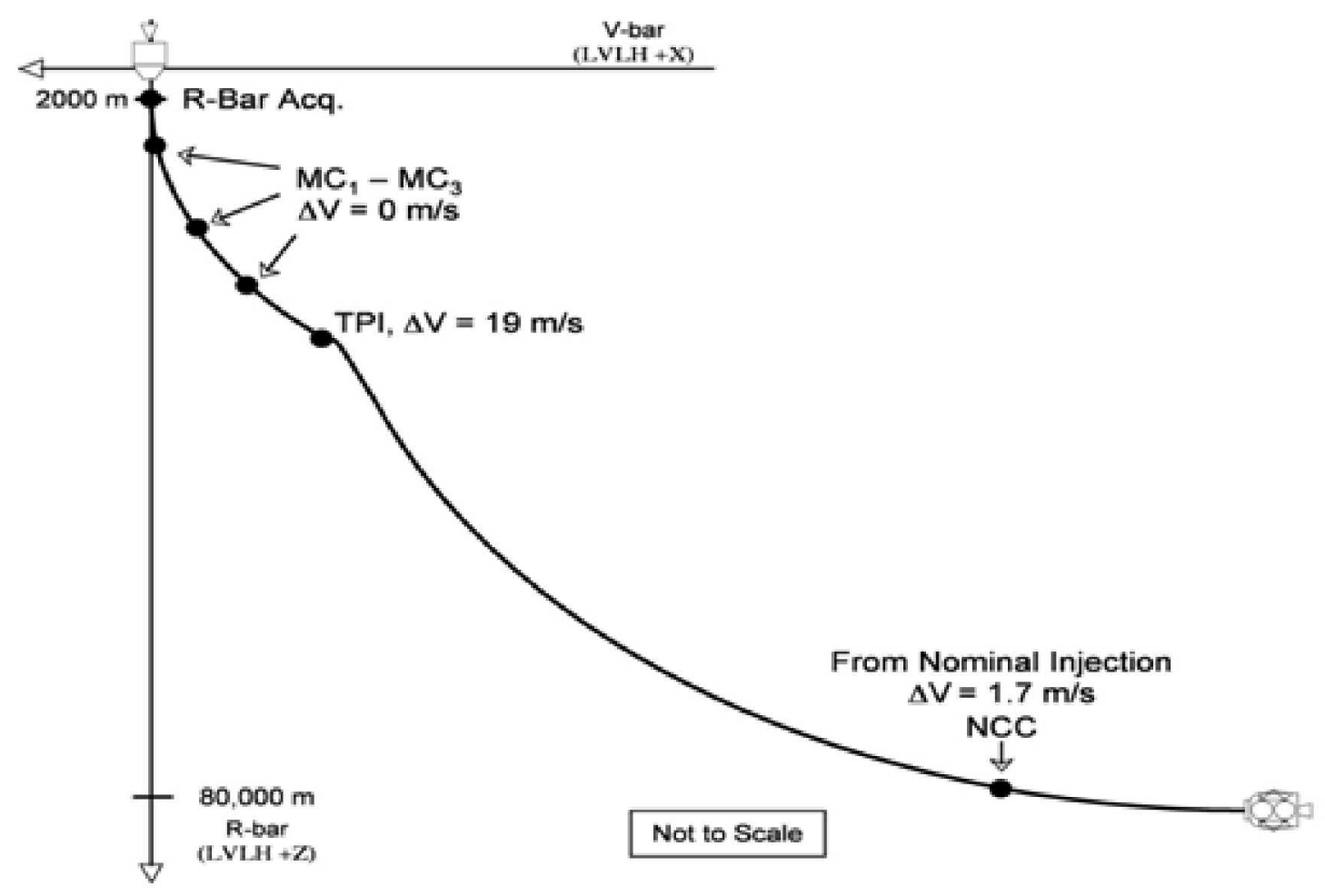

Figure 4. Rendezvous Trajectory Schematic. The RPOD phase is comprised of a rendezvous subphase, a proximity operations maneuvers, and a docking subphase.

\section{B. Proximity Operations}

The Proximity Operations phase begins at R-bar acquisition and concludes at docking port soft contact. To close the distance between the vehicles, Altair performs a series of "glide slope" maneuvers, along with two braking gates, the first a $0.2 \mathrm{~m} / \mathrm{s}$ burn at $100 \mathrm{~m}$, and the second a $0.1 \mathrm{~m} / \mathrm{s}$ burn at $50 \mathrm{~m}$, which serve to reduce the total profile time by nearly 15 minutes. The distance of the vehicles at the times of the braking gates, along with the time between the second braking gate and docking, should provide enough time for any perturbations on Orion from plume impingement to dampen out. However, this assumption should be validated in the future through simulation. At the conclusion of the glideslope maneuvers, Altair is delivered to a docking port-to-docking port (DP-to-DP) range of $10 \mathrm{~m}$ with the proper range-rate for docking, thanks to natural braking from orbital mechanics. This velocity is held constant at $-0.03 \mathrm{~m} / \mathrm{s}$ for the final $10 \mathrm{~m}$ until docking port contact.

\section{Docking}

Altair and Orion will utilize the Low-Impact Docking System (LIDS) for docking. LIDS is a fully androgynous docking system, and is the standard for all docking in the Constellation Program. Any docking system places constraints on the contact conditions at time of docking, and LIDS is no exception. As a 3-DOF tool, Linear Covariance (LinCov) analysis is inappropriate to perform docking analysis, and the simulation was terminated at the beginning of the constant approach. A detailed analysis of Altair/Orion docking in LLO has been performed, however, and the results indicate that the current Altair configuration is able to successfully complete the docking. ${ }^{16}$

A summary of the major RPOD events, the time frame, translational $\Delta \mathrm{Vs}$, and the apolune and perilune are provided in Table 4. The total deterministic $\triangle \mathrm{V}$ for RPOD is $24.4 \mathrm{~m} / \mathrm{s}$. 
Table 4. Altair Rendezvous Sequence for Altair to Orion (1-rev).

\begin{tabular}{|l|c|c|c|}
\hline Trajectory Event & $\begin{array}{c}\text { Phase Elapsed } \\
\text { Time, h:mm:ss }\end{array}$ & $\begin{array}{c}\Delta \text {, Translation } \\
\text { Maneuver }\end{array}$ & $\begin{array}{c}\text { Resultant Apolune } \\
\text { x Perilune }\end{array}$ \\
\hline AM Lunar Liftoff & $0: 00: 00$ & --- & --- \\
\hline Insertion / MECO & $0: 06: 46$ & --- & $79 \times 15 \mathrm{~km}$ \\
\hline Corrective Combination & $0: 16: 46$ & $1.7 \mathrm{~m} / \mathrm{s}$ & $86 \times 14 \mathrm{~km}$ \\
\hline Terminal Phase Initiation & $1: 02: 56$ & $19 \mathrm{~m} / \mathrm{s}$ & $99 \times 85 \mathrm{~km}$ \\
\hline Midcourse Corrections 1, 2,3 & $1: 14: 19-1: 38: 04$ & $0 \mathrm{~m} / \mathrm{s}$ & $99 \times 85 \mathrm{~km}$ \\
\hline R-bar Acquisition & $1: 42: 04$ & $0.4 \mathrm{~m} / \mathrm{s}$ & $99 \times 85 \mathrm{~km}$ \\
\hline 1st \& 2nd Braking Gates & $2: 07: 44,2: 11: 16$ & $0.3,0.1 \mathrm{~m} / \mathrm{s}$ & $100 \times 98,100 \times 99 \mathrm{~km}$ \\
\hline Glide slope maneuvers, total & ---- & $2.9 \mathrm{~m} / \mathrm{s}$ & --- \\
\hline Docking & $2: 23: 29$ & ---- & $100 \times 100 \mathrm{~km}$ \\
\hline \multicolumn{1}{r|}{ Totals: } & $\mathbf{2 : 2 3 : 2 9}$ & $\mathbf{2 4 . 4 ~ m / s}$ & \\
\hline
\end{tabular}

\section{RPOD Dispersions}

An initial analysis of the RPOD maneuver dispersions was performed as a part of the RAC-1 analysis. The tool utilized was a LinCov analysis code. One of the outputs of the LinCov analysis is the statistical mean and standard deviation for each maneuver. To determine the sensitivity of the RPOD profile to various dispersion sources, five different dispersion sources were considered one at a time. These error sources were environment process noise (from gravity perturbations or movement within Altair), the Orion initial navigation state knowledge, RCS performance (variations in thrust and $\mathrm{I}_{\mathrm{sp}}$ ), RCS misalignment, and an estimate of injection errors from a Monte Carlo simulation of the Ascent phase.

Table 5. $\Delta V$ Dispersion Analysis for Altair LLO RPOD.

\begin{tabular}{|c|c|c|c|c|c|}
\hline \multicolumn{8}{|c|}{$1 \sigma \Delta V$ Dispersion } \\
\hline FLAK & $\begin{array}{c}\text { Orion State } \\
\text { Error }\end{array}$ & $\begin{array}{c}\text { Thrust } \\
\text { / Isp }\end{array}$ & Injection & Misalignment & $\begin{array}{c}\text { All } \\
\text { Errors }\end{array}$ \\
\hline
\end{tabular}


The five individual error sources were then simultaneously run to estimate the total profile $\Delta \mathrm{V}$ dispersion. Since each burn occurs in the orbital plane, the nominal plus 3- $\sigma$ values were summed (rather than RSS'd) to obtain a conservative estimate of total dispersion $\Delta \mathrm{V}$. The resultant value was an additional $22.4 \mathrm{~m} / \mathrm{s}$ above the nominal $\Delta \mathrm{V}$, raising the total RPOD $\Delta V$ budget to $47 \mathrm{~m} / \mathrm{s}$. The results of this analysis is provided in Table 5 .

As part of the next analyses cycles, the dispersion sources will be updated with improved vehicle knowledge, and ANTARES simulation development will provide independent verification.

\section{Conclusion}

The current Altair maneuver budget captures all the major $\Delta \mathrm{V}$ needs for this set of missions (Global Access Sortie, Outpost, Cargo) and is a good foundation from which to continue improving fidelity of the trajectory analyses and simulation development. The Altair lunar lander $\Delta \mathrm{V}$ budget estimate and the dispersions for that estimate will continue to mature in fidelity and accuracy over time as the Altair Project Office (APO) Integrated Performance Team develops the Altair vehicle models and trajectory simulations further.

\section{References}

${ }^{1}$ Lee, A.Y., Ely, T., Sostaric, R., Strahan, A.L., Riedel, R.E., Ingham, M., Wincentsen, J., and Sarani, S., "An Overview of the Guidance, Navigation, and Control System Design of The Lunar Lander Altair" Proceedings of the AIAA Guidance, Navigation, and Control Conference, and Exhibit, Toronto, Ontario, Canada, August 2-5, 2010.

${ }^{2}$ Ely, T., Heyne, M., and Riedel, J.E., "Altair Navigation during Trans-Lunar Cruise, Lunar Orbit, Descent, and Landing," Proceedings of the AIAA Guidance, Navigation, and Control Conference, and Exhibit, Toronto, Ontario, Canada, August 2-5, 2010.

${ }^{3}$ Garn, M., Qu, M., Chrone, J., Su, P., Karlgaard, C., 'NASA's Planned Return to the Moon: Global Access and Anytime Return Requirement Implications on the Lunar Orbit Insertion Burns", AIAA-2008-7508, AIAA Astrodynamics Specialist Conference, Honolulu, HI, August 2008.

4 "Integrated Performance and Mission Design," Constellation Program Lunar Capability Concept Review, NASA, Houston, TX, June, 2008 (unpublished).

${ }^{5}$ Sostaric, R.R., Rea, J.R., "Powered Descent Guidance Methods For The Moon and Mars", AIAA-2005-6287, AIAA GN\&C Conference, San Francisco, CA, August 2005.

6 Johnson, Michael C., 'A Parameterized Approach to the Design of Lunar Lander Attitude Controllers', AIAA-2006-6564, AIAA GN\&C Conference, Keystone, CO, August 21-24, 2006.

${ }^{7}$ Paschall, S.C., Brady, T., Cohanim, B.E., Sostaric, R.R., "A Self Contained Method for Safe and Precise Landing", IEEE Aerospace Conference, Big Sky, MT, March 1-8, 2008.

${ }^{8}$ Davis, J.L., Striepe, S.A., Maddock, R.W., Hines, G.D., Paschall, S.C., Cohanim, B.E., Fill, T.J., Johnson, M.C., Bishop, R.H., DeMars, K.J., Sostaric, R.R., and Johnson, A.E., "Advances in POST2 End-to-End Descent and Landing Simulation for the ALHAT Project", AIAA-2008-7508, AIAA Astrodynamics Specialist Conference, Honolulu, HI, August 2008.

${ }^{9}$ Strahan, A.L., Law, H.G., Bilimoria, K.D., and Mueller, E.R., "A Review of Research Into GNC Performance and Interface Design for A Piloted Lunar Landing," Proceedings of the AIAA Guidance, Navigation, and Control Conference, and Exhibit, Toronto, Ontario, Canada, August 2-5, 2010.

${ }^{10}$ Strahan, A.L., and Johnson, A., "Terrain Hazard Detection and Avoidance during the Descent and Landing Phase of the Lunar Lander Altair Mission," Proceedings of the AIAA Guidance, Navigation, and Control Conference, and Exhibit, Toronto, Ontario, Canada, August 2-5, 2010.

11 Apollo Lunar Descent and Ascent Trajectories, NASA TM X-58040, March 1970 (presented at the AIAA 8th Aerospace Sciences Meeting, New York, New York, January 19-21, 1970).

${ }^{12}$ Lee, A.Y., Strahan, A.L., Tanimoto, R., and A. Casillas, "Thrust Vector Control of the Lunar Lander Altair in the Presence of Fuel Sloshing," Proceedings of the AIAA Guidance, Navigation, and Control Conference, and Exhibit, Toronto, Ontario, Canada, August 2-5, 2010.

13 Jaggers, Roland F., "Shuttle Powered Explicit Guidance (PEG) Algorithm", Rockwell Space Operations Company, November 1992, JSC-26122.

${ }^{14}$ McHenry, R.L, Brand, T.J., Long, A.D, Cockrell, B.F., Thibodeau, J.R., "Space Shuttle Ascent Guidance, Navigation, and Control", The Journal of the Astronautical Sciences, Vol. XXVII, No. 1, January-March, 1979.

${ }^{15}$ Ives, D.G., "Shuttle Powered Explicit Guidance Miscellaneous Papers", Aeroscience and Flight Mechanics Division, JSC28774, November 1999.

${ }^{16}$ Sullivan, J., Lee, A.Y., and Grover, R., "Rendezvous and Docking Sensor and Effector System Designs for the Lunar Lander Altair," Proceedings of the AIAA Guidance, Navigation, and Control Conference, and Exhibit, Toronto, Ontario, Canada, August 2-5, 2010. 


\section{AIAA-2010-xxxx}

Altair Descent \& Ascent Reference Trajectory Design and Initial Dispersions Analyses

LDAC-4 $\Delta V$ Budgets

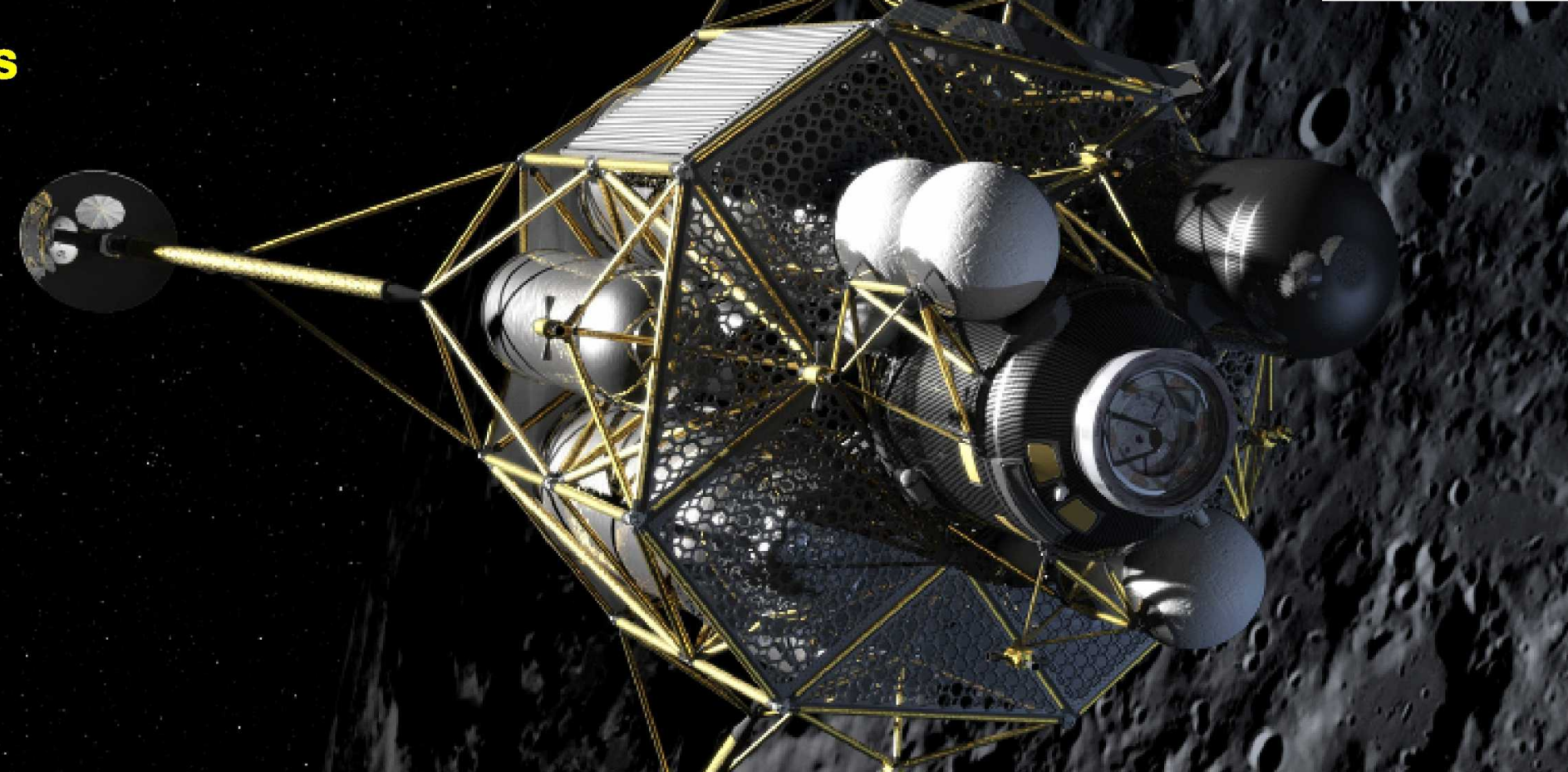

Larry Kos / MSFC/ED04 Altair Integfated Performance Giroup

T. Polsgrove, R. Sostaric, E. Braden, J. Sultivan, T. Ler Altair GN\&C Challenges: Mon. 8/2/2010, 3.30 AIAA GN\&C Conference - Toronto, Ontario, Ganada 


\section{Altair Performance: Outline/Mission Phases}

Mission Phases/Outline:

- Trans-Lunar Cruise/Coast

- TCM $\Delta V s$ \& dispersions

$\checkmark$ Lunar Orbit Insertion

- LOI $\Delta V(s) \&$ clean-up

$\checkmark$ Low Lunar Orbit Loiter

- Attitude and altitude maintenance

- Plane Change $\Delta \mathbf{V}$

- Descent Orbit Insertion $\Delta \mathbf{V}$

Powered Descent

- $\Delta \mathrm{V} \&$ dispersions

- Ascent

- MPS $\Delta$ Vs \& dispersion

- Rendezvous, Prox Ops \& Docking

- RCS $\Delta V s$ \& dispersions

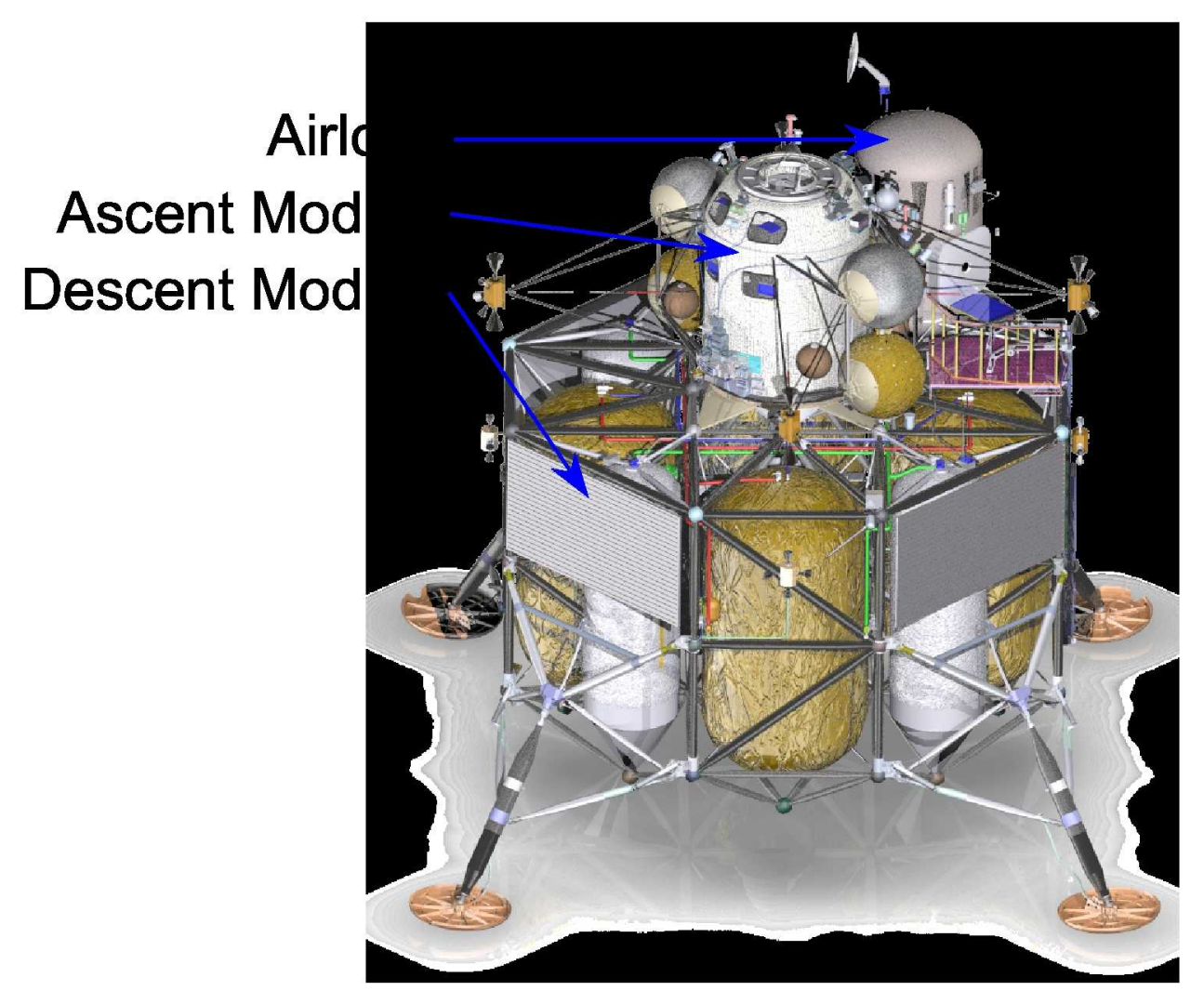


Altair Lunar Lander (LL)

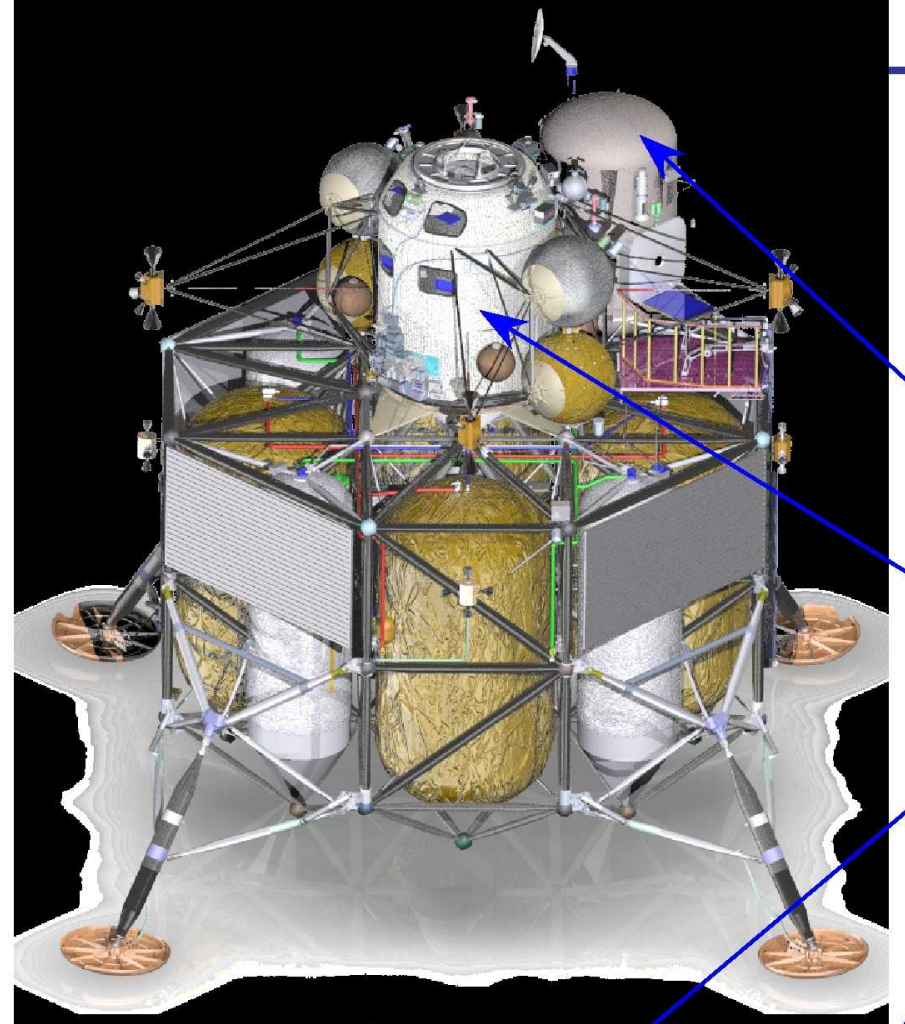

- Altair -- overall L

- $9.1 \mathrm{~m} \times 9.6 \mathrm{~m}$
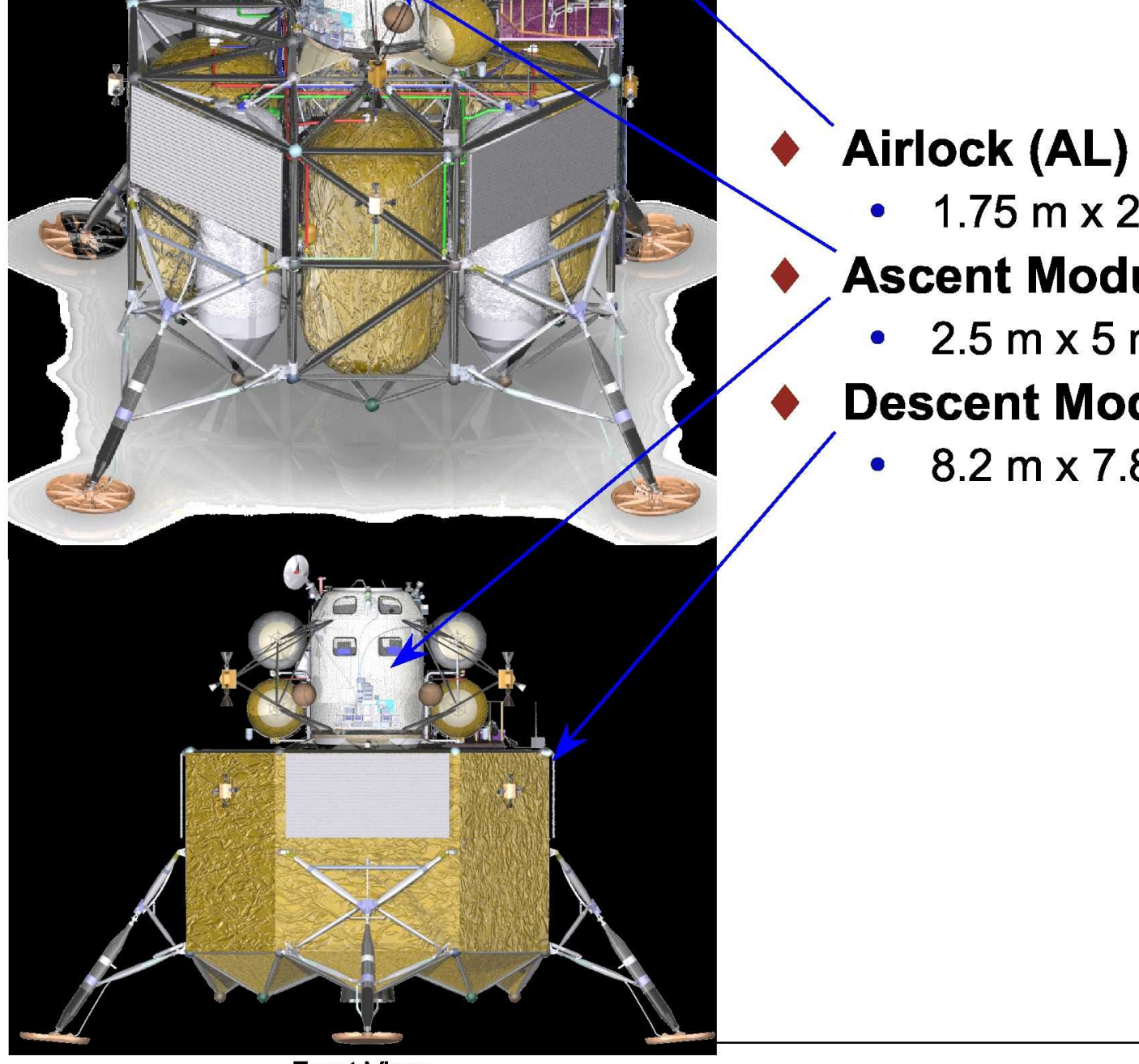

- $1.75 \mathrm{~m} \times 2.75 \mathrm{~m}$ Ascent Module (Al - $2.5 \mathrm{~m} \times 5 \mathrm{~m} \times 5.8$ - Descent Module (L - $8.2 \mathrm{~m} \mathrm{x} 7.8 \mathrm{~m} 6.2$
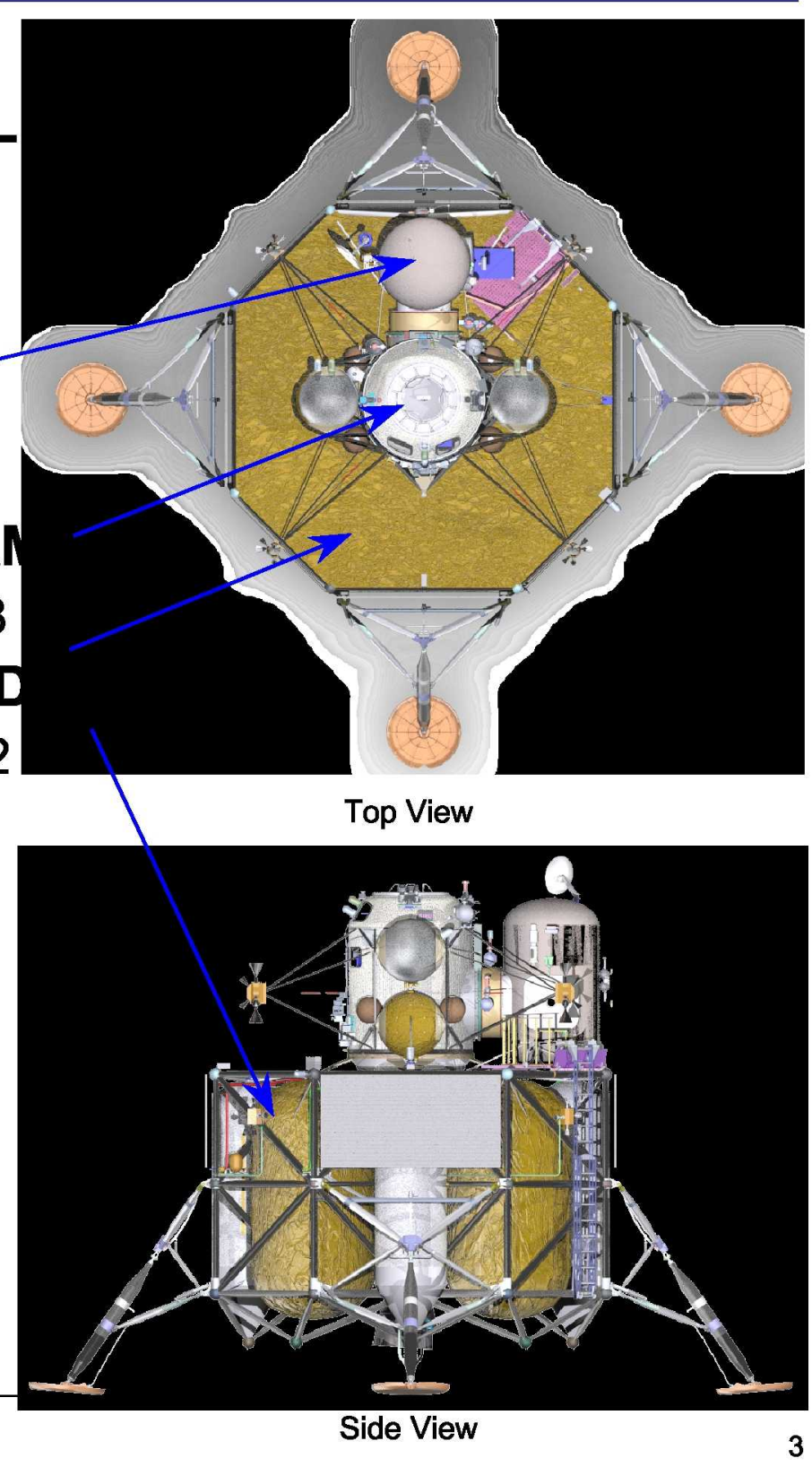


\section{Trans-Lunar Injection (TLI) \& Trans-Lunar Cruise (TLC)}

$\checkmark$ EDS completes the TLI burn (up to $\sim 3165 \mathrm{~m} / \mathrm{s}+$ gravity-losses) and separates from the LL/Orion (CEV)

$\checkmark$ TLC is between 3.7 to 4 days from TLI to Lunar Orbit Insertion (LOI)

$\checkmark$ The LL/CEV stack will fly w/ the CEV-tail-to-Sun most of the time

- This attitude will have the Sun at the head of the lander, with the LL partially shaded by the CEV.

- Due to the unknown direction the DM RCS thrusters will have to fire to perform the Trajectory Correction Maneuvers (TCMs/MCCs), the LL/CEV stack will need to alter its coasting attitude for the TCMs/MCCs, then return to the preferred coasting attitude.

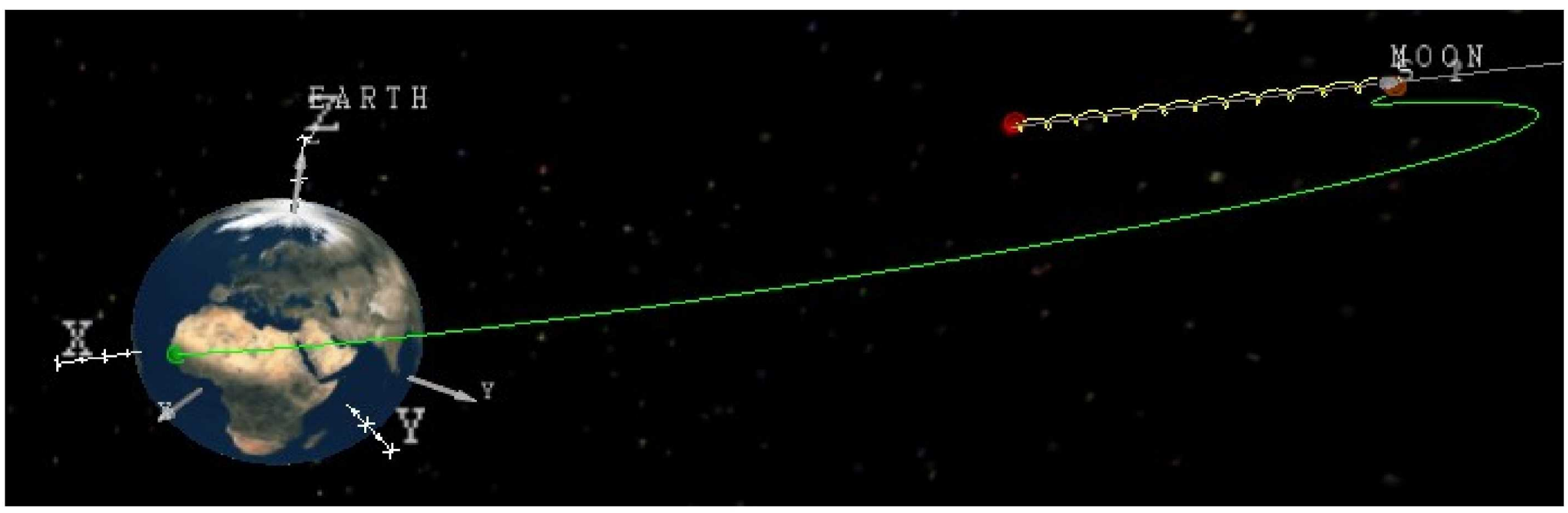

Trans-Lunar Cruise/Coast Trajectory (Earth-fixed frame, Copernicus Trajectory Tool) 


\section{Low Lunar Orbit (LLO) \& S.P. Descent Trajectory}

- LOI burn puts the LL/CEV into a $100 \mathrm{~km}$ circular orbit above the lunar poles

- After a LLO loiter of 1-5 days duration, the LL and CEV will separate

- CEV will do the separation burn

- LL will do up to $1^{\circ}$ plane change $\sim 3 / 4$ rev before descent orbit insertion (DOI)

- $\sim 20$-second burn with DM main engine at 60\% (not required for Cargo or Sortie DRMs)

- DOI to target South Pole $L Z$ uses the four $100-\mathrm{Ib}_{\mathrm{f}}$ axially pointing DM RCS thrusters

- $\sim 6$ minutes for the crewed mission; $~ 9$ minutes for cargo

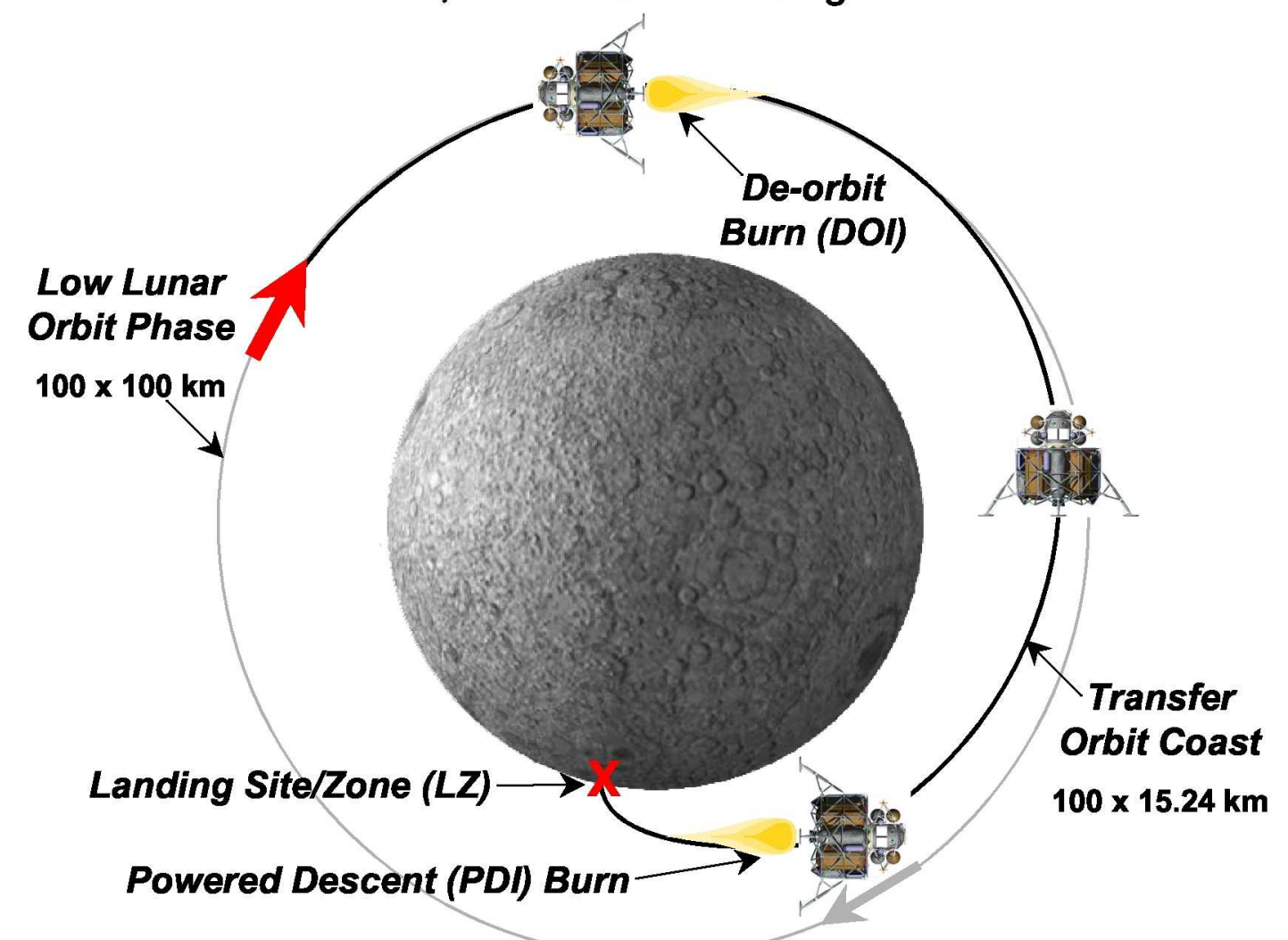




\section{Altair -- Baseline Separation in Polar Orbit}

Undocking to Landing Maneuver Sequence -- Free Return Separation

Initial orbit: Polar

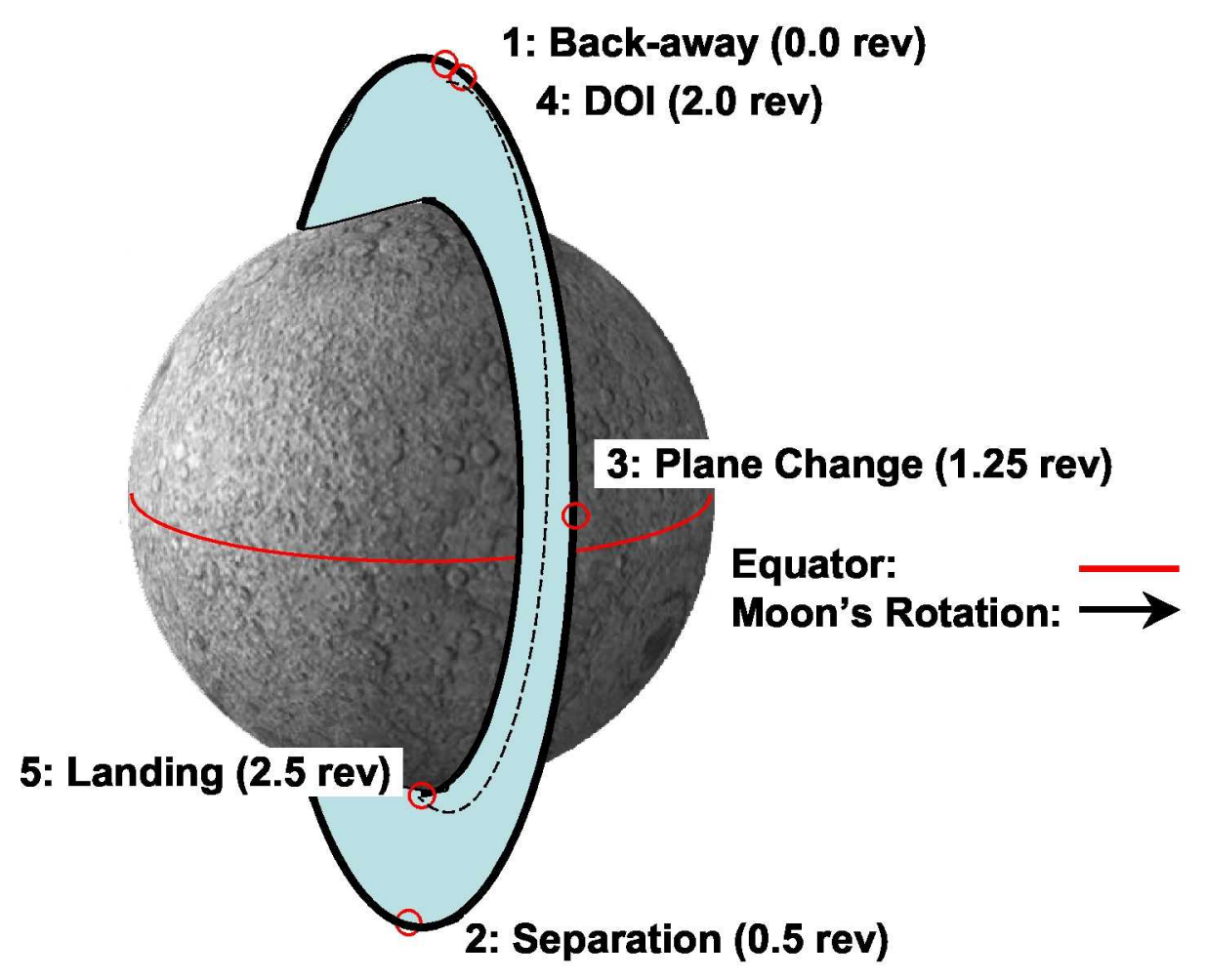

\begin{tabular}{|l|c|l|}
\hline \multirow{2}{*}{$\begin{array}{c}\text { Trajectory } \\
\text { Event }\end{array}$} & $\begin{array}{c}\text { Phase Elapsed } \\
\text { Time }\end{array}$ & $\begin{array}{c}\text { Active } \\
\text { Vehicle }\end{array}$ \\
\cline { 2 - 3 } & hh:mm:ss & \\
\hline Undocking & $00: 00: 00$ & Orion \\
Backaway 1 & $00: 00: 00$ & Orion \\
Backaway 2 & $00: 01: 00$ & Orion \\
Separation & $01: 00: 04$ & Orion \\
Plane Change & $02: 16: 04$ & Altair \\
DOI & $03: 55: 58$ & Altair \\
\hline
\end{tabular}

Aerosciences \& Flight Mechanics Division Robert Merriam / JSC / EG5 / 281-483-3298 


\section{Lunar Descent Trajectory Phases}

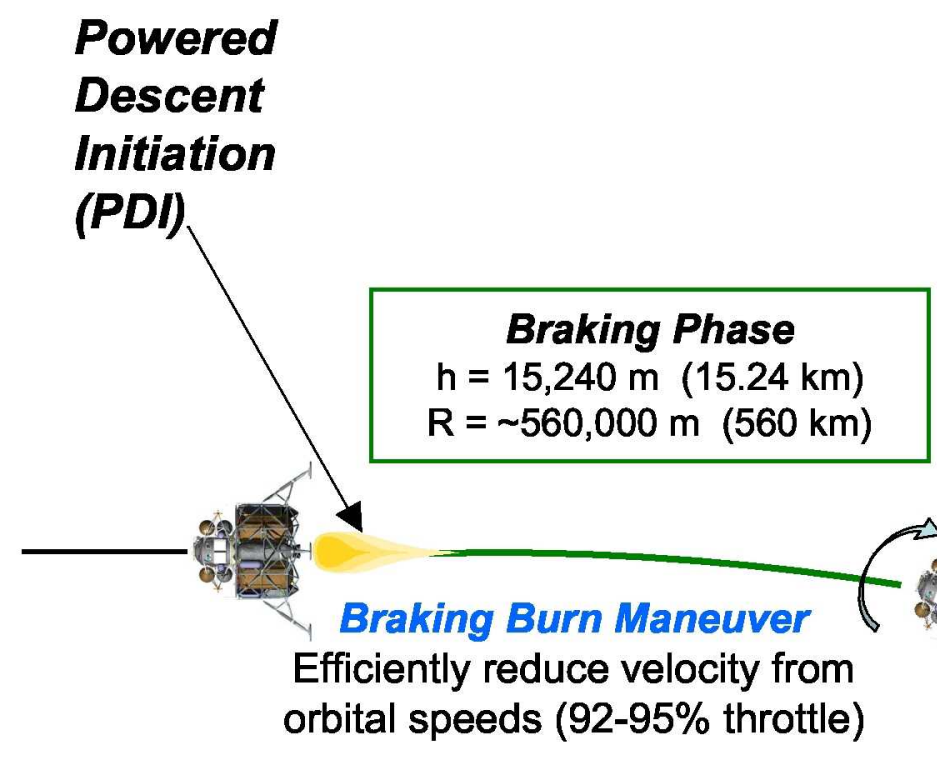

Approach Phase:

- Duration = $77 \mathrm{sec}$;

- $16^{\circ}$ approach path angle
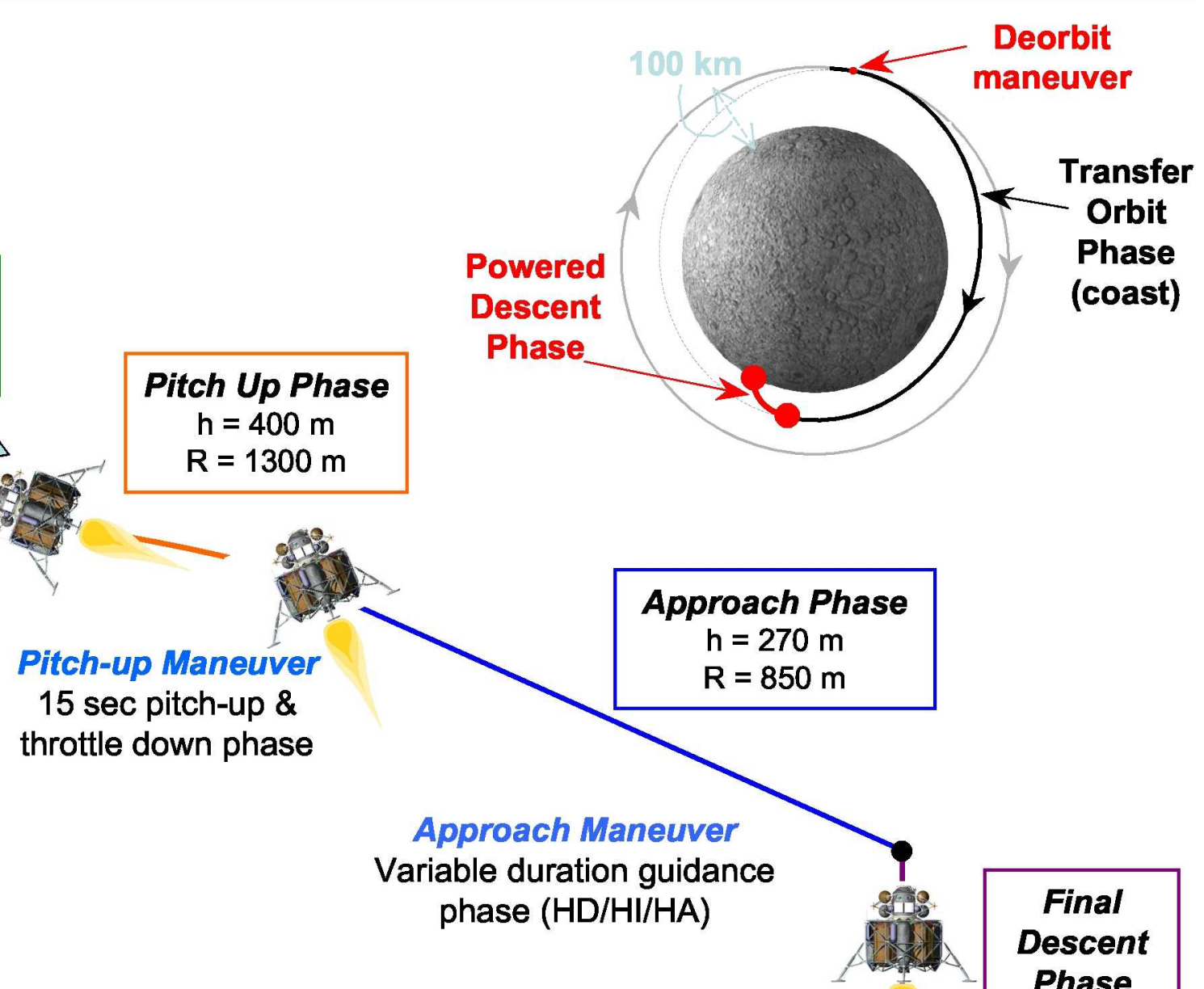

Final
Descent
Phase
$\mathrm{h}_{0}=30 \mathrm{~m}$

Terminal Phase/Vertical Descent Maneuver to Touchdown $30 \mathrm{sec}$ vertical descent to surface at constant acceleration 


\section{Lunar Descent Guidance}

- Algorithm based upon the Apollo Lunar Module Guidance:

- Acceleration profile is modeled/restricted to a quadratic (in each axis):

$$
a=c_{0}+c_{1} t+c_{2} t^{2}
$$

- Solve for coefficients at each guidance call

- Solve for $c_{1}$ and $c_{2}$ using $r_{0}$ and $v_{0}$ (tgo, $r_{t}, v_{t}$, at are given)

$$
\begin{aligned}
& c_{0}=a_{t}-6 \frac{\left(v_{t}+v_{0}\right)}{\operatorname{tgo}+12 \frac{\left(r_{t}-r_{0}\right)}{\operatorname{tgo}^{2}}} \\
& c_{1}=-6 \frac{a_{t}}{\operatorname{tgo}}+6 \frac{\left(5 v_{t}+3 v_{0}\right)}{\operatorname{tgo}^{2}}-48 \frac{\left(r_{t}-r_{0}\right)}{\operatorname{tgo}^{3}} \\
& c_{2}=6 \frac{a_{t}}{\operatorname{tgo}^{2}}-12 \frac{\left(2 v_{t}+v_{0}\right)}{\operatorname{tgo}^{3}}+36 \frac{\left(r_{t}-r_{0}\right)}{\operatorname{tgo}^{4}}
\end{aligned}
$$

$a=$ acceleration command

$t=$ time since last guidance call tgo = time to go until end of phase $v_{0}=$ current velocity $r_{0}=$ current position

$a_{t}=$ acceleration target (at end of phase)

$\mathbf{v}_{\mathbf{t}}=$ velocity target (at end of phase)

$r_{t}=$ position target (at end of phase)

At the time of each guidance call, $t=0$, therefore the command is equal to $c_{0}$

- $\mathrm{c}_{1}$ and $\mathrm{c}_{2}$ only needed between guidance cycles or near end of phase

$\checkmark$ Analytic expression for velocity \& position can be obtained from this solution 


\section{Lunar Descent Dispersions}

- Initial state at Powered Descent Initiation

- PDI: $-71.6^{\circ}$ latitude, $-179.8^{\circ}$ longitude, $15.24 \mathrm{~km}$ altitude

- Landing target (LZ): $-89.9^{\circ}$ latitude, $0^{\circ}$ longitude

- Perfect Navigation

- Guidance Phases

- Braking and Approach Phases: Quadratic acceleration profile

- Terminal Phase: Vertical descent at constant velocity following a proportional error feedback law

- Vehicle Mass Properties

- Constructed of 5 mass bodies (wet AM, dry DM, AL, 2 dynamic masses DM main engine propellant, DM RCS propellant)

DM Effectors

- $\quad$ Gimbaled Main Engine, Max thrust: $18,627 \mathrm{lb}_{\mathrm{f}}$, Isp = $448.6 \mathrm{sec}$

- Thrust Vector Control with a proportional-derivative controller

- Reaction Control System:

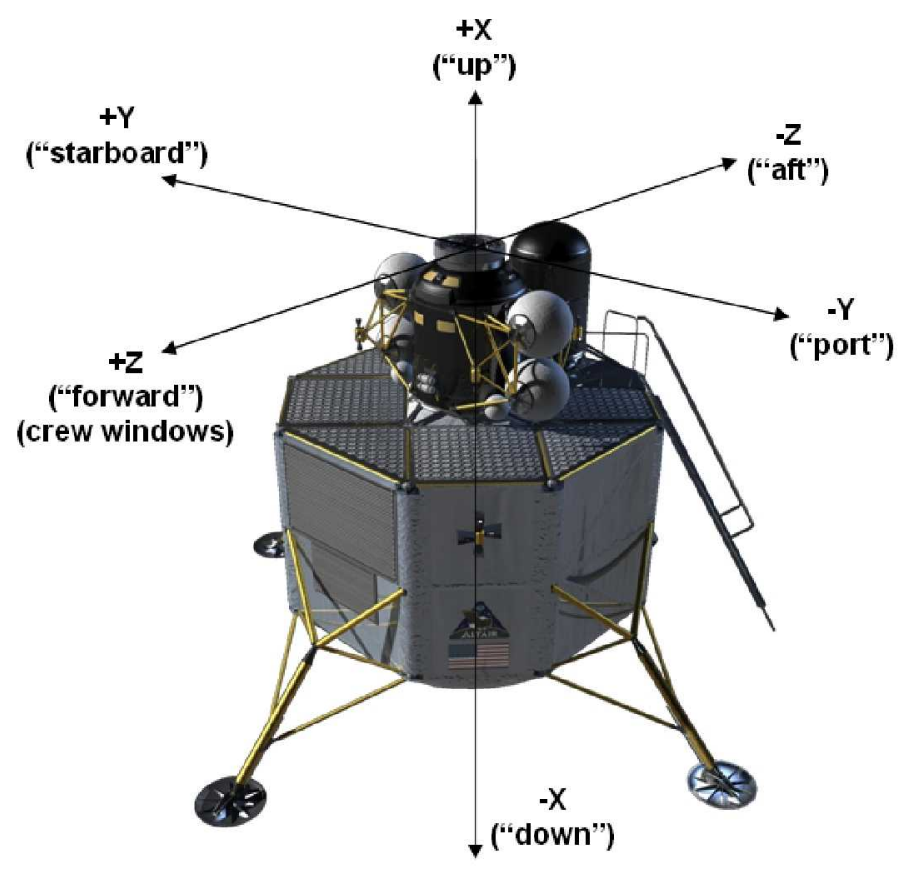

- Sixteen $100 \mathrm{lb}_{\mathrm{f}}$ jets grouped into 4 orthogonal clusters, $0^{\circ}$ skew

- Phase-plane controller

- Calculated cumulative $3 \sigma$ effect by taking root-sum-square of contributing terms: Thrust, $I_{\mathrm{sp}}$, Prop mass, c.g. location, inertias):

- $\left.3 \sigma_{\text {cumulative }}=\sqrt{ }\left[\left(3 \sigma_{\mathrm{Thr}}\right)^{2}+\left(3 \sigma_{\mathrm{lsp}}\right)^{2}+3 \sigma_{\text {prop }}\right)^{2}+\left(3 \sigma_{\text {c.g. }}\right)^{2} . .+\left(3 \sigma_{\text {Ixx }}\right)^{2}+..\right]$

- Cumulative dispersion effect on landing state and $\Delta V$ :

\begin{tabular}{|l|c|}
\hline & Cumulative 30 \\
\hline Range & $14.1 \mathrm{~m}$ \\
\hline Velocity & $3.6 \mathrm{~m} / \mathrm{s}$ \\
\hline Plumbline Pitch & $23.4^{\circ}$ \\
\hline Attitude Rate & $26.2^{\circ} / \mathrm{s}$ \\
\hline Propellant & $443.4 \mathrm{~kg}$ \\
\hline$\Delta \mathbf{V}$ & $\mathbf{2 8 . 3} \mathrm{m} / \mathrm{s}$ \\
\hline
\end{tabular}

With a subset of the variables that could possibly be dispersed, $28.3 \mathrm{~m} / \mathrm{s}$ is less than the Apollo 11/12 $\Delta V$ dispersion of $53 \mathrm{~m} / \mathrm{s}$. 


\section{LDAC-4 DM Sortie/Outpost \& Cargo $\Delta$ Vs}

\begin{tabular}{|c|c|c|c|c|c|}
\hline $\begin{array}{c}\text { Event } \\
*\end{array}$ & Event / Description & $\begin{array}{l}\text { Piloted LL } \Delta \mathbf{V} \\
(\mathrm{s} / \mathrm{o}, \mathrm{m} / \mathrm{s})\end{array}$ & $\begin{array}{l}\text { Burn time } \\
(s / 0, \text { min })\end{array}$ & $\underset{(\mathrm{m} / \mathrm{s})}{\text { Cargo }} \mathbf{L L} \Delta \mathbf{V}$ & $\underset{(\min )}{\text { Burn time }}$ \\
\hline $1-4$ & Midcourse Correction (MCC) & $\leq 25.4$ & $\leq 15.3$ & $\leq 23$ & $\leq 11.5$ \\
\hline 5 & Propellant Settling Burn & 0.55 & 0.3 & 0.65 & 0.3 \\
\hline 6 & Lunar Orbit Insertion (LOI) & $\underset{\text { (3-burn / 1-burn LO) }}{953 \text { / } 894 \text { * }}$ & $11.0 / 10.4$ & $\begin{array}{c}892^{*} \\
\text { (1-burn LOI) }\end{array}$ & 8.7 \\
\hline 7 & LOI Clean-up & $\leq 7$ & $\leq 3.4$ & $\leq 7$ & $\leq 2.9$ \\
\hline 8,9 & Altitude Maint. (Attitude $=30 \mathrm{~kg} / \mathrm{day}$ ) & $\leq 10.1 / 0$ & $\leq 4.8 / 0$ & -- & -- \\
\hline 10 & Plane Change (after CEV Sep.) & $0 / \leq 28.5$ & $0 / \leq 0.3$ & -- & -- \\
\hline 11 & De-Orbit Maneuver (DOI) & 19.4 & $5.6 / 5.7$ & 19.4 & 7.9 \\
\hline 12 & Propellant Settling Burn & 2.15 & 0.6 & 1.65 & 0.7 \\
\hline 13 & Powered Descent (PD+FAL) & 2016* & $12.8 / 13.1$ & $2149^{*}$ & 17.5 \\
\hline & Crew-in-the-Loop & $\mathbf{0}$ & -- & -- & -- \\
\hline & RCS/ACS for Powered Desc. & 11 & -- & 11 & -- \\
\hline & Dispersions & $\leq 53$ & incl. above & $\leq 53$ & incl. above \\
\hline & Landing site re-designation & 5 & incl. above & $\mathbf{0}$ & -- \\
\hline
\end{tabular}

Total: $3026 / 2996 \mathrm{~m} / \mathrm{s}$ (RCS $=76 / 66 \mathrm{~m} / \mathrm{s})$
Total: $3094 \mathrm{~m} / \mathrm{s}$ (RCS= $63 \mathrm{~m} / \mathrm{s}$ ) 


\section{LDAC-4 Ascent: Lift-Off to 1st Perilune (15x86 km)}
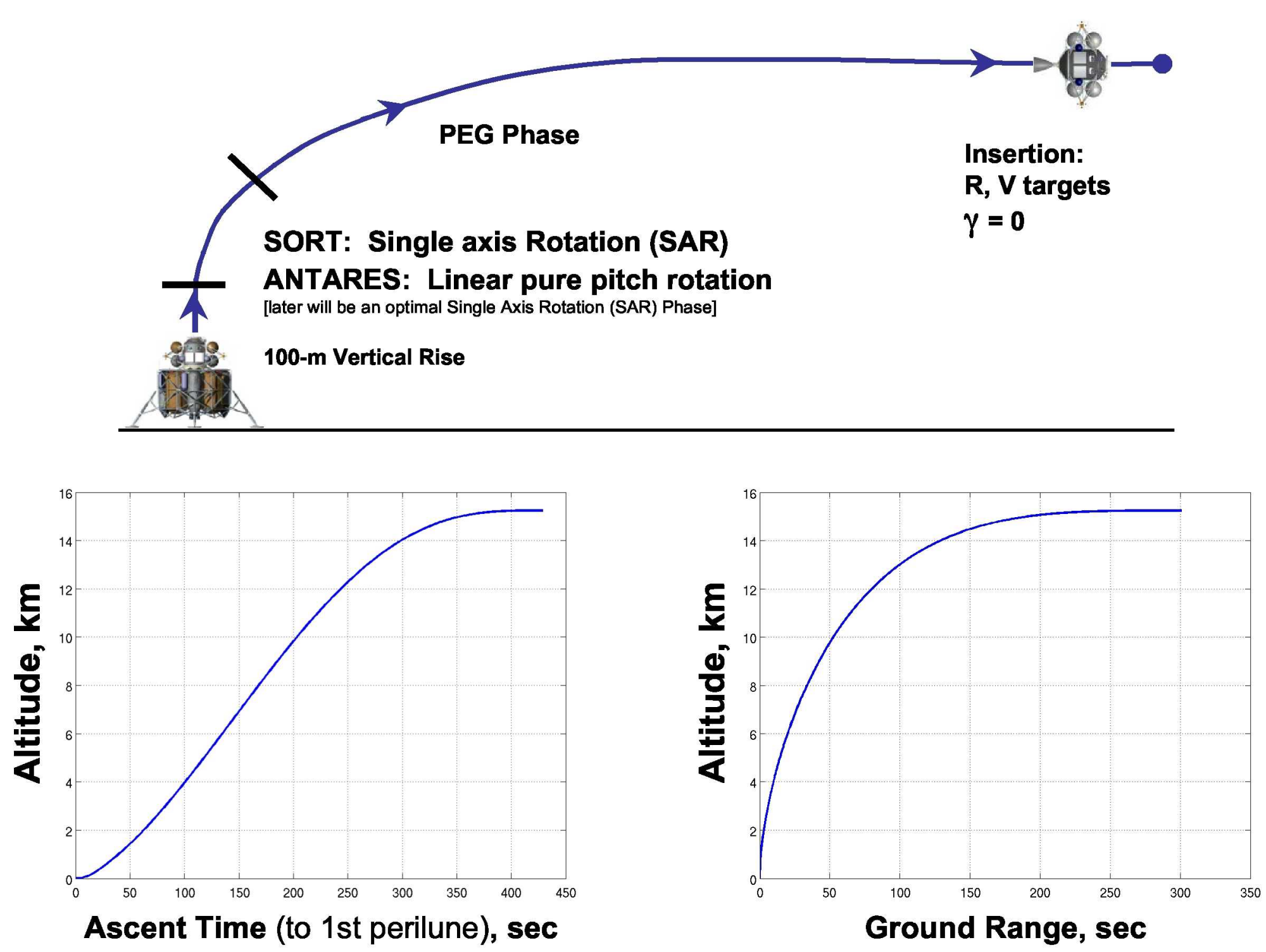


\section{Lunar Ascent Trajectory Profile/Guidance}

Optimal Ascent Region (to orbital insertion):

- Governed by Optimal Control Theory -- PEG

- Majority of ascent

- Final orbit: 15.24 km x $86.2 \mathrm{~km}$ perilune x apolune alt.

\section{Transition Region (SAR):}

- Initial FPA to Optimal FPA

- Pitch Rate $\sim 5 \% / \mathrm{sec}$

- 10-15 seconds in length

\section{Vertical Rise Region:}

- Constant Flight Path Angle (FPA)

- Rise Altitude $=100 \mathrm{~m}$

(for terrain clearance)

- 7-10 seconds in length

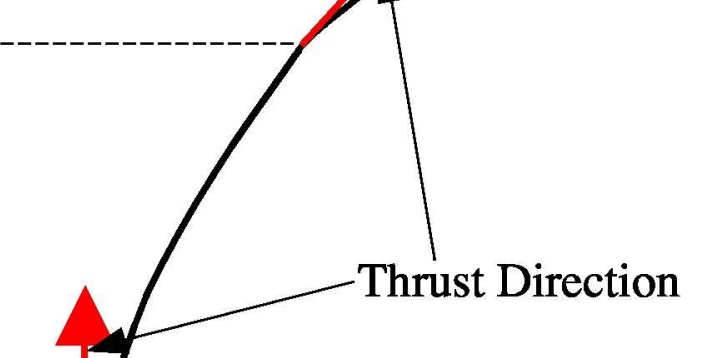

Sortie Summary:

$\Delta \mathrm{V}=1829.5 \mathrm{~m} / \mathrm{s}(\Delta \mathrm{V}$ from SORT simulation)

Total $\Delta \mathrm{V}=1973.4 \mathrm{~m} / \mathrm{s}(\Delta \mathrm{V}$ incl. $8+5+10+47+74 \mathrm{~m} / \mathrm{s})$

Total MPS burn-time: 6.7 minutes

Outpost Summary:

$\Delta \mathrm{V}=1840.6 \mathrm{~m} / \mathrm{s}(\Delta \mathrm{V}$ from SORT $\mathrm{sim})$

Total $\Delta \mathrm{V}=1984.5 \mathrm{~m} / \mathrm{s}(\Delta \mathrm{V}$ incl. $8+5+10+47+74 \mathrm{~m} / \mathrm{s})$

Total MPS burn-time: 7.2 minutes 


\section{Lunar Ascent Dispersions}

\section{- Ascent Module (AM) Initial State}

- $\quad 0^{\circ}$ long., $-89.9^{\circ}$ lat.; Body $+z$-axis (crew windows) facing north

- Perfect Navigation

- Guidance Phases

- 100-meter vertical rise

- Linear pure pitch rotation or SAR

- $5 \%$ s pitch, Single-Axis time optimal Rotation (SAR) equations are derived

- Powered Explicit Guidance (PEG) to orbit insertion (15.24 x $86.2 \mathrm{~km}$ alt.)

- AM Mass Properties

- Constructed of 4 mass bodies (dry AM, 4 propellant dynamic masses)

- AM Effectors

- $\quad$ Main Engine, Isp = $320 \mathrm{sec}$

- Fixed gimbal aligned w/ vehicle c/l; Max thrust: 5500 lbf

- Reaction Control System, Isp = $300 \mathrm{sec}$

- 20 jets grouped into 4 clusters; each cluster: two $200 \mathrm{lb}_{\mathrm{f}}$ thrusters, $\pm X$; one $100 \mathrm{lb}_{\mathrm{f}}$ thruster, $30^{\circ}$ from $\pm Y$ towards $-X$; two $25 \mathrm{l}_{\mathrm{f}}$ thrusters, $45^{\circ}$ from $\pm X$ towards $\pm Z$

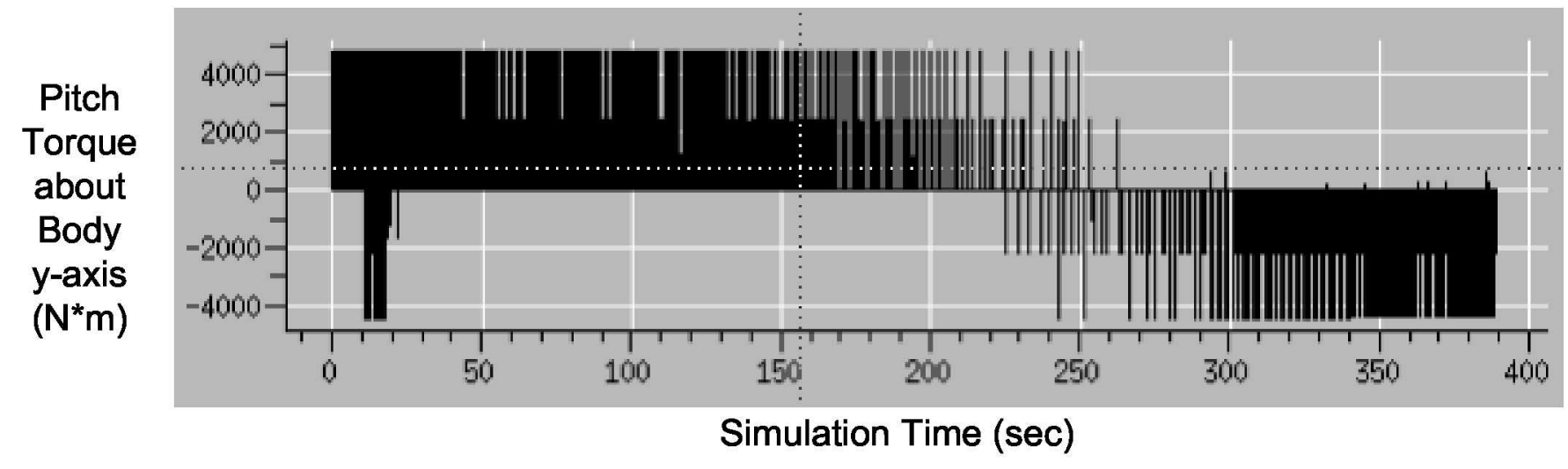




\section{Lunar Ascent Dispersions}

- Initial ANTARES ascent simulation uses $\sim 17 \mathrm{~kg}$ of RCS propellant

- Ascent engine was canted 2.9 from the center-line to align with c.g. location at mid-burn

- Large improvement from early cases

- Apollo ascent RCS fuel consumption was around $50 \mathrm{~kg}$

- Some of this prop was used to assist in liftoff thrust-to-weight

- Best case result (perfect world, constantly centered/balanced c.g.) requires 11 kg

\begin{tabular}{|c|c|c|c|}
\hline Final State & $\begin{array}{l}\text { Nominal } \\
\text { Result }\end{array}$ & & $\begin{array}{l}\text { All } 12 \text { dispersed } \\
\text { simultaneously }\end{array}$ \\
\hline \multirow[t]{2}{*}{ Burn Duration (s) } & 389.35 & mean & 389.16 \\
\hline & & $3 \sigma$ & 8.23 \\
\hline \multirow[t]{2}{*}{$\begin{array}{l}\text { Orbital Radius } \\
\text { Magnitude (m) }\end{array}$} & $1,752,704$ & mean & $1,752,703$ \\
\hline & & $3 \sigma$ & 8.40 \\
\hline \multirow[t]{2}{*}{$\begin{array}{l}\text { Orbital Velocity } \\
\text { Magnitude }(\mathrm{m} / \mathrm{s})\end{array}$} & 1623.02 & Mean & 1623.12 \\
\hline & & $3 \sigma$ & 1.31 \\
\hline \multirow[t]{2}{*}{$\begin{array}{c}\text { Attitude Rate } \\
\text { Magnitude (\%/s) }\end{array}$} & 0.71 & mean & 0.57 \\
\hline & & $3 \sigma$ & 0.75 \\
\hline \multirow[t]{2}{*}{ RCS Propellant (kg) } & 16.46 & mean & 19.10 \\
\hline & & $3 \sigma$ & 7.50 \\
\hline$\Delta V(\mathrm{~m} / \mathrm{s})$ & 1779.03 & mean & 1779.27 \\
\hline \multicolumn{2}{|c|}{$\begin{array}{r}\text { Dispersion result for this } \\
\text { subset of variables: }\end{array}$} & $3 \sigma$ & $3.74 \mathrm{~m} / \mathrm{s}$ \\
\hline
\end{tabular}

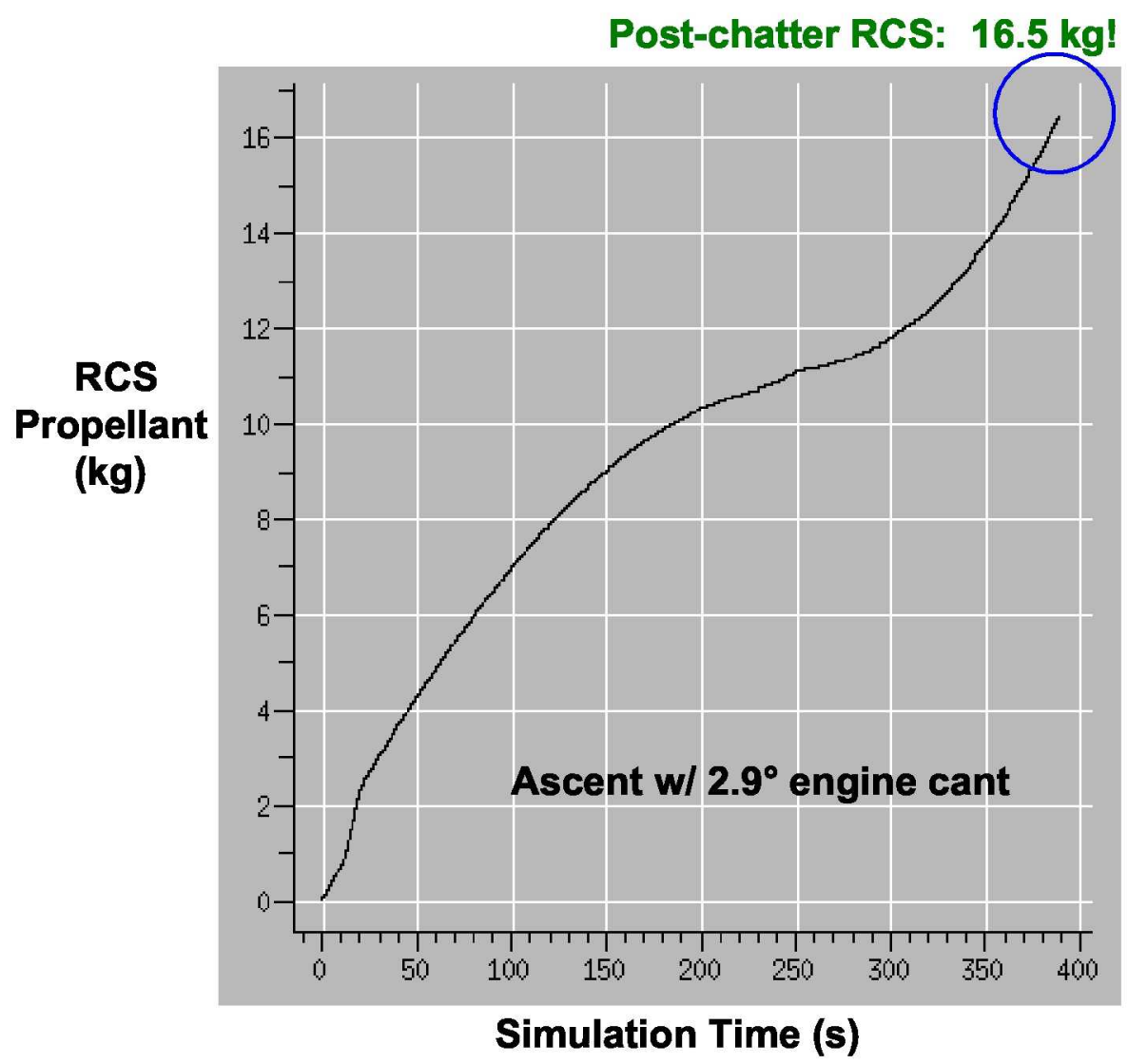

SORT result gives $5.1 \mathrm{~m} / \mathrm{s}$ 


\section{Rendezvous Phase -- Relative Motion}
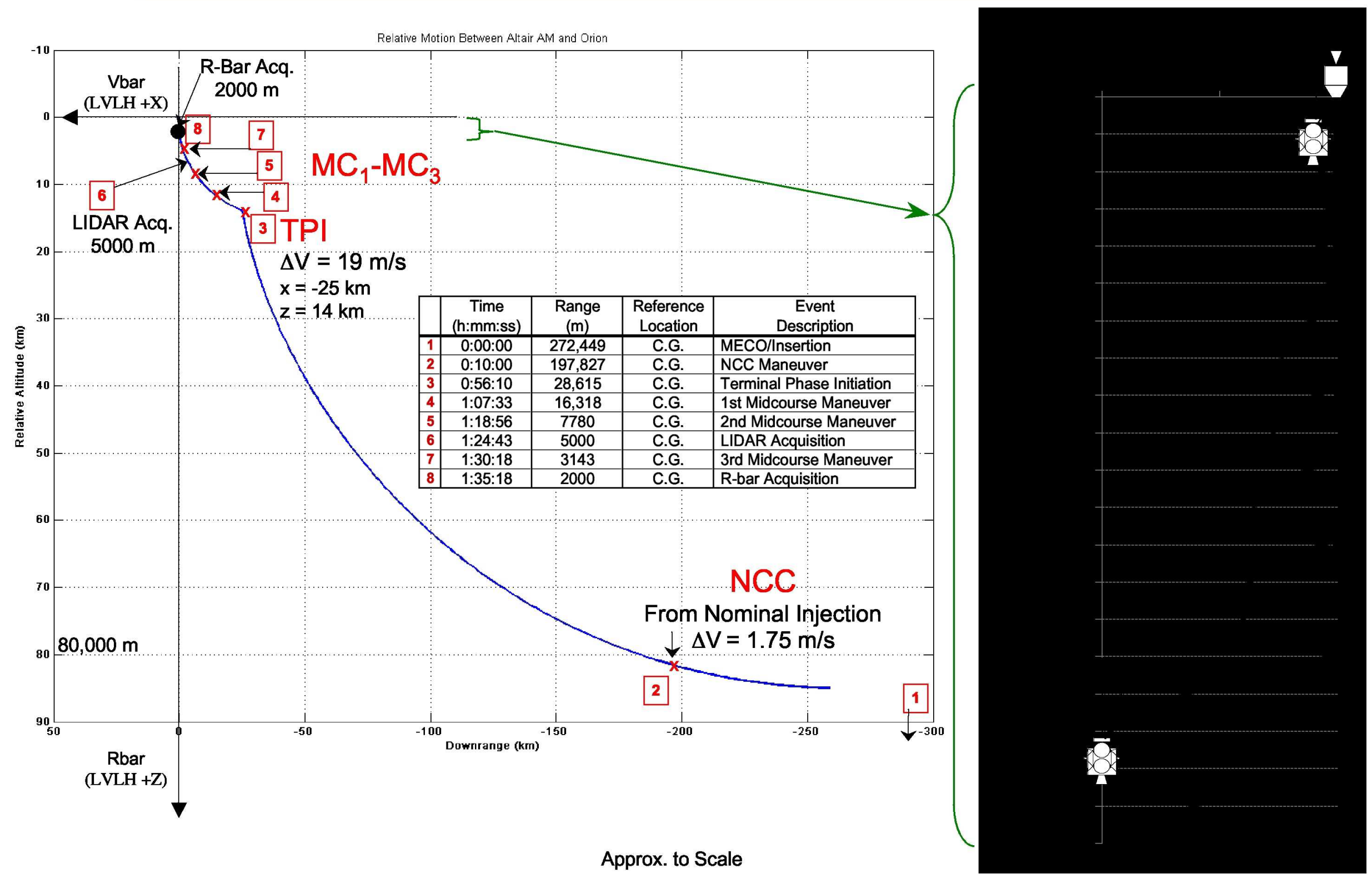

Approx. to Scale 


\section{LDAC-4 Sortie \& Outpost Ascent $\Delta$ Vs}

\begin{tabular}{|c|c|c|c|}
\hline $\begin{array}{c}\text { Event } \\
*\end{array}$ & Event / Description & $\underset{(\mathrm{m} / \mathrm{s})}{\operatorname{Sortie}} \mathbf{A M} \Delta \mathrm{Vs}$ & $\underset{(\mathrm{m} / \mathrm{s})}{\operatorname{Outp}} \mathbf{A V s}$ \\
\hline \multirow[t]{5}{*}{1} & Powered Ascent, deterministic & $1829.5^{\dagger}$ & $1840.6^{\dagger}$ \\
\hline & Ascent Launch Window (mainly Sortie) & 8 & 8 \\
\hline & Ascent Dispersions (MPS) & +5.1 & +5.1 \\
\hline & MPS $\Delta \mathrm{V}$ total: & 1842.6 & 1853.7 \\
\hline & Ascent RCS & $10^{*}$ & $10^{*}$ \\
\hline 2 & Ascent Abort & $74^{*}$ & $74^{*}$ \\
\hline 3 & (Number) Corrective Combination & $1.75^{*}$ & $1.75^{*}$ \\
\hline 4 & TPI & $19.0^{*}$ & $19.0^{*}$ \\
\hline \multirow[t]{5}{*}{$5-13$} & Rend., Prox Ops \& Docking, deterministic & $3.7^{*}$ & $3.7^{\star}$ \\
\hline & RPOD Dispersions & $22.4^{*}$ & $22.4^{*}$ \\
\hline & RPOD $\Delta V$ subtotal: & $+46.8^{*}$ & $+46.8^{*}$ \\
\hline & RCS+RPOD $\Delta V$ total: & $130.8^{*}$ & $130.8^{*}$ \\
\hline & Total $\Delta V$ (MPS+RCS): & 1973.4 & 1984.5 \\
\hline
\end{tabular}




\section{Lander Mission Flight Phases}

- Low Earth Orbit (LEO)

- Rendezvous \& Docking

- Loiter

- Attitude

- Trans-Lunar Injection (TLI) \& Coast

- Trajectory Correction Maneuvers (TCMs)

- Lunar Orbit Insertion (LOI-1, -2, -3)

- Low Lunar Orbit (LLO)

- TCM/MCC during loiter in LLO

- Separation from CEV (= active)

- Plane Change (PI.Ch.) for Polar LZ w/ MPS

- Descent Orbit Insertion (DOI) w/ RCS

\section{$\checkmark$ Descent}

- Powered Descent Initiation (PDI)

- Duration, minutes: PDI to TD

- Braking Burn (BB)

- Approach Phase

- Terminal/Final Approach \& Landing

- Ascent

- Vertical Rise

- Single Axis Rotation (SAR)

- Powered Explicit Guidance (PEG)

- LLO Rendezvous \& Docking

$\checkmark$ AM De-orbit
241 km (130 nmi) circ., $29^{\circ}$ incl.

As soon as Flight Day 1; As late as Flight Day 3 4 days $\max (\sim 93$ hours)

Gravity gradient except for RPOD

4-day trip (nominal)

4 TCM/MCCs @ $25.4 \mathrm{~m} / \mathrm{s}$ (23 m/s for cargo)

3-/1-burn $\Delta V=953 / 894 \mathrm{~m} / \mathrm{s}$ (Cargo $892 \mathrm{~m} / \mathrm{s}$ )

$100 \times 100 \mathrm{~km}$ circular, $\sim 90^{\circ}$ incl.

1 per day very likely, $|\Delta \mathrm{V}|$ uncertain (possibly 2 )

Polar: 2.5 revs prior to TD @ LZ / Global: 1.5 hrs $1^{\circ}=28.5 \mathrm{~m} / \mathrm{s}$

$6 \mathrm{~min}$ (from $100 \times 100 \mathrm{~km}$ to $100 \times 15$ ) (9 min. cargo)

$100 \times 15.24 \mathrm{~km}$ elliptical

$2074 \mathrm{~m} / \mathrm{s}$ (Piloted), $2202 \mathrm{~m} / \mathrm{s}$ (Cargo)

11.1 (Sortie), 10.5 (Outpost), 16.2 (Cargo)

$\sim 92-95 \%$ throttle

$\sim 77 \mathrm{sec}$

(FAL) $\sim 30 \mathrm{sec}$

6.7-7.2 minutes total (MPS to MECO only)

$100 \mathrm{~m}$ in $\sim 8-10 \mathrm{sec}$

$\sim 5^{\circ} / \mathrm{s}$ for $\sim 10-12 \mathrm{sec}$

Rest of AM MPS burn ( $\sim 380-410 \mathrm{sec})$ to $15 \times 86 \mathrm{~km}$

Nominal = $\leq 3 \mathrm{hrs}, 47 \mathrm{~m} / \mathrm{s}$ (14+ burns)

$0 \mathrm{~m} / \mathrm{s}$ currently (nominal $27-60 \mathrm{~m} / \mathrm{s}$ ) 


\section{Trajectory/Performance Back-up}

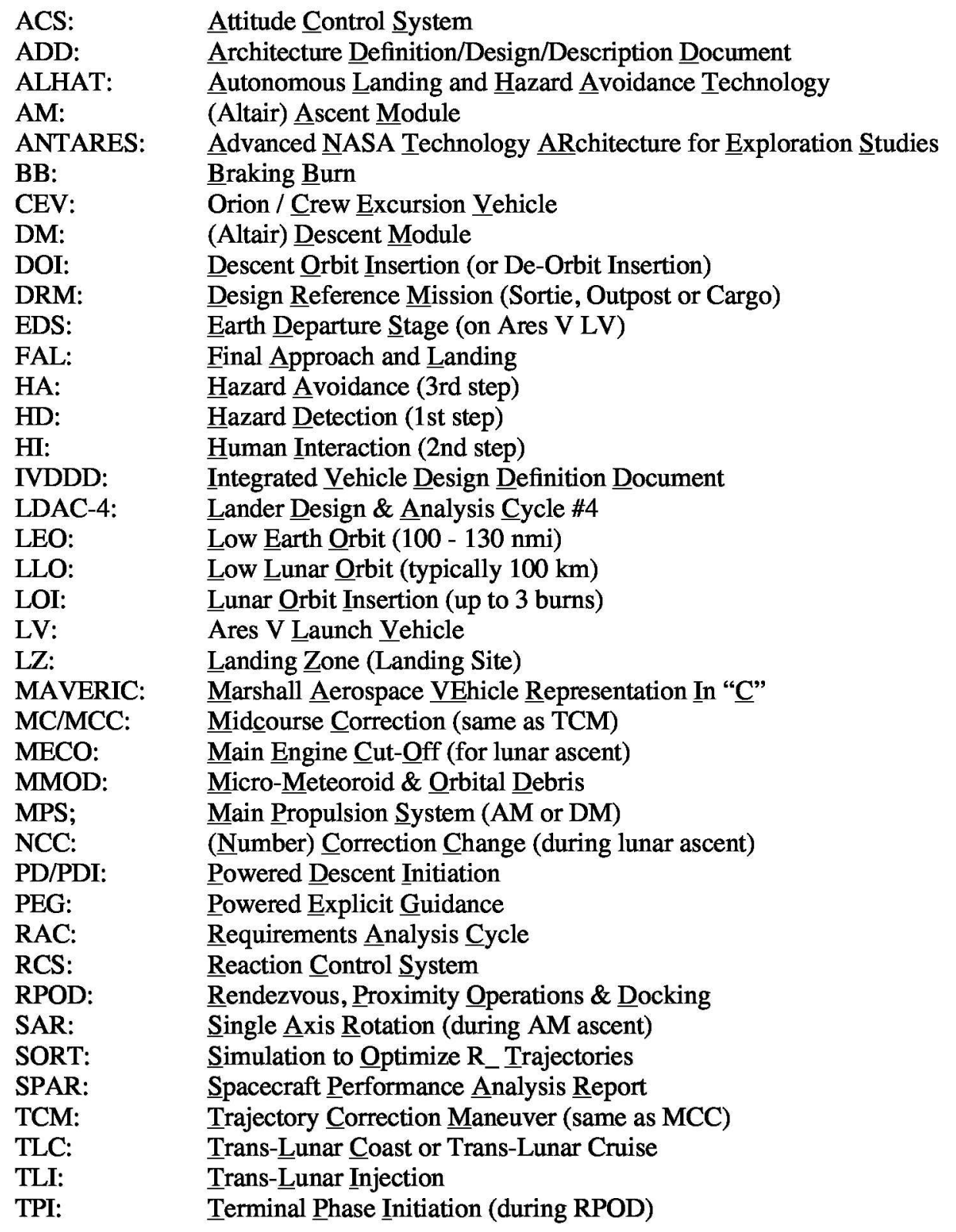




\section{Example Trajectories for Trans-Lunar Coast}

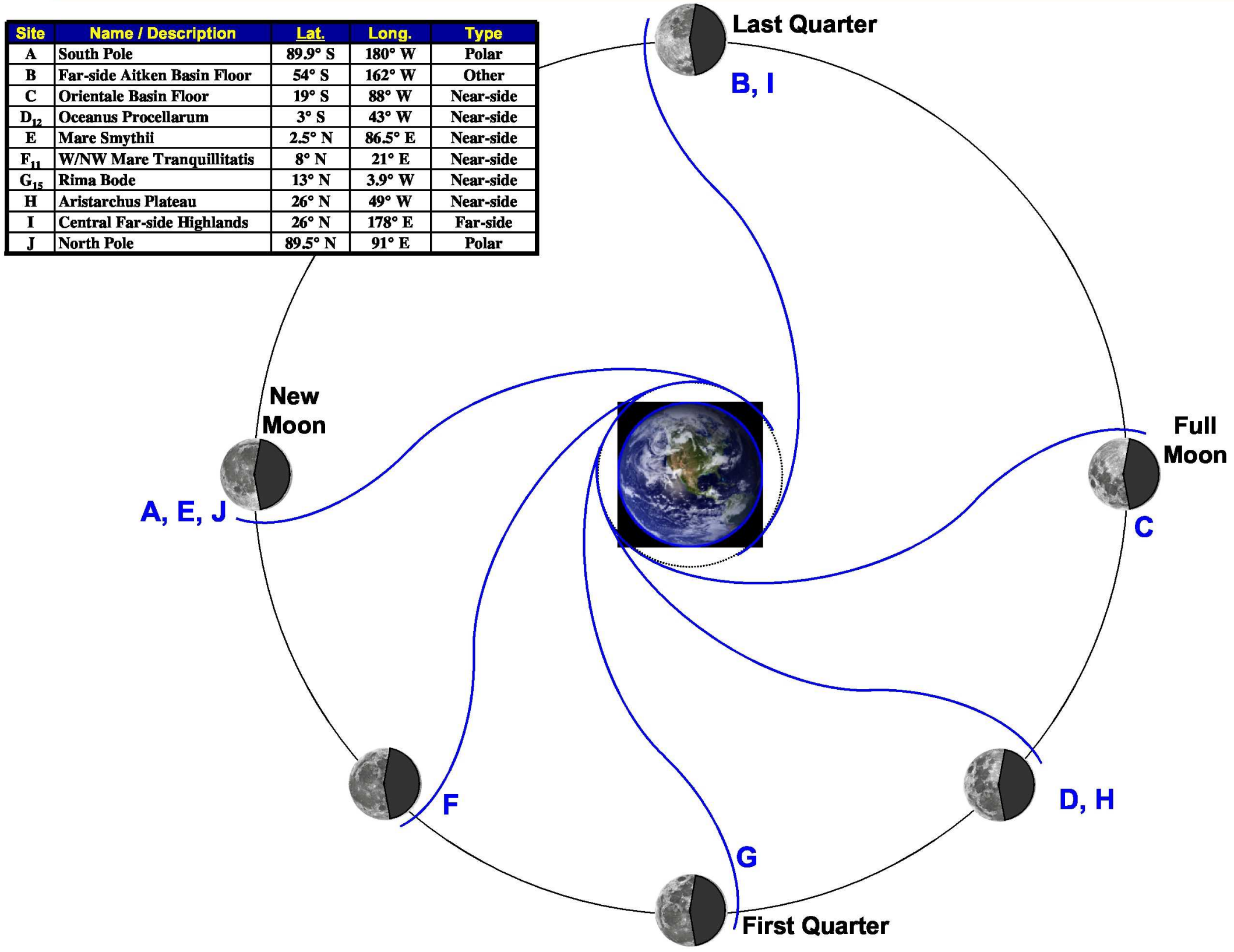




\section{The 10 ESAS Sites \& The 6 Apollo Sites}

\begin{tabular}{|c|c|c|c|c|c|}
\hline Site & Name / Description & Latitude & Longitude & Classification & \# LOI Burns \\
\hline $\mathbf{A}$ & South Pole & $89.9^{\circ} \mathrm{S}$ & $180^{\circ} \mathrm{W}$ & Polar & 1 \\
\hline $\mathbf{B}$ & Far-side Aitken Basin Floor & $54^{\circ} \mathrm{S}$ & $162^{\circ} \mathrm{W}$ & Other & 3 \\
\hline $\mathbf{C}$ & Orientale Basin Floor & $19^{\circ} \mathrm{S}$ & $8^{\circ} \mathrm{W}$ & Near-side & 1 (probably) or 3 (unlikely) \\
\hline $\mathbf{D}_{12}$ & Oceanus Procellarum & $3^{\circ} \mathrm{S}$ & $43^{\circ} \mathrm{W}$ & Near-side & 1 \\
\hline $\mathbf{E}$ & Mare Smythii & $2.5^{\circ} \mathrm{N}$ & $86.5^{\circ} \mathrm{E}$ & Near-side & 1 \\
\hline$\overline{F_{11}}$ & W/NW Mare Tranquillitatis & $8^{\circ} \mathbf{N}$ & $21^{\circ} \mathrm{E}$ & Near-side & 1 \\
\hline$\overline{\mathbf{G}_{15}}$ & Rima Bode & $13^{\circ} \mathbf{N}$ & $3.9^{\circ} \mathrm{W}$ & Near-side & 1 (probably) or 3 (unlikely) \\
\hline $\mathbf{H}$ & Aristarchus Plateau & $26^{\circ} \mathrm{N}$ & $49^{\circ} \mathrm{W}$ & Near-side & 1 (probably) or 3 (possible) \\
\hline $\mathbf{I}$ & Central Far-side Highlands & $26^{\circ} \mathrm{N}$ & $178^{\circ} \mathrm{E}$ & Far-side & 1 (probably) or 3 (possible) \\
\hline $\mathbf{J}$ & North Pole & $89.5^{\circ} \mathrm{N}$ & $91^{\circ} \mathrm{E}$ & Polar & 1 \\
\hline
\end{tabular}

\begin{tabular}{|c|c|c|c|c|c|}
\hline Site & Name / Description & \multicolumn{2}{|c|}{$\begin{array}{l}\text { Latitude / Longitude } \\
\text { Source: National Space Science Data Center }\end{array}$} & Classification & $\begin{array}{l}\text { \# LOI Burns }(\mathbf{\Delta V}, \mathbf{m} / \mathbf{s}) \\
\text { Source: Apollo By The Numbers, SP-4029 }\end{array}$ \\
\hline Apollo 11 & Mare Tranquillitatis & $0.67^{\circ} \mathrm{N}$ & $23.47^{\circ} \mathrm{E}$ & Near-side & $1(889 \mathrm{~m} / \mathrm{s})$ \\
\hline Apollo 12 & Ocean of Storms & $3.01^{\circ} \mathrm{S}$ & $23.42^{\circ} \mathrm{W}$ & Near-side & $1(881 \mathrm{~m} / \mathrm{s})$ \\
\hline Apollo 14 & Fra Mauro & $3.65^{\circ} \mathrm{S}$ & $17.47^{\circ} \mathrm{W}$ & Near-side & $1(921 \mathrm{~m} / \mathrm{s})$ \\
\hline Apollo 15 & Hadley-Apennine region & $\mathbf{2 6 . 1 3}^{\circ} \mathrm{N}$ & $3.63^{\circ} \mathrm{E}$ & Near-side & $1(914 \mathrm{~m} / \mathrm{s})$ \\
\hline Apollo 16 & Descartes Highlands & $8.97^{\circ} \mathrm{S}$ & $15.50^{\circ} \mathrm{E}$ & Near-side & $1(854 \mathrm{~m} / \mathrm{s})$ \\
\hline Apollo 17 & Taurus-Littrow Highlands & $20.19^{\circ} \mathrm{N}$ & $30.77^{\circ} \mathrm{E}$ & Near-side & $1(911 \mathrm{~m} / \mathrm{s})$ \\
\hline
\end{tabular}




\section{High Priority Lunar Exploration Sites}

\section{Near Side}

Far Side

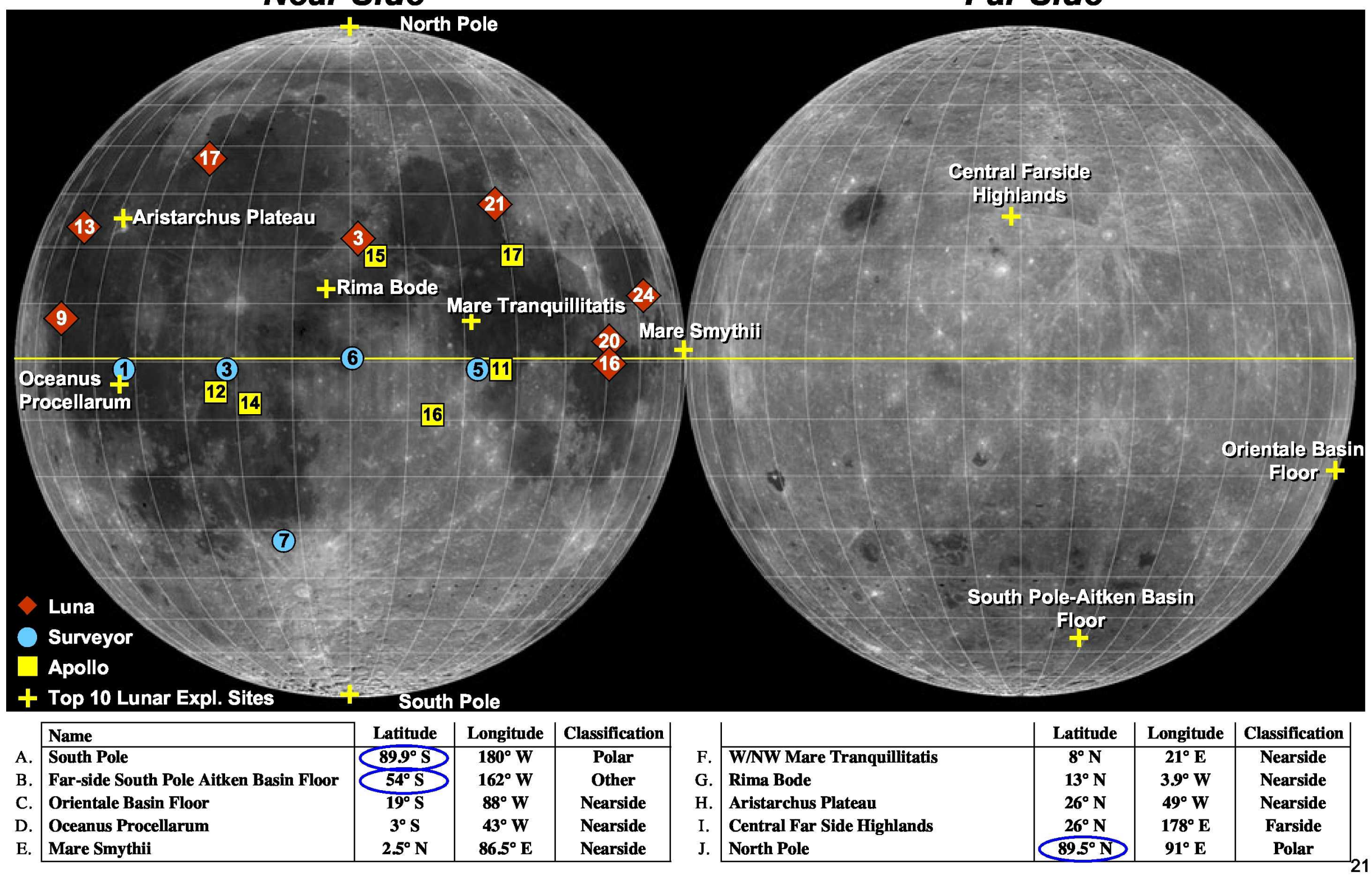




\section{High Priority Lunar Exploration Sites}

\section{Near Side}

Far Side

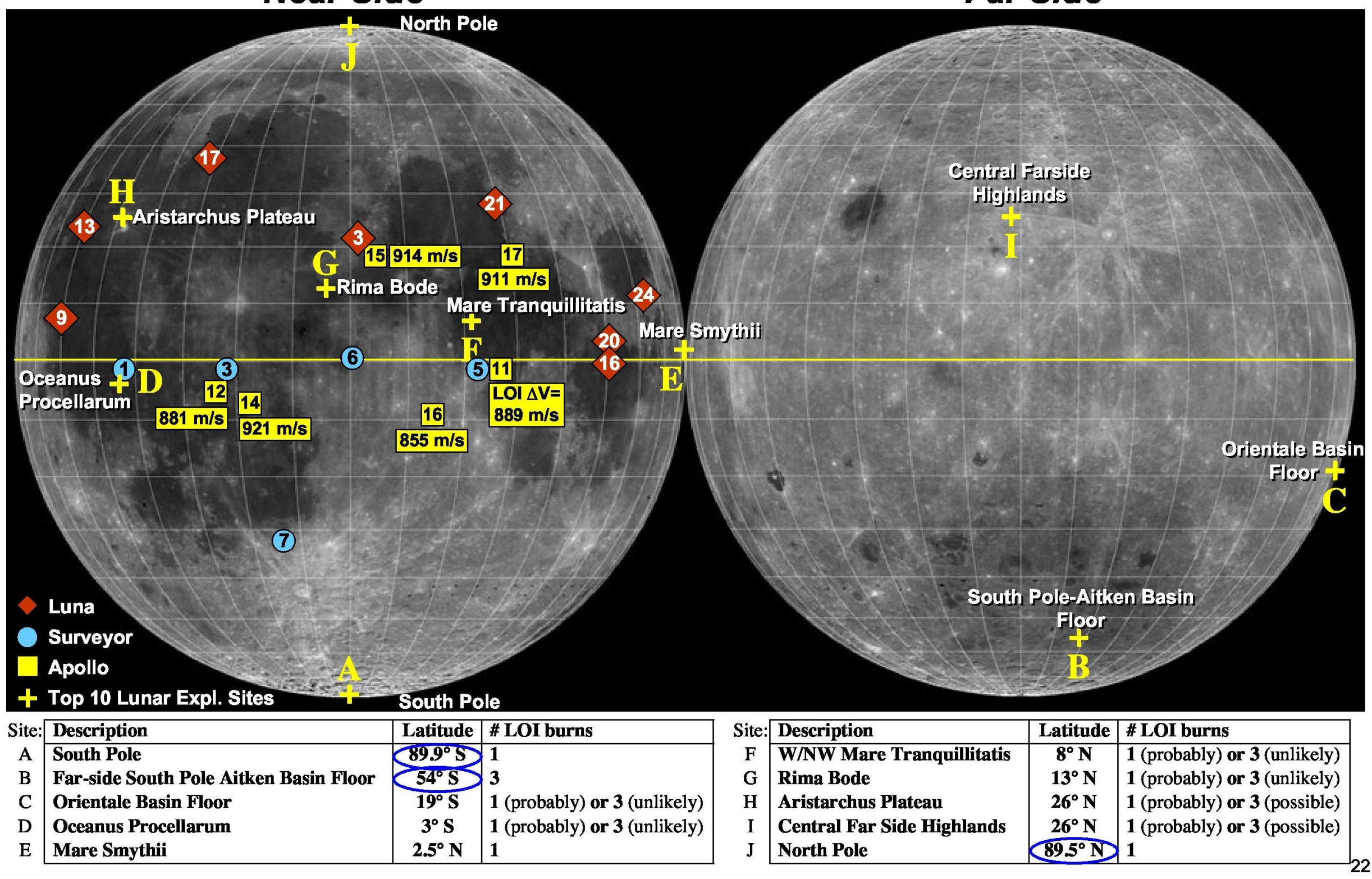




\section{Geometry of the Earth-Moon System}

1-1175-1-21D

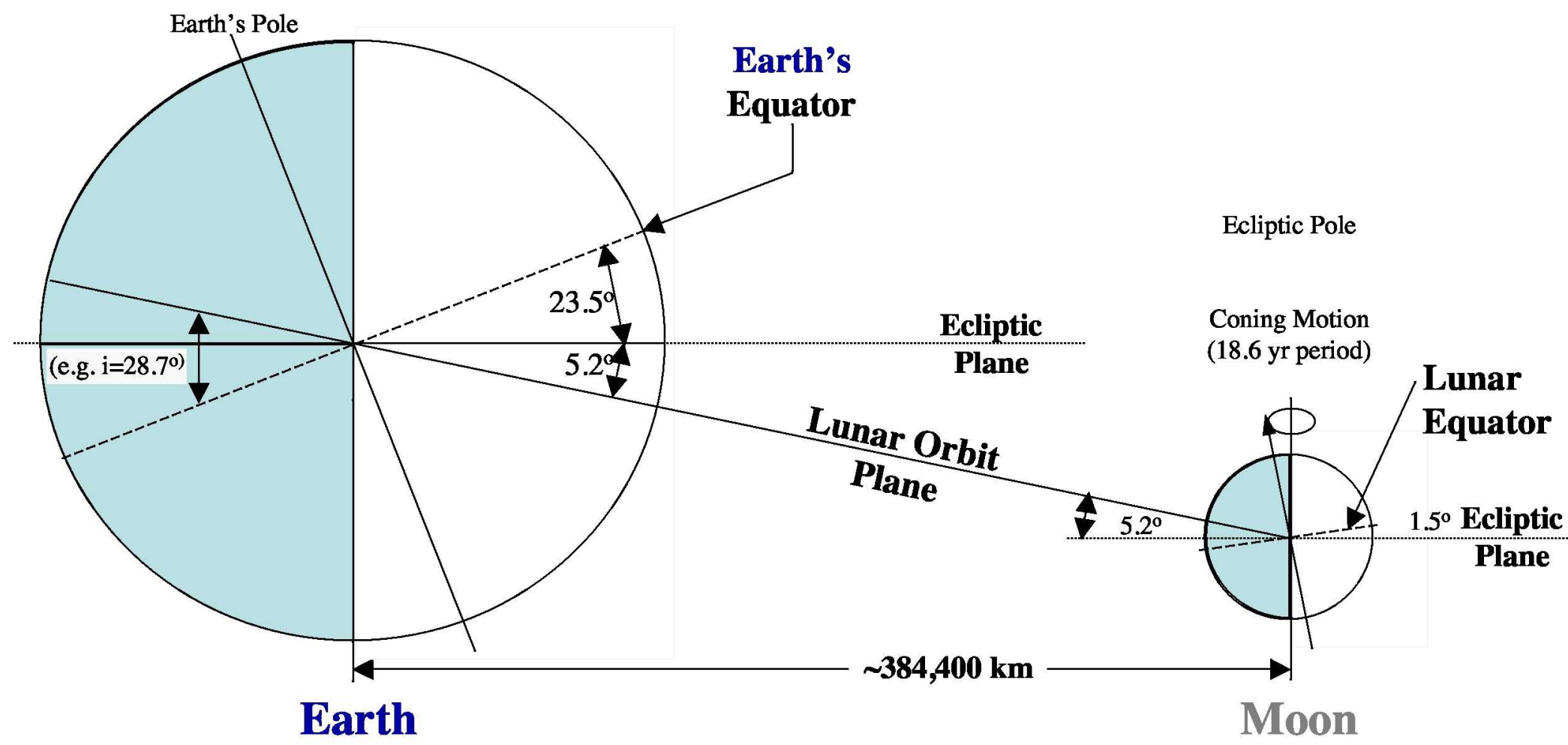

S

$\mathrm{U}$

$\mathbf{N}$

S

$\mathrm{N} \longleftarrow$

Jim McCarter / PD32

1-1175-11-21D 


\section{Translunar Injection and Coast}

- Other Views: Moon-centered (top); Rotating (bottom)

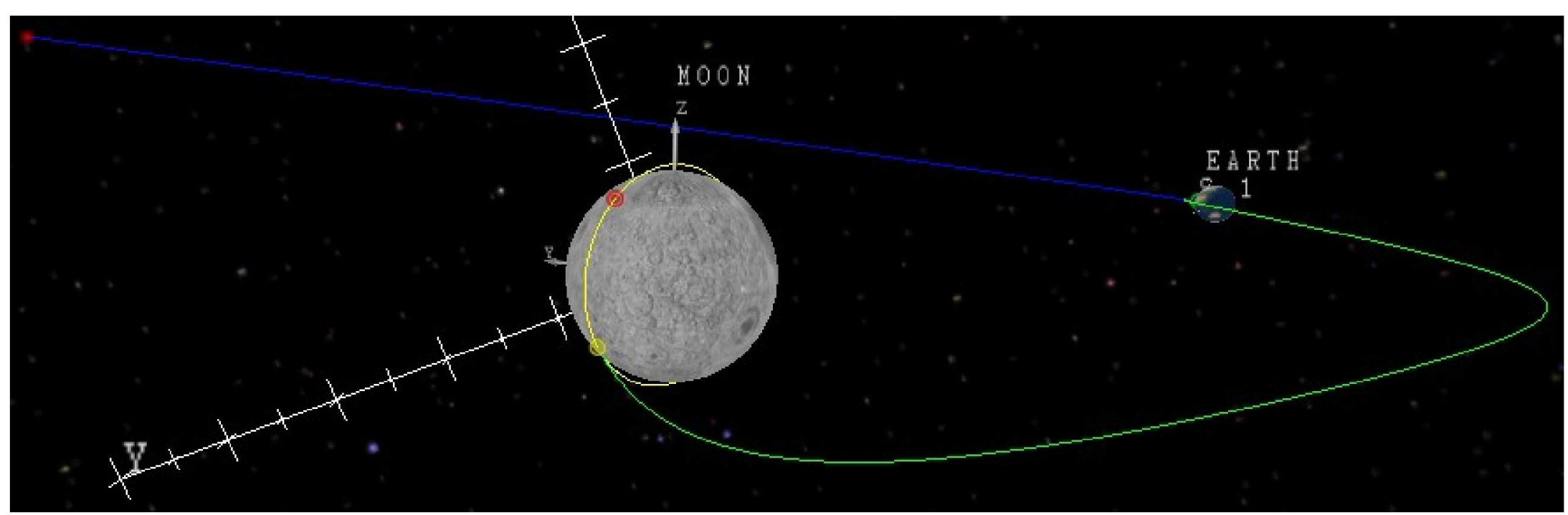

Trans-lunar coast trajectory (Moon-fixed frame)

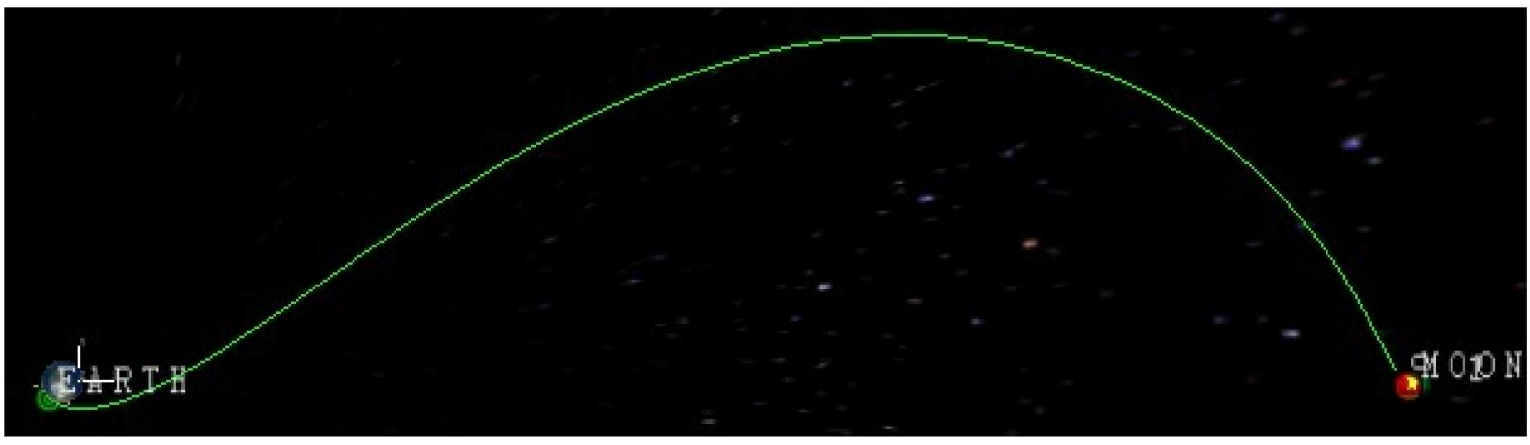

Trans-lunar coast trajectory (Rotating frame) 


\begin{tabular}{|c|c|c|c|}
\hline Event / Description & $\begin{array}{l}\text { LDAC-1 } \Delta V s \\
\text { (Ltd., } \mathrm{m} / \mathrm{s} \text { ) }\end{array}$ & $\begin{array}{c}\operatorname{LRAC-2} \Delta \mathrm{Vs} \\
\left(3 \sigma, \mathrm{m} / \mathrm{s}^{*}\right)\end{array}$ & $\begin{array}{c}\text { Apollo } 14 \Delta \mathrm{Vs} \\
\text { (ABTN, m/s) }\end{array}$ \\
\hline Trajectory/Midcourse Correction (TCM/MCC)-1 & 2 & $\begin{array}{c}21.5 \\
\text { (MET: } \mathrm{TLI}+2 \text { to } 3 \text { ) }\end{array}$ & $\begin{array}{c}21.7 \\
\text { (GET: TLI + 28:08) }\end{array}$ \\
\hline TCM / MCC-2 & $\mathbf{0}$ & $\begin{array}{c}2.0 \\
\text { (MET: TLI+ 24) }\end{array}$ & $\mathbf{0}$ \\
\hline TCM / MCC-3 & $\mathbf{0}$ & $\begin{array}{c}3.7 \\
\text { (MET: TLI + 62) }\end{array}$ & $\mathbf{0}$ \\
\hline TCM / MCC-4 & $\mathbf{0}$ & $\begin{array}{c}2.6 \\
\text { (MET: LOI - 8) }\end{array}$ & $\begin{array}{c}1.1 \\
\text { (GET: TLI+ 74:38) }\end{array}$ \\
\hline Totals (Statistical: RSS'd, Actual: Summed): & 2 & 25.4 & 22.8 \\
\hline
\end{tabular}

GR\&A for LRAC-2 TCM Analyses:

- FLAK = un-Fortunate Lack of Acceleration Knowledge

- Maneuver execution errors (Gates Method)

- Dynamic modeling errors

- Measurement noise and modeling errors including 


\section{Apollo TLC TCMs (Historical)}

Apollo By The Numbers, NASA-SP-4029, pg. 31-265

\section{"Apollo By The Numbers" (NASA SP-2000-4029)}

\begin{tabular}{|c|c|c|c|c|c|c|c|}
\hline Mission: & $\begin{array}{l}\text { Outbound M/C 1: } \\
\qquad(\mathrm{m} / \mathrm{s})\end{array}$ & $\begin{array}{l}\text { Outb } M / C 2 \text { : } \\
(\mathrm{m} / \mathrm{s})\end{array}$ & $\begin{array}{c}\text { Subtotal } \\
(\mathrm{m} / \mathrm{s})\end{array}$ & $\begin{array}{c}\text { Inbound M/C 1: } \\
(\mathrm{m} / \mathrm{s})\end{array}$ & $\begin{array}{c}\text { Inb M/C 2: } \\
(\mathrm{m} / \mathrm{s})\end{array}$ & $\begin{array}{c}\text { Subtotal } \\
(\mathrm{m} / \mathrm{s})\end{array}$ & $\begin{array}{c}\text { Total } \mathrm{M} / \mathrm{C} \\
(\mathrm{m} / \mathrm{s})\end{array}$ \\
\hline Apollo 8 & 6.2 & 0.4 & 6.6 & 1.5 & 0.0 & 1.5 & 8.1 \\
\hline Apollo 10 & 15.0 & & 15.0 & 0.7 & & 0.7 & 15.7 \\
\hline Apollo 11 & 6.4 & & 6.4 & 1.5 & & 1.5 & 7.8 \\
\hline Apollo 12 & 18.8 & & 18.8 & 0.6 & 0.7 & 1.3 & 20.2 \\
\hline Apollo 15 & 1.6 & 1.6 & 3.3 & 1.7 & 0.0 & 1.7 & 5.0 \\
\hline Apollo 16 & 3.8 & & 3.8 & 1.0 & 0.7 & 1.8 & 5.6 \\
\hline \multirow[t]{2}{*}{ Apollo 17} & 3.2 & & 3.2 & 0.6 & & 0.6 & 3.8 \\
\hline & & $\begin{array}{r}\text { AVERAGE }= \\
\text { SORT(DEVSO) }=\end{array}$ & $\begin{array}{l}10.9 \\
22.0\end{array}$ & & & 2.9 & \\
\hline
\end{tabular}




\section{Lunar Orbit Insertion}

$\checkmark$ MAVERIC Simulation:

- Pre-LOI $\left(\mathrm{C}_{3}=\sim 1.0 \mathrm{~km}^{2} / \mathrm{s}^{2}\right)$

- LOI (MAVERIC was $894 \mathrm{~m} / \mathrm{s}$ )

- $\sim 1$ rev in LLO

- DOI ( 6 minutes)

- Powered Descent (PD), \& Touchdown (TD)

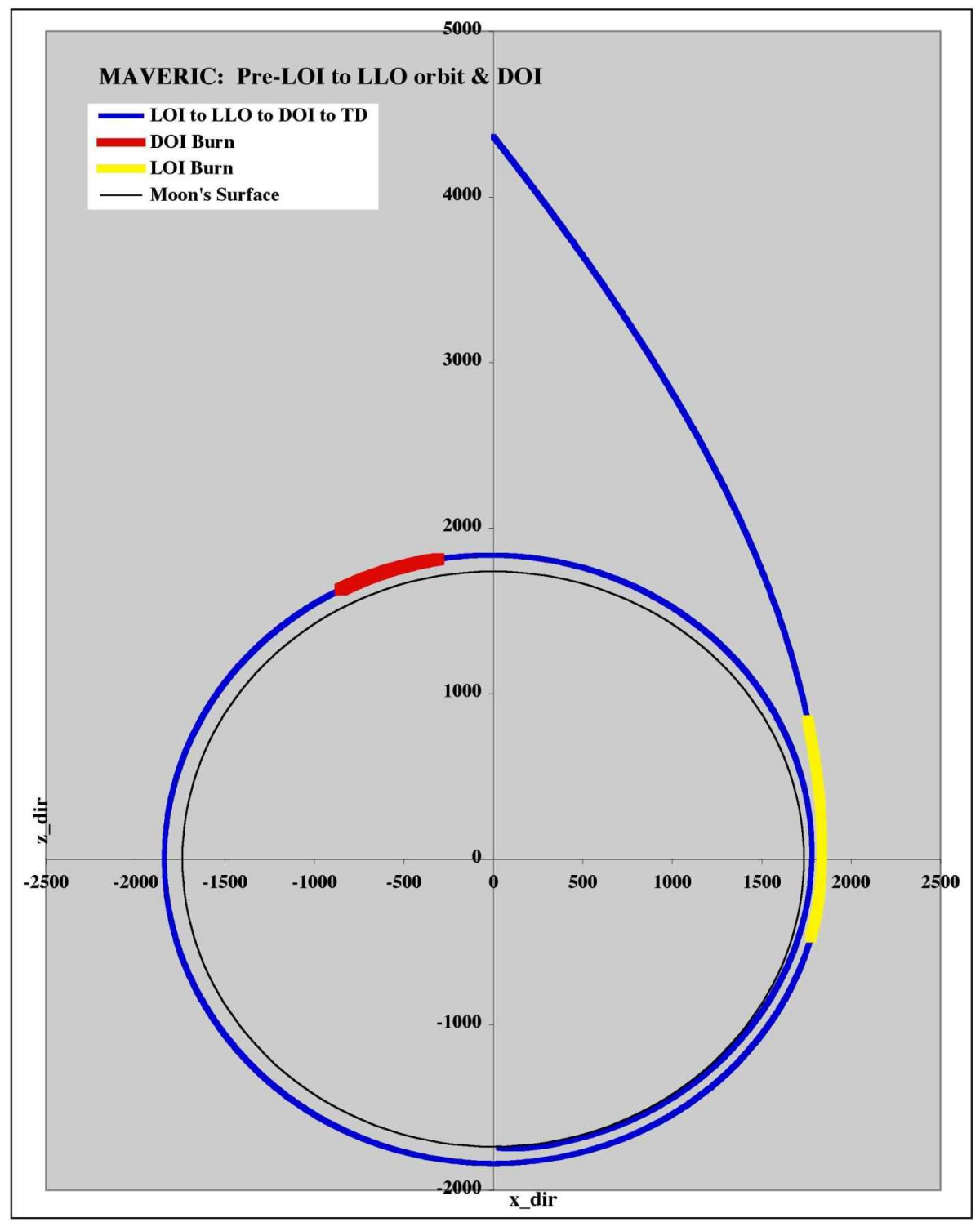

Pre-LOI thru Touchdown Trajectory (MAVERIC 3-DOF) 


\section{Example 24-hour Parking Orbits ( to scale)}

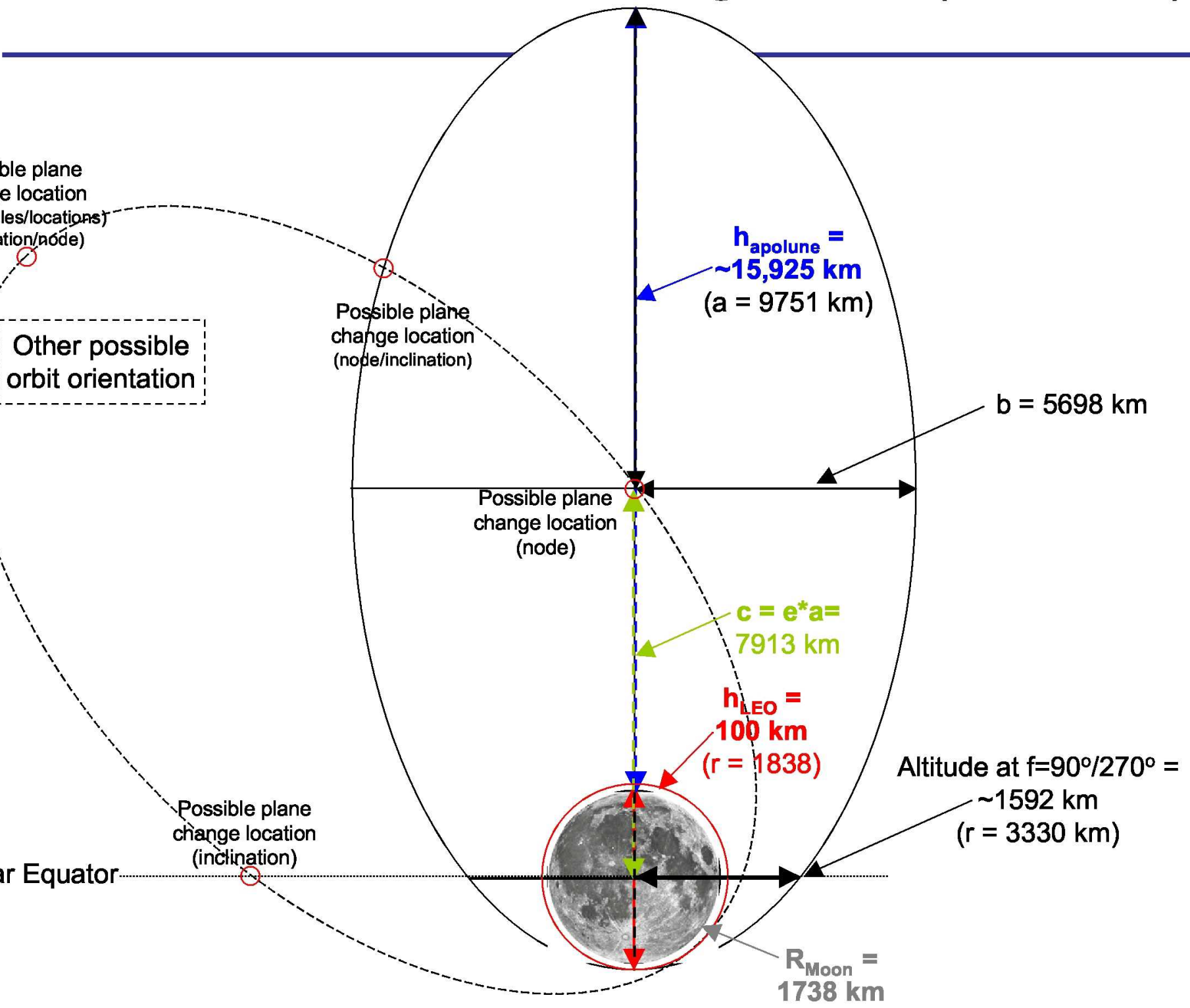




\section{LLO Altitude, Attitude \& Boil-off Propellant}

Altitude Maintenance for 4 additional days of LLO loiter (DM RCS)

- $90 \mathrm{~km}$ minimum results in $10 \mathrm{~m} / \mathrm{s}, 176 \mathrm{~kg}$ of RCS propellant for 5 days LLO loiter

- Boil-off Propellant (DM MPS)

- New analysis indicates $100-138 \mathrm{~kg}$ of $\mathrm{LH}_{2}$ boil-off in needed for mission

- Attitude Maintenance (DM RCS)

- Analysis indicates $30 \mathrm{~kg}$ of ACS prop is needed per day in LLO for loiter

\begin{tabular}{|c|c|}
\hline Time in LLO, days & Prop Budget for $\theta=40^{\circ}, \mathbf{k g}$ \\
\hline 1 & 30 \\
\hline 2 & 60 \\
\hline 3 & 90 \\
\hline 4 & 120 \\
\hline 5 & 150 \\
\hline 5 (LLO) $+1(24-\mathrm{hr})$ & $\sim 156$ \\
\hline
\end{tabular}
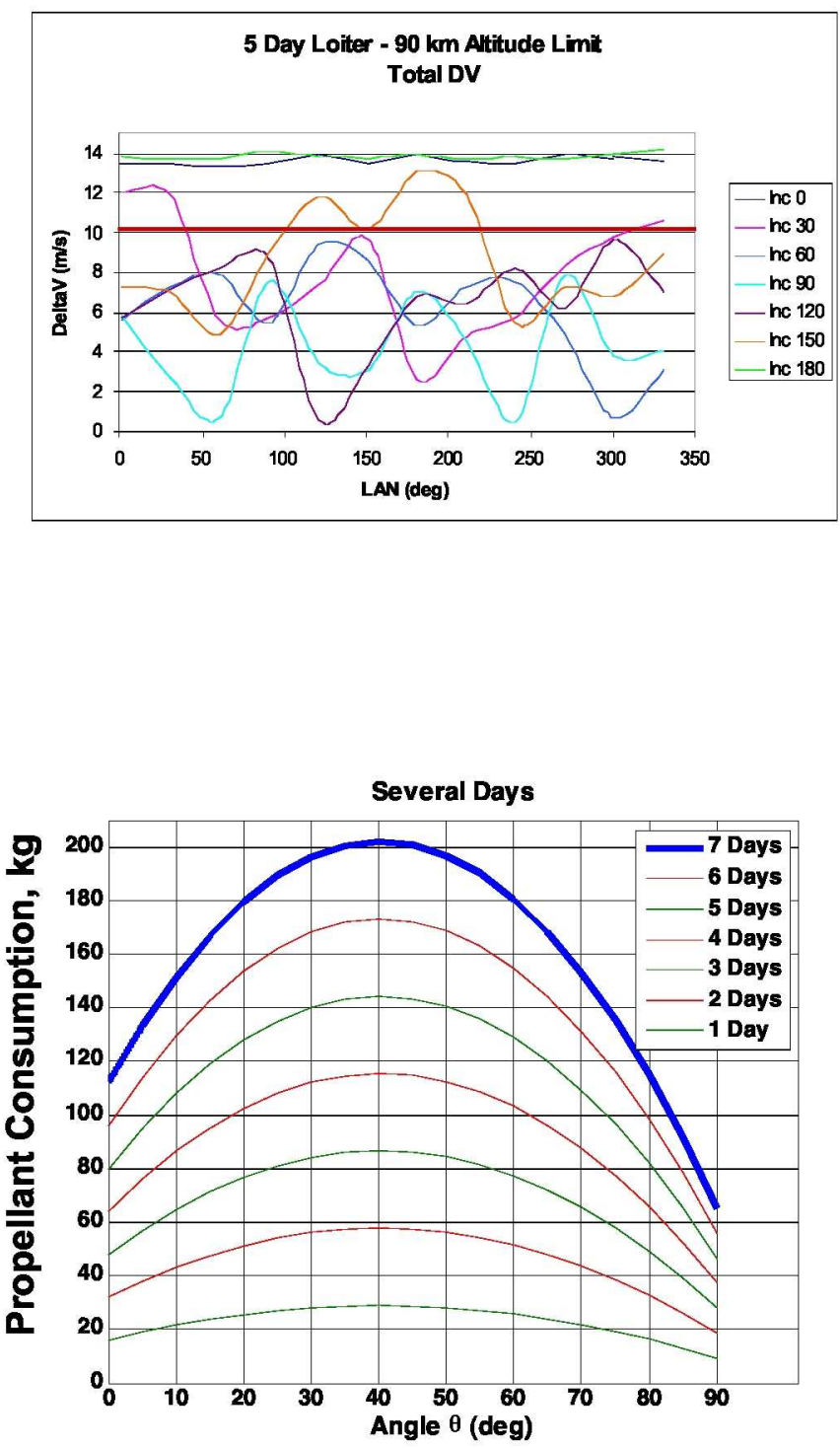


\section{Ascent: Why Is the DMZ So Long?}

\section{Piloted Ascent:}

- Derived from previous apside plots

- RCS assist to complete MECO can help only the last few seconds (chart § following)

- Note the very smooth energy addition all the way to MECO

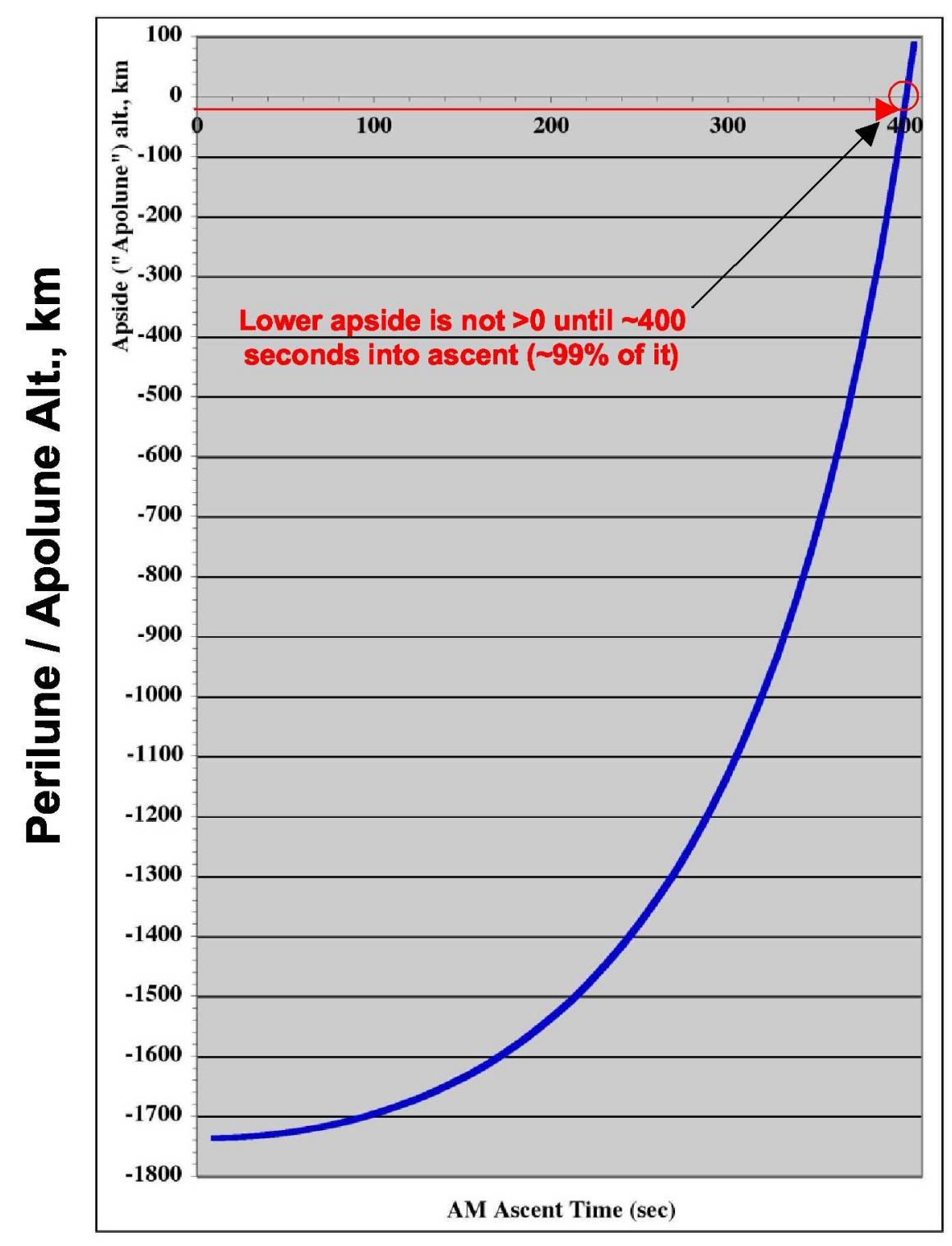

Ascent Time (to MPS burn-out/1st perilune), sec 


\section{Post-ascent Rendezvous, Prox. Ops \& Docking}

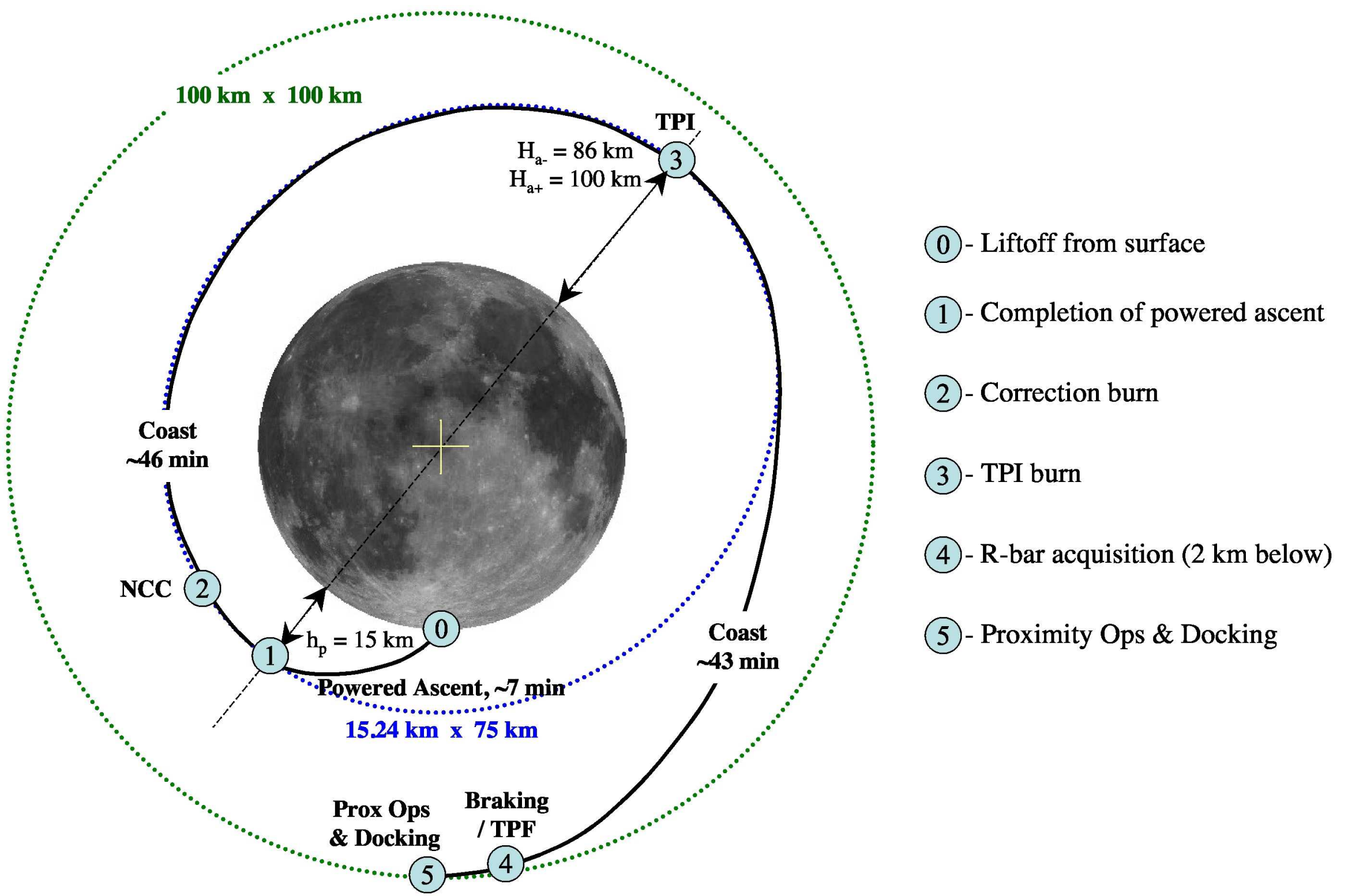




\section{RPOD $\Delta$ Vs + Dispersions Results}

\begin{tabular}{|c|c|c|c|c|c|c|c|c|}
\hline Maneuver & Nom. $\Delta \mathbf{V}$ & \multicolumn{6}{|c|}{ 1o $\Delta V$ Dispersion } & $\Delta \mathbf{V}+3^{*}$ (all errors) \\
\hline TPI: & 18.903 & 0.080 & 2.655 & 0.081 & 1.005 & 0.019 & 2.875 & 27.528 \\
\hline MC-1: & 0.000 & 0.040 & 0.079 & 0.096 & 0.010 & 0.165 & 0.209 & 0.627 \\
\hline MC-3: & 0.001 & 0.098 & 0.164 & 0.235 & 0.018 & 0.028 & 0.265 & 0.796 \\
\hline R-bar 1 & 0.411 & 0.075 & 0.155 & 0.151 & 0.015 & 0.024 & 0.176 & 0.939 \\
\hline R-bar 2 & 0.687 & 0.017 & 0.003 & 0.017 & 0.001 & 0.002 & 0.026 & 0.765 \\
\hline R-bar 3 & 0.468 & 0.011 & 0.002 & 0.015 & 0.000 & 0.003 & 0.019 & 0.525 \\
\hline R-bar 4 & 0.382 & 0.006 & 0.001 & 0.014 & 0.000 & 0.002 & 0.017 & 0.433 \\
\hline R-bar 7 & 0.212 & 0.004 & 0.001 & 0.014 & 0.000 & 0.001 & 0.015 & 0.257 \\
\hline R-bar 8 & 0.177 & 0.003 & 0.001 & 0.014 & 0.000 & 0.001 & 0.015 & 0.222 \\
\hline R-bar 9 & 0.150 & 0.003 & 0.001 & 0.014 & 0.000 & 0.001 & 0.015 & 0.195 \\
\hline R-bar 10 & 0.129 & 0.003 & 0.001 & 0.014 & 0.000 & 0.001 & 0.015 & 0.174 \\
\hline R-bar 11 & 0.115 & 0.002 & 0.001 & 0.014 & 0.000 & 0.001 & 0.014 & 0.157 \\
\hline R-bar 12 & 0.233 & 0.002 & 0.001 & 0.013 & 0.000 & 0.001 & 0.014 & 0.275 \\
\hline R-bar 13 & 0.124 & 0.003 & 0.006 & 0.027 & 0.000 & 0.006 & 0.028 & 0.208 \\
\hline Nominal $\Delta \mathbf{V}: \|$ & 24.315 & (no dis & Jersions) & Total Req & uired $3 \sigma \mathbf{R}$ & POD $\Delta V$ (Budget & $=30 \mathrm{~m} / \mathrm{s}):$ & 46.723 \\
\hline
\end{tabular}


LDAC-4 Kick-off: Summary of Dispersion $\Delta V s$-- CFP-1P

Blue/Bold = Inputs

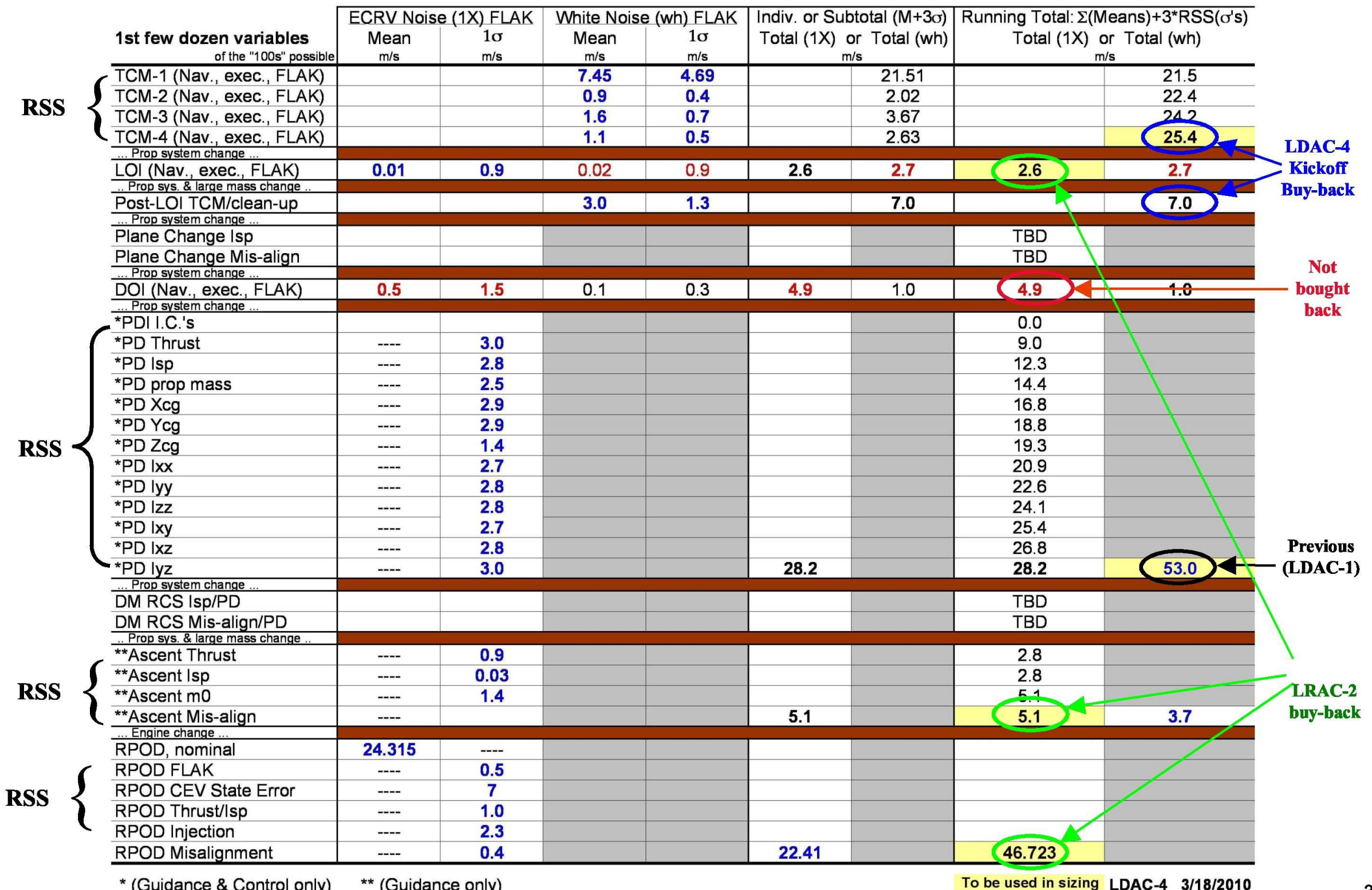

* (Guidance \& Control only)

** (Guidance only)

To be used in sizing LDAC-4 $3 / 18 / 2010$ 


\section{Bio data: Larry Kos}

$\checkmark$ Education:

- Master of Aerospace Engineering, Auburn University, 1996

$\checkmark$ Work Experience:

- Marshall Space Flight Center (MSFC),1982-present

- MSFC Technical Lead, Human Mars Mission, 1996-1999

- Agency Technical Lead, Integrated In-Space Propulsion Technology Plan, '01-'04

- Agency Technical Lead, Low-Thrust Trajectory Tool Development, 2003-2006

- Altair Integrated Performance Group Lead, 2007-2009

- Human Exploration Mission Designer/Analyst, 1993-present

- Awards: More than 20 NASA awards including --

- Agency-level: NASA Commendations

- MSFC-level: Director's Commendations, Space Flight Awareness Awards, Special Service Awards, Certificates of Appreciation, On-the-Spot Awards, Time-off Awards, Group Achievement Awards

Publications:

- Mr. Kos has published 20 papers, including papers and NASA TMs on the Exploration activities above

- Featured/invited presentations at LOGSA ('98) \& JANNAF ('03) conferences 